\title{
WestVirginiaUniversity
}

THE RESEARCH REPOSITORY @ WVU

Graduate Theses, Dissertations, and Problem Reports

2010

\section{Long-term climate trend in Mid-Atlantic Region, USA}

Chenjie Wu

West Virginia University

Follow this and additional works at: https://researchrepository.wvu.edu/etd

\section{Recommended Citation}

Wu, Chenjie, "Long-term climate trend in Mid-Atlantic Region, USA" (2010). Graduate Theses,

Dissertations, and Problem Reports. 4674.

https://researchrepository.wvu.edu/etd/4674

This Thesis is protected by copyright and/or related rights. It has been brought to you by the The Research Repository @ WVU with permission from the rights-holder(s). You are free to use this Thesis in any way that is permitted by the copyright and related rights legislation that applies to your use. For other uses you must obtain permission from the rights-holder(s) directly, unless additional rights are indicated by a Creative Commons license in the record and/ or on the work itself. This Thesis has been accepted for inclusion in WVU Graduate Theses, Dissertations, and Problem Reports collection by an authorized administrator of The Research Repository @ WVU. For more information, please contact researchrepository@mail.wvu.edu. 


\title{
Long-Term Climate Trend in Mid-Atlantic Region, USA
}

\section{Chenjie Wu}

\author{
Thesis submitted to the \\ College of Engineering and Mineral Resources \\ at West Virginia University \\ in partial fulfillment of the requirements \\ for the degree of \\ Master of Science \\ in \\ Civil Engineering \\ Lian-Shin Lin, Ph.D., Chair \\ Donald D. Gray, Ph.D. \\ Department of Civil and Environmental Engineering \\ \& \\ James T. Anderson, Ph.D. \\ Division of Forestry and Natural Resources \\ Morgantown, West Virginia \\ 2010
}

Keywords: Trend analysis; Mid-Atlantic Region; Climate variability; Air

temperature; Precipitation extremes

Copyright 2010 Chenjie Wu 


\section{Abstract \\ Long-Term Climate Trend in Mid-Atlantic Region, USA \\ Chenjie Wu}

Climate change on global scale has been studied by many researchers while regional studies are limited. The most recent international summary of climate change science (IPCC 2007) suggested a remarkable trend of increasing global surface temperature but no statistically significant trend in precipitation on a global average due to large variability in both space and time. Thus, this study focused on detecting climate changes and effects in the Mid-Atlantic Region, an important ecological system in the US and the world. Climate data from 25 stations with daily measurements for more than 100 years from the National Climate Data Center were analyzed.

The primary aim of this study was to examine the trends of the air temperature and precipitation time series for all the available stations in the region using the Mann Kendall statistical test. The Z statistic for each season as well as for the whole time period was calculated. The median slope of trends was estimated by Sen's method. Regional trends were formed by statistically combining the results of the Mann Kendall test for each individual trend. Extreme event indices were developed to study the trends of severe conditions. Winter and summer seasons were selected to study seasonal effects.

The secondary objective of this study was to detect relations between landscape attributes (e.g., elevation, altitude, forestry) and the long-term trend. The analyses were expected to provide information that can help answer questions related to regional climate changes such as elevation-dependent climate changes in this region. Stations were divided into three groups-low, medium, high according to their elevation. Kruskal-Wallis test was performed to detect the differences among the three groups.

All statistical analyses were conducted using SAS software 9.1 and SYSTAT 12. Results indicated variations between stations. Both negative and positive trends for all parameters were detected. Homogeneous trend was not found for the whole region. Our results showed coastal stations and inland stations have opposite results. One of the possible reasons could be the bigger cities and faster population growth rate at the coastal area which urbanization effect was more pronounced. Annual trends and seasonal trends were consistent for most parameters. The only differences was the increasing rate of warm days in winter compared with decreasing rate at most stations for summer and annual trends. Due to the insignificant of the differences among our three elevation groups, the dependency was not well established. Our study is the first look of the available data, more work are needed to justify the results. 


\section{Acknowledgement}

I thank my advisor Dr. Lian-Shin Lin who made great efforts in supervising me through my master project. His profound knowledge and nice personality enabled me a smooth and joyful journey of study. Also I thank Dr. Donald Gray and Dr. James Anderson for their support and guidance. I appreciate their time on serving on my committee and also I benefited a lot from their classes.

The same thanks go to all the other faculty and staff members at WVU, Dr. Xinchao Wei, Dr. Karen Buzby, and Research Assistant Will Ravenscroft. Life is always easier when others offer their warm hands.

Also, I thank my parents and my twin sister. They supported me unconditionally with their love. I could not have the strength without them.

In addition, I thank my friends and fellow students: Dongyang Deng, Isabel Cardona, Jinyan Sun, Khaled, Lina Cui, Ning Zhang, and Yushun Chen. 


\section{Table of content}

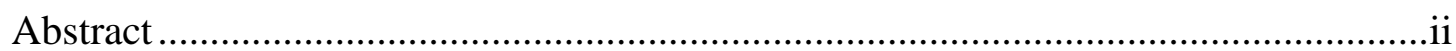

Acknowledgement ……….................................................................................... iii

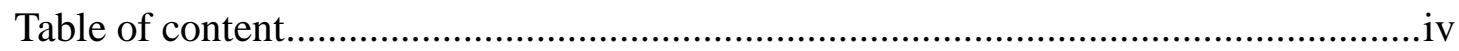

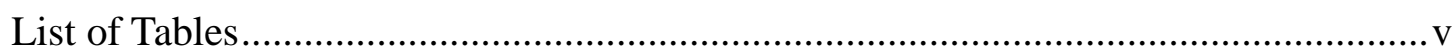

List of Figures .....................................................................................................vii

Chapter 1 Introduction .........................................................................................

Chapter 2: Literature Review .................................................................................

2.1 Mid-Atlantic Region .......................................................................................

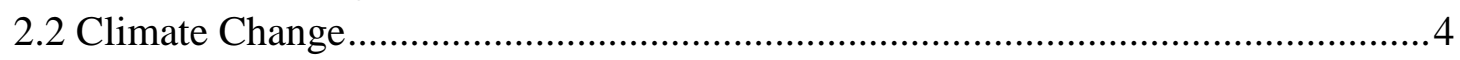

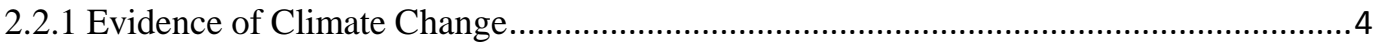

2.2.2 Elevation Dependence of Climate Change............................................................. 7

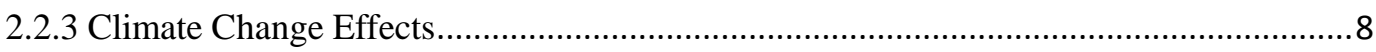

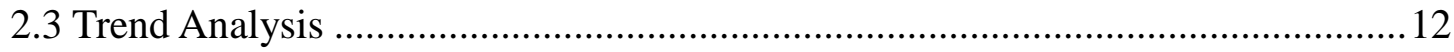

2.3.1 Quality Control for Climate Data..................................................................... 12

2.3.2 Statistical Methods ......................................................................................... 15

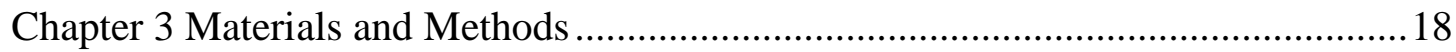

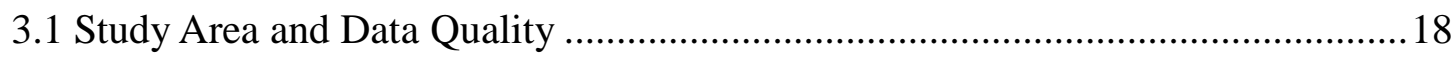

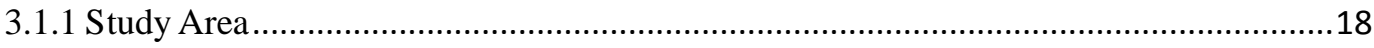

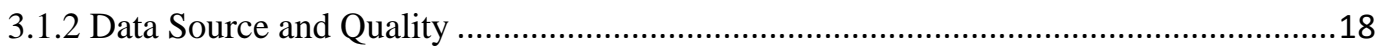

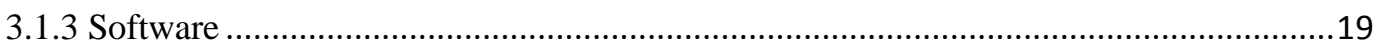

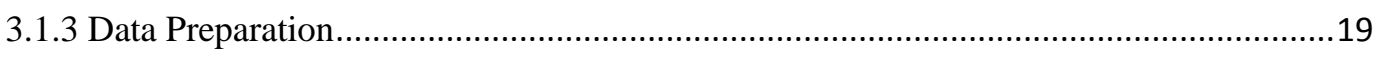

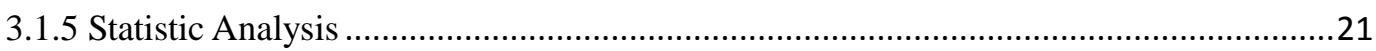

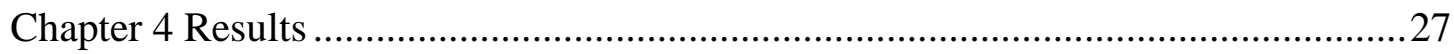

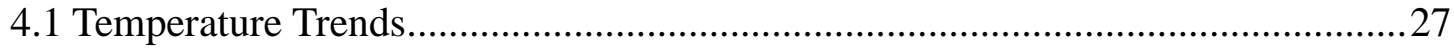

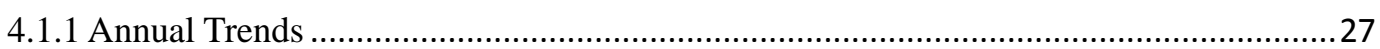

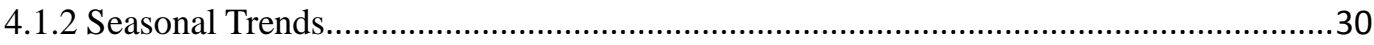

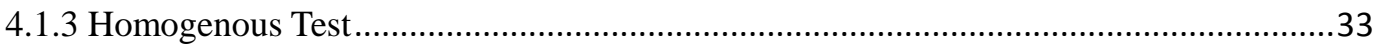

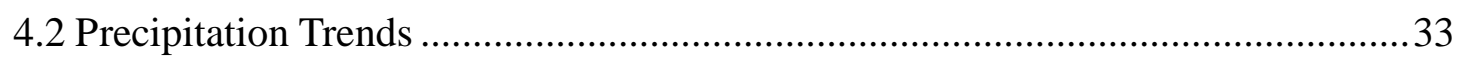

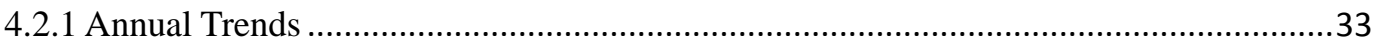

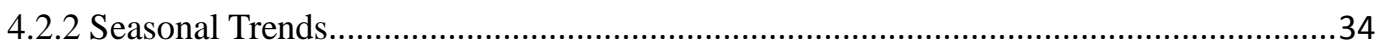

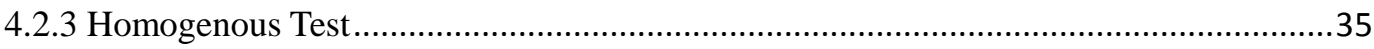

Chapter 5 Discussion and Conclusion …………………......................................92

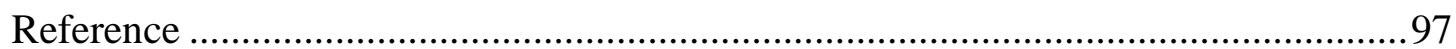




\section{List of Tables}

Table 3-1 List of climate stations in the four states (Land cover results are from NLCD 2001).

Table 3-2 Temperature and Precipitation Indices...........................................26

Table 4-1 Slopes and P values for annual temperature. Significant tends are indicated in bold characters $(\mathrm{P}<0.05)$. Italic stands for increasing trend and normal format stands for decreasing trends.

Table 4-2 Slopes and P values for the difference between annual maximum and annual minimum temperature. Significant tends are indicated in bold characters $(\mathrm{P}<0.05)$. Italic stands for increasing trend and normal format stands for decreasing trends.

Table 4-3 Slopes and P values for warm days and cool days. Significant tends are indicated in bold characters $(\mathrm{P}<0.05)$. Italic stands for increasing trend and normal format stands for decreasing trends.

Table 4-4 Slopes and P values for warm nights and cool nights. Significant tends are indicated in bold characters $(\mathrm{P}<0.05)$. Italic stands for increasing trend and normal format stands for decreasing trends.

Table 4-5 Slopes and $\mathrm{P}$ values for maximum annual maximum temperature and annual minimum temperature. Significant tends are indicated in bold characters $(\mathrm{P}<0.05)$. Italic stands for increasing trend and normal format stands for decreasing trends.

Table 4-6 Slopes and P values for minimum annual maximum temperature and annual minimum temperature. Significant tends are indicated in bold characters $(\mathrm{P}<0.05)$. Italic stands for increasing trend and normal format stands for decreasing trends.

Table 4-7 Slopes and $\mathrm{P}$ values for annual temperature for the summer season. Significant tends are indicated in bold characters $(\mathrm{P}<0.05)$. Italic stands for increasing trend and normal format stands for decreasing trends.

Table 4-8 Slopes and P values for annual temperature for the winter season. Significant tends are indicated in bold characters $(\mathrm{P}<0.05)$. Italic stands for increasing trend and normal format stands for decreasing trends.

Table 4-9 Slopes and $\mathrm{P}$ values for annual temperature for summer and winter season. Significant tends are indicated in bold characters $(\mathrm{P}<0.05)$. Italic stands for increasing trend and normal format stands for decreasing trends.

Table 4-10 Slopes and P values for TX90 (warm days) and TX10 (cool days) during the summer season. Significant tends are indicated in bold characters $(\mathrm{P}<0.05)$. Italic stands for increasing trend and normal format stands for decreasing trends.

Table 4-11 Slopes and P values for TX90 (warm days) and TX10 (cool days) during the winter season. Significant tends are indicated in bold characters $(\mathrm{P}<0.05)$. Italic stands for increasing trend and normal format stands for decreasing trends. 
Table 4-12 Slopes and P values for TN90 (warm nights) and TN10 (cool nights) during the summer season. Significant tends are indicated in bold characters $(\mathrm{P}<0.05)$. Italic stands for increasing trend and normal format stands for decreasing trends.

Table 4-13 Slopes and P values for TN90 (warm nights) and TN10 (cool nights) during the winter season. Significant tends are indicated in bold characters $(\mathrm{P}<0.05)$. Italic stands for increasing trend and normal format stands for decreasing trends.

Table 4-14 Slopes and $\mathrm{P}$ values for wet day precipitation and wet days. Significant tends are indicated in bold characters $(\mathrm{P}<0.05)$. Italic stands for increasing trend and normal format stands for decreasing trends. 50

Table 4-15 Slopes and P values maximum number of consecutive days with no precipitation and maximum annual precipitation intensity in in/day. Significant tends are indicated in bold characters $(\mathrm{P}<0.05)$. Italic stands for increasing trend and normal format stands for decreasing trends.

Table 4-16 Slopes and P values maximum number of consecutive days with no precipitation and maximum annual precipitation intensity in in/day during summer season. Significant tends are indicated in bold characters $(\mathrm{P}<0.05)$. Italic stands for increasing trend and normal format stands for decreasing trends.

Table 4-17 Slopes and P values maximum number of consecutive days with no precipitation and maximum annual precipitation intensity in in/day during winter season. Significant tends are indicated in bold characters $(\mathrm{P}<0.05)$. Italic stands for increasing trend and normal format stands for decreasing trends.

Table 4-18 Slopes and $\mathrm{P}$ values for wet day precipitation during summer and winter season. Significant tends are indicated in bold characters $(\mathrm{P}<0.05)$. Italic stands for increasing trend and normal format stands for decreasing trends. 


\section{List of Figures}

Figure 3-1The Mid-Atlantic Region of the United States (National Land Cover Data 2001 are used.)

Figure 4-1 Slopes of TX10 (cool days) in different elevation groups. .................55

Figure 4-2 Slopes of TX10 (cool days) during summer season in different elevation groups.

Figure 4-3 Slopes of TX10 (cool days) during winter season in different elevation groups.

Figure 4-4 Slopes of TXN (minimum annual maximum temperature) in different elevation groups 58

Figure 4-5 Slopes of TXN in different elevation groups. 59

Figure 4-6 Slopes of annual maximum temperature during summer season in different elevation groups. 60

Figure 4-7 Slopes of annual maximum temperature during winter season in different elevation groups.

Figure 4-8 Slopes of TX90 (Warm days) in different elevation groups. 62

Figure 4-9 Slopes of TX90 (Warm days) during summer season in different elevation groups.

Figure 4-10 Slopes of TX90 (Warm days) during winter season in different elevation groups.

Figure 4-11 Slopes of P95 (Annual total precipitation exceeding $95^{\text {th }}$ percentile) in different elevation groups.

Figure 4-12 Slopes of P95 (Annual total precipitation exceeding $95^{\text {th }}$ percentile) during summer season in different elevation groups.

Figure 4-13 Slopes of P95 (Annual total precipitation exceeding $95^{\text {th }}$ percentile) during winter season in different elevation groups.

Figure 4-14 Slopes of PX (maximum precipitation intensity) in different elevation groups.

Figure 4-15 Slopes of PX (maximum precipitation intensity) during summer season in different elevation groups.

Figure 4-16 Slopes of PX (maximum precipitation intensity) during winter season in different elevation groups.

Figure 4-17 Slopes of P95D (numbers of days with precipitation exceeding $95^{\text {th }}$ percentile) during in different elevation groups.

Figure 4-18 Graphic view of trends for station 185111, a. annual mean temperature, b. annual maximum temperature, c. annual minimum temperature $\mathrm{d}$. $\mathrm{T}_{\text {RANGE }}$

Figure 4-19 Graphic view of trends for station 185111, a. Tmax90, b. Tmin90, c. Tmax10 d. Tmin10.

Figure 4-20 Graphic view of trends for station 185111, a. P95, b. P95D, c. CDD d. $\mathrm{PX}$.

Figure 4-21 Graphic view of trends for station 185111, a. TXX, b. TXN, c. TNX d. TNN. 
Figure 4-22 Spatial distribution of trends for annual mean temperature.

Figure 4-23 Spatial distribution of trends for annual maximum temperature.......77

Figure 4-24 Spatial distribution of trends for annual minimum temperature. ......78

Figure 4-25 Spatial distribution of trends for binaural temperature range. ..........79

Figure 4-26 Spatial distribution of trends for TX90 (warm days)........................80

Figure 4-27 Spatial distribution of trends for TX10 (cool days). .........................81

Figure 4-28 Spatial distribution of trends for TN90 (warm nights).....................82

Figure 4-29 Spatial distribution of trends for TN10 (cool nights)......................83

Figure 4-30 Spatial distribution of trends for maximum annual maximum temperature.

Figure 4-31 Spatial distribution of trends for minimum annual maximum temperature.

Figure 4-32 Spatial distribution of trends for maximum annual minimum temperature.

86

Figure 4-33 Spatial distribution of trends for minimum annual minimum temperature.

Figure 4-34 Spatial distribution of trends for annual total precipitation exceeding $95^{\text {th }}$ percentile.

Figure 4-35 Spatial distribution of trends for annual total days with precipitation exceeding $95^{\text {th }}$ percentile.

Figure 4-36 Spatial distribution of trends for consecutive dry days. .90

Figure 4-37 Spatial distribution of trends for maximum annual precipitation intensity. 


\section{Chapter 1 Introduction}

It is obvious to us all that the earth's climate has been changing over time from ice age to present. Changes in climate may involve just single parameter such as temperature or precipitation, but usually it is the shift of meteorology conditions. Lots of evidences supported the fact that the earth is facing different climate conditions along time. Study revealed that the rate of sea level raise in the last decade was nearly double that of the last century (Church et al. 2006). Totally, they reported that global sea level had risen about 17 centimeters. Synthesis and Assessment Product (SAP) 3.4 report summarized an acceleration of flow and thinning with the velocity of some glaciers increasing more than twofold at the edges of the Greenland and West Antarctic ice sheets. Data from National Snow and Ice Data Center (NSIDC) showed a decline of $2.9 \%$ per decade of arctic sea ice extent. Levitus, Antonov et al. (2009) showed warming of $0.168{ }^{\circ} \mathrm{C}$ of the top 701 meters of the oceans. Global mean surface temperatures have risen by $0.74^{\circ} \mathrm{C}$ over the last 100 years (1906-2005). The rate of warming over the last 50 years is almost double that over the last 100 years $\left(0.13^{\circ} \mathrm{C}\right.$ vs. $0.07^{\circ} \mathrm{C}$ per decade) (Intergovernmental Panel on Climate Change, IPCC 2007).

Work done by climatologists showed evidence that the past climate change on the earth was caused by a limited number of factors (Pidwirny and Sidney, 2010). Changes may be caused by the variability of nature itself such as volcanoes, sunspots and solar activities, continental drift and other factors. However, debate over current climate change caused by human activities has been going on all over the world. Vincent (2008) considered that global warming was man-made. The top concern was greenhouse gas emissions. Data from National Oceanic \& Atmospheric Administration (NOAA) showed that atmospheric $\mathrm{CO}_{2}$ has increased since the industrial revolution. The amount of atmospheric $\mathrm{CO}_{2}$ had never been above 300ppm until 1950. The current level is above 380ppm and there is a continuous increase. The discovery of ozone hole in the 1980s provided dramatic evidence of the global impacts of human activates towards the atmosphere as well. Daily 
maximum area in 2009 was reported to be 24 million square km (NASA). In addition, desertification and deforestation and dust and aerosols can also be the causes of climate change (Burroughs 2007).

Scientists are making efforts towards uncovering the mystery of climate variations. "The essential point is, in considering climate change; we are concerned about the statistics of the weather phenomena that provide evidence of longer term changes.” says Burroughs (2007). Lots of studies have been done to find trends of climate using historical data as well as predicting future climate using model approaches. Other scientists also tried to discover the effects of the changing climate on the environment and human society. The primary objective of this study is to examine the trends of climatic parameters of Mid-Atlantic Region to see the regional responses of the changes on earth. Secondly, find correlations between the landscape attributes and climatic trends in order to aid future study of the impacts of such changes in climate. 


\section{Chapter 2: Literature Review}

\subsection{Mid-Atlantic Region}

The Mid-Atlantic Region (MAR) includes all parts of West Virginia, Virginia, Maryland, Pennsylvania, New Jersey, Delaware and part of North Carolina, and New York which makes 200,000 $\mathrm{km}^{2}$ in area with diverse landscape and landforms (Herlihy, Stoddard et al. 1998). With a wide range of physiographic characters such as Blue Ridge Mountains, Ridge and Valley, Coastal Plain, Appalachian Plateau, MAR composes one of the most diverse physical and ecological regions in the nation.

The two most dominant land-cover types in the Mid-Atlantic Region are forest and agriculture which covers about $70 \%$ and $25 \%$ of the area, respectively. Most of the watersheds are primarily forested with some approaching complete forest cover. Forest ecosystems of the MAR plays an import role in providing crucial habitats for wildlife, and communities such as limestone and dolomite glades that are home to endangered plant species (Jones, Riitters et al. 1997). On the coastal plain, pine-oak forest form unique habitats for rare plants and animals. Despite the significant role that wetlands play in nutrient cycling, crucial fish and wildlife habitats, and pollutants removal from water, MAR is also the home to one of the most critically endangered ecosystems in the United States the distinctive Atlantic white-cedar Chamaecyparis thyoides swamp forest. There are also important coastal ecosystems within the region. The Chesapeake Bay is considered the largest and most productive estuary in the United States; and the Delaware Bay is an extremely important habitat for migratory shorebirds. The importance of freshwater ecosystems to residents of MAR is blatantly obvious as people are deeply attached to water (Rogers and McCarty 2000). 


\subsection{Climate Change}

\subsubsection{Evidence of Climate Change}

Concerns for climate change caused by anthropogenic activities have attracted global attention towards its potential effects on the environment. Enormous efforts by international researchers have been directed to seeking evidence of climate changes, such as analyzing historical data for notable trends in temperature and precipitation. The fourth Intergovernmental Panel on Climate Change report (IPCC 2007) suggested a warming of $0.74{ }^{\circ} \mathrm{C}$ in global surface temperature over the years of 1906 to 2005 with a more rapid warming trend during the second half of the century. Alexander et al. (2006) reported a significant warming throughout the $20^{\text {th }}$ century with over $70 \%$ of the global land area sampled, a significant increase in the annual occurrence of cold nights, and a significant increase in the annual occurrence of warm nights. Precipitation trend on a global scale was hard to predict due to large variability in both space and time (IPCC 2007).

Over Europe, the average indices of precipitation extremes was found to increased during the 1946-1999 period, although the spatial patterns were not coherent (Tank et al. 2003). The indices of temperature extremes indicated "symmetric" warming of the cold and warm tails of the distributions of daily minimum and maximum temperature during the same period. A general tendency towards more intense precipitation extremes during the $20^{\text {th }}$ century in winter and a warming trend for all temperature indices over western and Central Europe was confirmed by Moberg et al. (2006). Other scholars from different parts of Europe have found similar trends either warming in temperature or increasing in precipitation (Brunetti, Buffoni et al. 2004; Hundecha and Bárdossy, 2005; De Toffol, Laghari et al. 2009; Tecer and Cerit 2009). Contradictorily, a study in Bulgaria showed an overall decrease in annual precipitation in the area (Alexandrov et al. 2004). It was stated that the country has experienced several drought episodes during the $20^{\text {th }}$ century, most notably in the 1940s and 1980s. No significant warming trend in the country 
was found in spite of the warming observed during the last two decades. Increases in the magnitude of dryness and pronounced trends were found over most of southern Portugal in the 1955-1999 periods, highlighting the fact that large areas are threatened by drought and desertification (Costa et al. 2008). In Greece, study showed a cooling trend in winter for the period of 1955-2001 and an overall warming trend in summer. However, both trends were not statistically significant (Feidas et al. 2004). In Asia, researchers (Jung et al. 2002) have saw an increase in the annual mean temperature at a rate of $0.23{ }^{\circ} \mathrm{C}$ per decade in the past four to five decades in South Korea. The occurrence frequency of extreme maximum temperature events showed an increasing trend, with higher values in the 1980s and 1990s. Minimum temperature showed opposite result with a decreasing trend in magnitude. In the Tibetan Plateau in China, temperature during the last several decades showed a long-term warming trend and precipitation amount exhibiting a decreasing trend in the western part and an increasing trend in the eastern and central part (Xu et al. 2008). Upward trend in annual precipitation was found in the same region by other researchers as well (Zhao et al. 2009). Moreover, statistically significant positive trends in annual mean air temperature and negative trend in precipitation were detected by another group (Zhao et al. 2008) studying the Yellow River basin. In southeast China, enhanced precipitation extremes defined as the largest 1- and 5-day precipitation total were detected after the early 1990s (Zhang et al. 2009a). They also investigated moisture flux variations to further explore the possible causes behind the changes in precipitation extremes. Cumulative departure analysis results confirmed the influences of moisture flux on the variations of precipitation extremes in the study region. Another study covering a larger study area substantiated the increases of precipitation maxima in this part of China (Zhang et al. 2009b).

A study in ten Asia-Pacific Network (APN) countries on the changes of spatial and temporal patterns in extreme events of temperature and precipitation and their associations with changes in climate means was conducted for the 1955-2007 period (Choi et al. 2009). Averaged over the APN region, annual frequency of cool nights (days) had decreased by 6.4 days/decade (3.3 days/decade), and the frequency 
of warm nights (days) has increased by 5.4 days/decade (3.9 days/decade). Additionally, they concluded that most rates of changes in extreme temperature events were generally less than that of mean temperatures. Regional trends over the study period in total precipitation, or in the frequency and duration of extreme precipitation events were not discovered in their research. Correspondingly, study done by Manton et al. (2001) in the same region gave consistent results.

Across the United States, nearly two-thirds of the trends in the 2-, 5-, and 10-yr return-period rainfall amounts, as well as the GEV (generalized extreme value) distribution location parameter, were positive. Significant positive trends in these values tend to cluster in the Northeast, western Great Lakes, and Pacific Northwest. Slopes were more evident in the 1960-2007 period when compared with the 1950-2007 interval (DeGaetano 2009). Intense warming was found by Robeson (2004) in the lowest minimum temperatures as well as daily maximum air temperature over western and central North America during the months through January to March. Other times of year in western North America, as well as much of eastern North America, showed little change in either minimum or maximum air temperature during the last half-century. Study region extending from the border areas of New Mexico and Texas southward into the altiplano of north central Mexico was investigated for maximum and minimum temperature records (1941-2000) by Englehart and Douglas (2003). They used data collected at 21 stations located in a variety of land-use environments ranging from large urban settings to rural areas and suggested rapid urbanization influence based on positive linear trend of minimum temperatures at stations in urban areas. A similar, but comparatively minor, urban effect was also apparent in the maximum temperature records during the warm seasons (June-September). A simple linear analysis indicated that the overall trend of the occurrence of short duration extreme precipitation events covering the period of 1931-96 was statistically significant upward over the southwest United States and in a broad region from the central Great Plains across the middle Mississippi River and southern Great Lakes basins. The national trend for the United States is upward at a rate of 3\% per decade for period 1931-96, while the annual trend for Canada is 
upward for the period of 1951-93, which was not statistically significant (Kunkel et al. 1999).

Seasonal temperature trends in the Mediterranean region were reported to be negative trends during winter and spring and no significant trends for the summer and fall season (El Kenawy et al. 2009). Elmallah and Elsharkawy (2009) studied summer temperature anomalies in Egypt during the $20^{\text {th }}$ century. The temperature in the North of Egypt was elevated by $1.05{ }^{\circ} \mathrm{C}$ during the summer seasons in the last century, comparing to non-significant changes with very low warming trend in the southern part of Egypt.

\subsubsection{Elevation Dependence of Climate Change}

One interesting finding of researchers is elevation dependency of climate change. Beniston and Rebetez (1996) proposed that surface climate change associated with global warming might show an elevation signal. Their analysis of wintertime minimum temperature anomalies from 88 Swiss stations revealed a significant altitudinal dependency. They suggested that the warming at high elevation sites would be more pronounced than those at low elevations which implied that an amplified response at high elevations could be utilized as an early climate change detection tool. A later study (Giorgi et al. 1997) also showed an evident elevation signal in the simulated temperature and precipitation changes with more manifested changes at higher elevations. They gave several possible reasons to explain the phenomenon. They argued that high elevation stations were less affected by ameliorating anthropogenic factors for they were more directly in contact with the free troposphere than the low elevation stations. The snow-albedo feedback was considered as a strong force towards elevation dependency. More solar radiation is absorbed at the surface as snow is depleted at high altitudes resulting in a decrease in surface albedo which could lead to an enhancement of surface warming at higher elevation. The dominant contribution for the elevation dependency of precipitation stated in the article is associated with the gradient of topography. 
The elevation dependency of warming in Tibetan Plateau was also observed (Liu et al. 2009). Enhancement of warming trend with increasing elevation was shown after summarizing linear trends of temperature by elevation zones. They also pointed out that snow-albedo and cloud-radiation feedbacks could be one of the reasons for the amplification of warming trends. You et al. (2008) examined the correlation between elevation and climate extremes in Tibetan Plateau. Seventy one stations was classified into three topography types (summit, flat and valley) and two land use types (urban and rural) to investigate the influence of topography and/or urbanization towards climate changing rates. The significant relation between trend magnitudes and elevation in their analysis might be superseded by the strong influence of both topographic type and degree of urbanization. Analysis of maximum temperature data from 49 stations in Nepal for the period of 1971-94 revealed warming trends after 1977 ranging from 0.068 to $0.128{ }^{\circ} \mathrm{C} / \mathrm{yr}$ in most of the Mountain regions (Shrestha et al. 1999). The southern plains regions showed warming trends less than $0.038{ }^{\circ} \mathrm{C} / \mathrm{yr}$ which confirmed that high elevation areas could be more sensitive.

Pepin and Lundquist (2008) studied records from 1000 high elevation stations around the globe to examine free atmospheric change and topography feedback as the causes of the changing temperature trend with elevation. Although no global relation between elevation and warming trends were observed, data still showed that high elevation stations could be a good indicator of the plant climate for they are free from the effects of urbanization and topographic sheltering.

\subsubsection{Climate Change Effects}

\subsubsection{Water and Climate Change}

Many modeling studies of the impact of climate change and water quality have been conducted by different groups of researchers. Using meteorological input calculated by a GCM A2 scenario with averaged $3{ }^{\circ} \mathrm{C}$ temperature increase and 200 mm precipitation increase by the year 2090 resulted in an increase of surface water 
temperature by $3.8^{\circ} \mathrm{C}$ and the water temperature of the hypolimnion by $2.8^{\circ} \mathrm{C}$ for Shimajigawa reservoir (Komatsu et al. 2007). This change might expand the thermal stratification period and deepen the thermocline of the reservoir. In addition, the higher surface water temperature could greatly increase algae growth. Cruise, Limaye et al. (1999) predicted dissolved oxygen problems and high nitrogen levels in basins in the southeast United States under conditions based on the United Kingdom Hadley Center climate model. In addition, the stream flow was projected to decline over the next 30-50 years which would exacerbate these water quality problems. Similar conclusions were found by various researchers (Mimikou et al. 2000; Arheimer et al. 2005; Wilby et al. 2006).

Chang et al. (2001) used GWLF (Generalized Watershed Loading Function) to simulate stream flow and nutrient loading in the Mid-Atlantic region under future climate scenario. Under the prediction of increasing temperature and precipitation for future climate, their results suggested that nitrogen loads increase in winter (January and February) for all watersheds and decreased in some months (e.g., April, July, and August) as a result of the reduction in stream flow during this period for most watersheds. Eutrophication problems might be weakened during spring and late summer. Neff et al. (2000) reported that nutrient loads could be expected to increase in winter and spring because of the expected increase in stream flow and ameliorate problems associated with estuarine stratification and eutrophication in late summer in the same region.

By rewetting the dried acid sulfate soils with Murray River water after a drought period in south-eastern Australia et al. (2010) found the concentrations of dissolved $\mathrm{Al}, \mathrm{Cu}$ and $\mathrm{Zn}$ were greater than 100 times the Australian water quality guidelines. A high level of land and water management should be required to counter the effects of such climate change events.

Hydrology of water not only impact water quality but also affects water quantity. Scientists also paid great attention to the relation of its changes with climate. Using climate change scenarios based on GCM A2 and B2 scenarios, the overall results showed that runoff in the Tarim River basin showed a slight decreasing 
trend; while evapotranspiration exhibited an increasing trend which implied that water availability in the area is likely to become more critical in the future (Chen et al. 2008).

Using Parallel Climate Model for climate scenarios, results showed increase for temperature but the annual averaged precipitation remained equivalent for the years of 2000 to 2100 in the San Joaquin River Basin. A number of water resource management factors were affected. Spring snow water equivalent (SWE) and basin-average monthly stream flow would decrease during the whole period (VanRheenen et al. 2004).

Whitfield and Cannon (2000) analyzed climatic and hydrologic variations between 1976 and 1995 in Canada. Significant increases in temperatures during spring and fall was found for most stations. On the contradictory, significant decreases in temperature were found during winter in eastern Canada. The amount of precipitation decreased in the north part of Canada while increased in the south. Observed hydrographs showed an early spring flood and increased winter mean discharge as well as smaller summer flows. Similar study was done by Regonda et al. (2005) in the United States. Attributed to climate change, an advancing trend in the timing of peak spring flows was observed. Results also suggested that the precipitation trend was offset by higher temperatures and increased winter seasonal melt and more liquid precipitation .for not translating into higher spring discharges while winter precipitations increased.

Using a spatially distributed hydrology model (the Distributed Hydrology-Soil-Vegetation Model, DHSVM), Cuo et al. (2009) studied the effects of changing climate (primarily temperature) and land cover in the Puget Sound basin. In the lowlands, land cover signal dominated temperature change. In the uplands, both land cover and temperature change played important roles. Warmer temperatures reduced the occurrence of snowfall and increased rainfall occurrences, resulting in substantial shifts in runoff from spring and summer to winter. A secondary effect was that winter ET was increased.

Groisman et al. (2001) discovered a significant relationship in the eastern 
half of the United States between the frequency of heavy precipitation and high streamflow events both annually and during the months of maximum streamflow. An increase of spring heavy precipitation events over the eastern United States indicated with high probability that during the twentieth century an increase of high streamflow conditions has also occurred.

Study by Hodgkins et al. (2003) suggested that the geophysical and biological changes in the New England area were caused by a common mechanism, temperature increase. Winter/spring center of volume (WSCV) dates have become significantly earlier where snowmelt runoff has the most effect on spring river flows.

Olsen et al. (1999) studied the correlation between flood frequency and precipitation. Although the there was no direct relation between the both, large and statistically significant upward trends for flood frequency were found in many gauge which challenged the traditional assumption that flood series are independent and identically distributed random variables and suggested that flood risk changes over time.

\subsubsection{Ecological System and Climate Change}

Walther et al. (2002) listed numbers of ecological responses to recent climate change. Changes to phenology were one of the simplest processes to reflect the responses of ecology of species to climate change. Studies revealed common changes in the timing of spring activities include earlier breeding or first singing of birds, earlier arrival of migrant birds, earlier appearance of butterflies, earlier choruses and spawning in amphibians and earlier shooting and powering of plants (Bradley et al. 1999; Inouye et al. 2000; Chmielewski 2001; Both et al. 2006; Menzel et al. 2006; etc).

Many studies of the biological impacts of climate change also focused on abundances and distributions of species. It is well known that species' distribution is influenced by climatic parameters through the thresholds of temperature and precipitation tolerance. Studies were done by various researchers on difference specie behaviors (Murawski 1993; Condit et al. 1996; Pearson and Dawson 2003; Perry et al. 2005). 
Mulholland et al. (1997) listed 8 ecological effects of climate change on freshwaters of Gulf of Mexico which included a general increase in rates of primary production, organic matter decomposition and nutrient cycling as a result of higher temperatures and longer growing seasons, reduction in habitat for cool water species in Appalachian streams, reduction in water quality and in suitable habitat in summer owing to lower baseflows and intensification of the temperature-dissolved oxygen squeeze, reduction in organic matter storage and loss of organisms during more intense flushing events, shorter periods of inundation of riparian wetlands and greater drying of wetland soils, particularly in northern and inland areas, expansion of subtropical species northwards, expansion of wetlands in Florida and coastal Mexico, but increase in eutrophication of Florida lakes, changes in the flushing rate of estuaries that would alter their salinity regimes, stratification and water quality as well as influence productivity in the Gulf of Mexico.

\subsection{Trend Analysis}

\subsubsection{Quality Control for Climate Data}

For long-term climate analyses to be accurate, the climate data used must be homogeneous. Conrad (2007) defined a homogeneous climate time series as data variations caused only by variations in weather and climate. Unfortunately, most long-term climatological time series had been affected by a number of non-climatic factors such as changes in instruments, observing practices, station locations, formulae used to calculate means and station environment that made these data unrepresentative of the actual climate variation occurring over time. Direct and indirect methodologies for homogeneity testing were reviewed by Peterso et al. (1998). Three direct and four indirect methods are discussed in the followings.

Station history metadata files could provide valuable information on station moves, changes in instrumentation, problems with instrumentation, new formulae used, changes in the nearby environment such as buildings, vegetation and etc. 
Variations caused by instrument changes can be tested either by side by side comparisons of different instruments or a statistical study of the effects of an instrument change. A graphic view of time series could also show abrupt changes by comparing one station with another.

Reference time series could be developed to isolate the effects of station discontinuities from regional climate change using nearby stations as a reference. Alexandersson (2007) described three techniques to create reference data using arithmetic mean of the homogeneous and complete stations, arithmetic mean of normalized data or a weighted mean of normalized data where the weighting was based on a distance function that was determined by spatial correlation. Brunetti et al. (2001) adopted an procedure consists of the following steps: carrying out cross checks among the stations; considering as possible errors the data which may be very different from the rainfall records of all other stations; checking these data by means of comparison with precipitation data of nearby stations. After these checks, monthly precipitation series were calculated for each station and then the monthly dataset was tested for homogeneity by means of the Craddock homogeneity test (Craddock 1979). Parallel cumulative sums of seasonally adjusted series from neighboring stations were used by Rhoades and Salinger (1993) as a useful exploratory tool for recognizing site-change effects at a station that has a number of near neighbors.

Several scientists came up with methods to test homogeneity when stations were isolated with each other or lack of information from nearby stations. Lazaro et al. (2001) described a Thom test for testing homogeneity. The theory was that code 'a' was assigned to values greater than median and code 'b' was assigned to values smaller than median value. For sample size larger than 25, the data series was considered homogenous when the numbers of ' $a$ ' and ' $b$ ' follow a normal distribution. On the other hand, Zurbenko et al. (1996) illustrated the use of an adaptive moving average filter in detecting systematic biases.

Data gaps were another issue for climate analyses as incomplete data was unavoidable while dealing with real world data sources. A number of methods had 
been chosen by experts to deal with this matter. The simplest way was perhaps to ignore the missing instances. Alternatively, researchers chose the most common feature values or mean value to replace all the missing values.

A more sophisticated approach is to use regression or classification model for substituting missing values. Seven functions were divided into three groups in a study by Kemp et al. (1983) to estimate missing values. The first group defined as within-station techniques contained linear regression and moving averages. A between-station additive procedure used the average of the estimates of the between station predictions to form a replacement value. The remaining four functions were correlative procedures which were similar to each other.

A yearly temperature equation developed by Kouremenos and Antonopoulos (1993) was selected in Kotsiantis, Kostoulas et al. (2006)'s paper to replace the missing values for each year. Approximation of temperature increasing from spring to summer was simulated by sin function.

$$
T(D)=A+B \sin \left(\frac{360}{365} D-f\right)
$$

where $D$ is the day of the year, $A$ is the mean yearly temperature in ${ }^{\circ} \mathrm{C}, B$ is the width of the yearly temperature variation in ${ }^{\circ} \mathrm{C}$ and $f$ is the phase shift expressed in degrees or days.

Schneider (2001) proposed regularized expectation maximization (EM) algorithm to estimate and exploit the imputation of missing values, both synchronic and diachronic covariance matrices. They claimed that the regularized EM algorithm was applicable to typical sets of climate data and that it led to more accurate estimates of the missing values than a conventional non-iterative imputation technique.

The method described by Twala (2009) built decision trees to determine the missing values of each attribute, and then filled the missing values of each attribute by using its corresponding tree. Separate trees were built using a reduced training set for each attribute. The original class was treated as another attribute, while the value of the attribute becomes the "class" to be determined. The attributes used to grow 
the respective trees are unordered. These trees were then used to determine the unknown values of that particular attribute.

\subsubsection{Statistical Methods}

Various methods for detecting the existence of trends in time series of random variables have been used by different groups of researchers. Both parametric and non-parametric statistical tests could be used to decide whether there was a statistically significant trend.

The most common parametric test is the simple linear regression to explore the (linear) relationship between random variable $Y$ (dependent variable) and time $X$ (independent variable):

$$
Y=\beta_{1} X+\beta_{0}+\varepsilon
$$

The regression coefficient $b_{1}$ or the Pearson correlation coefficient $r$ was computed from the data to measure the global fit of the model.

$$
\mathrm{r}=\frac{1}{\mathrm{n}-1} \sum_{\mathrm{i}=1}^{\mathrm{n}}\left(\frac{\left(\mathrm{x}_{\mathrm{i}}-\overline{\mathrm{x}}\right.}{\mathrm{s}_{\mathrm{x}}}\right)\left(\frac{\mathrm{y}_{\mathrm{i}}-\overline{\mathrm{y}}}{\mathrm{s}_{\mathrm{y}}}\right)
$$

where $\mathrm{s}_{\mathrm{x}}=\sum_{\mathrm{i}=1}^{\mathrm{n}}\left(\mathrm{x}_{\mathrm{i}}-\overline{\mathrm{x}}\right)^{2}, \mathrm{~s}_{\mathrm{y}}=\sum_{\mathrm{i}=1}^{\mathrm{n}}\left(\mathrm{y}_{\mathrm{i}}-\overline{\mathrm{y}}\right)^{2}$

The student's $t$ test with degree of freedom of $n-2$ was used to test if the slope is statistically significant:

$$
\mathrm{t}=\frac{\mathrm{r} \sqrt{\mathrm{n}-2}}{\sqrt{1-\mathrm{r}^{2}}}=\frac{\mathrm{b} 1}{\mathrm{~g} / \sqrt{\mathrm{SS}}}
$$

where $n$ is the sample size, $s$ is the standard deviation of residuals, and $S S_{X}$ is the sums of squares of independent variable (Önöz and Bayazit 2003).

The nonparametric test Spearman's rho can be used to testify trends as well. The null hypothesis $\mathrm{H}_{0}$ can be stated as that the data series, $X_{i}$ 's, were independent and identically distributed; the alternate hypothesis $\mathrm{H}_{1}$ is that $X_{i}$ ss increased or decreased with $i$. The test statics was given by:

$$
\mathrm{D}=1-\frac{6 \sum_{\mathrm{i=1}}^{\mathrm{n}}[\mathrm{R}(\mathrm{Xi})-\mathrm{i}]^{\mathrm{x}}}{\mathrm{n}\left(\mathrm{n}^{2}-1\right)}
$$

where $R\left(X_{i}\right)$ is the rank of $i^{\text {th }}$ observation $X_{i}$. The distribution of $D$ followed the normal distribution. 


$$
\begin{aligned}
& \mathrm{Z}=\frac{\mathrm{D}}{\sqrt{\mathrm{V(D)}}} \\
& \mathrm{V}(\mathrm{D})=\frac{1}{\mathrm{n}-1}
\end{aligned}
$$

One of the most command nonparametric methods used is the Mann-Kendall test. The test describe by Mann is a particular application of Kendall's test for correlation (Hirsch, Slack et al.). The null hypothesis of $\mathrm{H}_{0}$ was that the data $\left(x_{1}\right.$, $x_{2} \ldots x_{n}$ ) are a sample of $n$ independent and identically distributed random variables. The alternative hypothesis $\mathrm{H}_{1}$ of a two sided test is that the distribution of data is not identical. Each pair of observed values $X_{i}, X_{j}$ of the random variable was compared. The test static $S$ is defined as:

$$
S=\sum_{j=1}^{n-1} \sum_{i=j+1}^{n} \operatorname{sgn}(X i-X j)
$$

where

$$
\operatorname{sgn}(X i-X j)= \begin{cases}1 & \text { if } X i>X j \\ 0 & \text { if } X i=X j \\ -1 & \text { if } X i<X j\end{cases}
$$

Normal approximation is used for the distribution of $S . \quad Z$ is calculated as:

$$
\begin{aligned}
& \mathrm{Z}=\left\{\begin{array}{cc}
\frac{S-1}{\sigma_{s}} & \text { if } S>0 \\
0 & \text { if } S=0 \\
\frac{S+1}{\sigma_{s}} & \text { if } S<0
\end{array}\right. \\
& \sigma_{s}=\sqrt{\frac{n(n-1)(2 n+5)}{18}}
\end{aligned}
$$

For the two nonparametric tests abovementioned, the magnitudes of the slopes can be estimated by methods described by Sen (1968):

$$
\text { slope }=\operatorname{median} \frac{\mathrm{Xi}-\mathrm{xj}}{\mathrm{i}-\mathrm{j}} \quad \mathrm{j}<i
$$

Shrestha et al. (1999) computed seasonal and annual temperature trends for 
all stations in Nepal using linear regression for the period 1971-1994. Vuille and Bradley (2000), Zhang et al. (2000), Böhm et al. (2001) also chose the regression method to study the trend of temperature. Studying precipitation trends using linear regression methods were reported by various groups of scholars (Suppiah and Hennessy 1998; Frei and Schär 2001; Gemmer et al. 2004; Schmidli and Frei 2005; Wang and Zhou 2005).

Spearman's rho test was another method for detecting trends in the metrology data. Neelin et al. (2006) used it to examine tropical drying trends in global warming models and observations. The method was also used to study trends in other water quality and stream flow (Lettenmaier et al. 1999; Kahya and Kalayc 2004).

Most paper cited in this article used Mann-Kendall test for studying temperature and precipitation trends. Yue and Pilon (2004) compared the power of t-test and Mann-Kendall for trend detection and the results showed only slight difference between the two tests. The power of $t$-test is slightly higher than MK for normally distributed data. Another study by the same group indicated that p-values computed by Mann-Kendall test and Spearman's rho test were almost identical (Yue et al. 2002). 


\section{Chapter 3 Materials and Methods}

\subsection{Study Area and Data Quality}

\subsubsection{Study Area}

The four states located in Mid-Atlantic Region including West Virginia, Pennsylvania, Virginia and Maryland spread cross the domain of $75^{\circ} \mathrm{W}-82^{\circ} \mathrm{W}, 36^{\circ} \mathrm{N}-$ $42^{\circ} \mathrm{N}$ (Fig. 3.1). The most common climate in this region is humid subtropical climate according to the Köppen climate classification which covers the southwestern part of West Virginia, most of Pennsylvania, Virginia and Maryland (McKnight et at. 2000). Humic subtropical climate is chacterized by hot, humid summers and cold winters. The rest part of West Virginia falls into the category of humid continental climate. The total study area is approximately $200,000 \mathrm{~km}^{2}$. Elevation ranges from 3 to 900 meters above mean sea level.

Twenty five stations in the region were selected for our study for precipitation and twenty four were selected for temperature. Weston, WV station was excluded from the analysis involving maximum and minimum temperature. Of the twenty five stations, eight stations are in West Virginia and Pennsylvania and Virginia each has six stations. The other five stations are located in Maryland. The criterion for selecting the stations was stations with more than 100 years of climate data. Information about the stations is summarized in Table 3.1.

\subsubsection{Data Source and Quality}

The climate data were obtained from the National Climate Data Center (NCDC). According to the metadata, NCDC has made numerous efforts to ensure the quality of the data (NCDC data document for data set 3200). The observing equipments used were calibrated and maintained by National Weather Service (NWS) field representatives, Cooperative Program Managers and Hydro-Meteorological 
Technicians for the purpose of accurate and consistent measurement. The data collected have received a high measure of quality control through computer and manual edits. Data have gone through internal consistency checks, and been compared against climatological limits and evaluated against surrounding stations. Suspicious values were flagged and excluded from the analysis.

Several steps were taken before using the data for analysis: (1) flagged values using alphabetic letters or unique numbers such as 999.99 or 99999 were replaced as missing values; (2) percentage of missing values was calculated and only stations with less than $10 \%$ missing values were selected for the study; (3) a quick scan of the whole data set for each station was occupied to see if the missing data were randomly distributed; (4) data entirety was computed by counting the months in each year; and (5) inventory informing which months were missing in a year was developed for decision making in the latter part of the study.

\subsubsection{Software}

Statistical software SYSTAT (SYSTAT Software, Inc., ver. 12) and SAS 9.1.2 (SAS Institute Inc.) were used for analyses in the study. For data points less than 1,000 , SYSTAT was chosen as primary option for analysis. Due to its memory capacity, larger data sets were analyzed using SAS 9.1.2. Climate station maps were prepared using ArcGIS 9.3 (ESRI Inc.).

\subsubsection{Data Preparation}

Sixteen indices of temperature and precipitation listed in Table 3.2 were selected in our study. Annual mean, maximum and maximum were calculated for each station using daily temperature. To avoid biased results caused by incomplete data set, years with less than 300 days were excluded from our analysis, which resulted in one missing year per station on average. In addition to annual average, the difference between maximum temperature and minimum temperature for each year was calculated and termed as $\mathrm{T}_{\text {RANGE. }}$ The $90^{\text {th }}$ and $10^{\text {th }}$ percentiles were used 
to define extreme temperature events. Total number of days in a year with temperature value greater than the $90^{\text {th }}$ percentile for each station was counted as warm days or nights and temperature value less than the $10^{\text {th }}$ percentile was counted as cool days or nights (Choi et al. 2009).

Precipitation intensity of a rainfall event was quantified by dividing total amount of rainfall (inches) during the event by the number of consecutive days. In addition, consecutive days without rainfall were counted and the maximum number of the consecutive days was used to indicate drought condition. Rainfall amount exceeding the $95^{\text {th }}$ percentile value was defined as extreme precipitation (Choi et al. 2009). Wet day precipitation was calculated by adding up the total amount of rainfall (inches) which exceeded the $95^{\text {th }}$ percentile. The total number of days per year was counted for the extreme events. Separate computer programs were written in Visual Basic (VB) language for each task.

Missing values were interpolated by local quadratic smoothing during the analysis process incorporated in SYSTAT. Results presented in Duffy et al. (2001) suggested that the observed near-surface temperature trend of about $0.6{ }^{\circ} \mathrm{C}$ over 1900 1998 was unlikely to have been significantly overestimated by incomplete and time-varying observed data coverage. Another paper studied the impact of missing data on calculated monthly mean temperature by randomly removing 1-10 consecutive days of data from the stations with complete data (Stooksbury et al. 1999). This represented 3\%-30\% missing data and the consequent temperature deviations from the true value varied from $0.18{ }^{\circ} \mathrm{C}$ to $2.28{ }^{\circ} \mathrm{C}$. Most researchers chose a threshold for missing data at around 20\% as (Brunetti, et al. 2000; Manton, et al. 2001; Klein 2002; Knowles, et al. 2006). In this study, 10\% missing data was used as a criterion for non-biased results as better quality.

Zhai et al. (1999) considered a year was missing for having 20 days or more missing data and a station was rejected with more than 5 years of random missing or 3 years of consecutive missing data. In our study, there were only few days of data were missing in one year and thus no action was taken on the precipitation data.

The missing value analysis in SYSTAT suggested that our data met the 
criteria of MCAR (Missing complete at random), thus neglecting the missing value from the analysis was adaptable.

Winter and summer season were selected to study seasonal trend. If warming were primarily a phenomenon during summer which represented the warmest air masses, social cost and energy consumption would be more stressed than winter. Winter warming might be benefitial in some circumstances than concerns (Balling 1998). However mild winter would increase the survival of diseases since winter season was the major period of pathogen mortality (Harvell and Mitchell 2002). It is reported that summer temperature as well as winter temperature have significant effect on plant distribution as well (Naurzbaev et al. 2002; Kirdyanov et al. 2003).

\subsubsection{Statistic Analysis}

Shapiro-Wilk test was chosen to test the normality of the climate data used in the study (Shapiro and Wilk 1965). The test statistic was defined as:

$$
W=\frac{\left(\sum_{i=1}^{n} a_{i} x_{i=1}\right)^{2}}{\sum_{i=1}^{n}\left(x_{i}-\bar{x}\right)^{2}}
$$

where $x_{(i)}$ is the ranked $i^{\text {th }}$ order $x$ and $\bar{x}$ is the sample mean. The coefficient $a_{i}$ is given by

$$
\left(a_{1}, \ldots, a_{n}\right)=\frac{m^{\mathrm{T}} V^{-1}}{\left(m^{\mathrm{T}} V^{-1} V^{-1} m\right)^{1 / 2}}
$$

where $m=\left(m_{1}, \ldots, m_{n}\right)^{\mathrm{T}}$ and $m_{1}, \ldots, m_{n}$ are the expected values of the order statistics of independent and identically-distributed random variables sampled from the standard normal distribution. $V$ is the covariance matrix of those order statistics.

A non-parametric test, Mann-Kendall, was selected for trend analysis in our study. The advantages of non-parametric tests over parametric methods include no requirement for data normality and resistance to outliers. In the trend analysis, time variable was set as year.

Regional trends were calculated using the trends at individual climate stations and a method presented in Helsel and Frans (2006). Data from different stations were expressed as the following matrixes: 


$$
X=\left(\begin{array}{ccc}
X_{11} & \cdots & X_{1 q} \\
\vdots & \ddots & \vdots \\
X_{n 1} & \cdots & X_{n q}
\end{array}\right)
$$

where $q$ is the number of stations, and $n$ is the number of years.

The Mann-Kendall test statistic for each station is given as:

$$
S_{g}=\sum_{i<j} \operatorname{sgn}\left(X_{j g}-X_{i g}\right) g=1,2 \ldots, q
$$

The regional Kendall test statistic is:

$$
S^{\prime \prime}=\sum_{g=1}^{q} S_{g}
$$

The same estimate standard as Mann-Kendall test was used to compute the statistic and $p$ value of the normal approximation for the overall regional Kendall test.

$$
\begin{gathered}
Z= \begin{cases}\frac{s^{s}-1}{\sigma_{s^{s}}} & \text { if } S^{\prime}>0 \\
0 & \text { if } S^{\prime}=0 \\
\frac{s^{s}+1}{\sigma_{s^{s}}} & \text { if } S^{\prime}<0\end{cases} \\
\sigma_{s^{\prime}}=\sqrt{\sum_{g=1}^{q}\left(\frac{n_{g}}{18}\right)\left(n_{g}-1\right)\left(2 n_{g}+5\right)}
\end{gathered}
$$

where $n_{g}$ is the number of data at the $g^{\text {th }}$ of $q$ locations.

The statistic $Z_{g}^{2}$ was used instead of $Z_{g}$ to test the homogeneity of the regional trend (Van Belle and Hughes 1984). Given the null $\mathrm{H}_{0}$ : $\quad \tau=0$, each $Z^{2}$ has approximately a chi-square distribution with 1 degree of freedom.

The overall statistic is

$$
\begin{gathered}
\chi_{\text {total }}^{2}=\sum_{g=1}^{p} Z_{g}^{2} \\
\chi_{\text {homogenous }}^{2}=\chi_{\text {total }}^{2}-\chi_{\text {trend }}^{2}
\end{gathered}
$$

where $\chi_{\text {trend }}^{2}=m Z^{2}$

To examine if the climate trends are elevation-dependent, of the climate stations were divided into three groups based on their elevation - low, medium and high equally from lowest value to largest value. Krusal-Wallis test was used to compare the different groups. The null hypothesis is the populations from which the 
$k$ data sets have been drawn have the same mean; the alternative hypothesis is at least one population has a mean larger or smaller than at least one other population. The test statistic is given by:

$$
K=\left(\frac{12}{N(N+1)} \sum_{j=1}^{k} n_{j}\left[\overline{R_{j}}-\frac{N+1}{2}\right]^{2}\right.
$$

$N$ is the total number of variables in $j$ groups, $\bar{R}_{j}=\frac{\sum_{i=1}^{n_{j}} R_{i j}}{n_{j j}}, R_{i j}$ is the rank of variables in each group according the whole variables in $j$ groups.

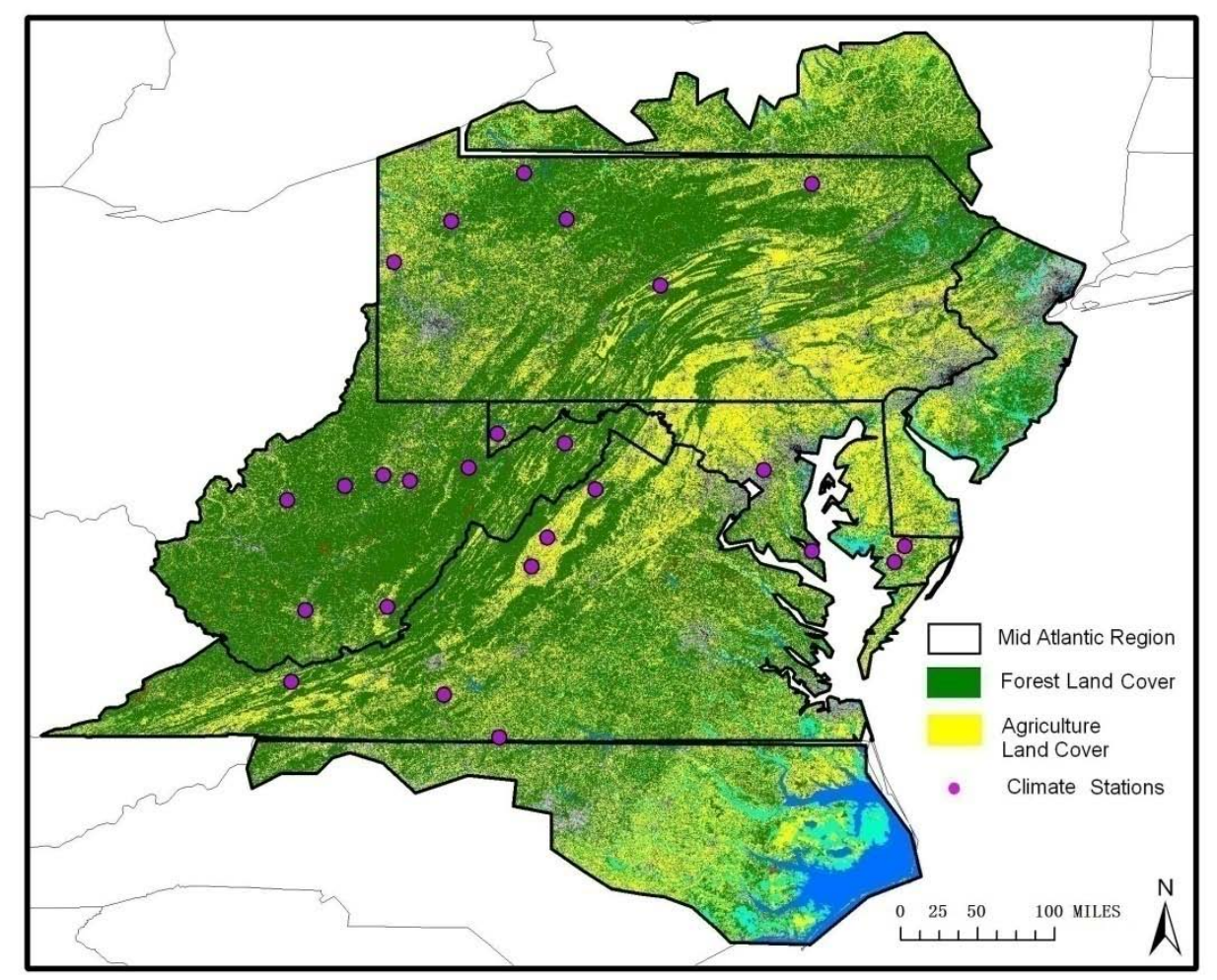

Figure 3-1The Mid-Atlantic Region of the United States (National Land Cover Data 2001 are used.) 
Table 3-1 List of climate stations in the four states (Land cover results are from NLCD 2001).

\begin{tabular}{|c|c|c|c|c|c|}
\hline Station ID & Name & State & Land cover & Elevation(m) & Data range \\
\hline 185111 & Laurel $3 \mathrm{~W}$ & MD & Urban & 121.9 & 1890s present \\
\hline 186620 & $\begin{array}{l}\text { Oakland } 1 \\
\text { SE }\end{array}$ & MD & Urban & 737.6 & 1890s present \\
\hline 187330 & $\begin{array}{l}\text { Princess } \\
\text { Anne }\end{array}$ & MD & $\begin{array}{l}\text { Agriculture } \\
\text { (distance to } \\
\text { urban less } \\
\text { than } 1 \text { mile) }\end{array}$ & 6.1 & 1890s present \\
\hline 188000 & Salisbury & MD & Urban & 3.0 & 1900s present \\
\hline 188405 & Solomons & MD & Urban & 3.7 & $1890 s \sim 1983$ \\
\hline 363028 & Franklin & $\mathrm{PA}$ & Urban & 309.4 & 1890s present \\
\hline 366233 & $\begin{array}{l}\text { New Castle } \\
1 \mathrm{~N}\end{array}$ & $\mathrm{PA}$ & Urban & 251.5 & 1890s present \\
\hline 367477 & Ridgway & PA & Urban & 414.5 & 1900s present \\
\hline 368449 & $\begin{array}{l}\text { State } \\
\text { College }\end{array}$ & PA & Urban & 356.6 & 1890s present \\
\hline 368905 & $\begin{array}{l}\text { Towanda } 1 \\
\text { S }\end{array}$ & PA & $\begin{array}{l}\text { Forest } \\
\text { (distance to } \\
\text { urban less } \\
\text { than } 1 \text { mile) }\end{array}$ & 231.6 & 1890s present \\
\hline 369298 & Warren & PA & Urban & 368.8 & 1890s present \\
\hline 441209 & $\begin{array}{l}\text { Burkes } \\
\text { Garden }\end{array}$ & VA & Agriculture & 935.1 & 1890s present \\
\hline 442208 & $\begin{array}{l}\text { Dale } \\
\text { Enterprise }\end{array}$ & VA & $\begin{array}{l}\text { Agriculture } \\
\text { (distance to } \\
\text { urban less } \\
\text { than } 1 \text { mile) }\end{array}$ & 426.7 & 1890s present \\
\hline 442245 & Danville & VA & Urban & 125 & 1900 s present \\
\hline 447338 & Rocky Mt & VA & Urban & 400.8 & 1890s present \\
\hline 448062 & $\begin{array}{l}\text { Staunton } \\
\text { Water } \\
\text { Trmtmt Plt }\end{array}$ & VA & Urban & 499.9 & 1890s present \\
\hline 449263 & Woodstock & VA & Urban & 271.0 & 1890s present \\
\hline 460580 & $\begin{array}{l}\text { Beckley Va } \\
\text { Hospital }\end{array}$ & WV & Urban & 710.2 & 1890s present \\
\hline 461220 & Buckhannon & WV & Urban & 443.5 & 1890s present \\
\hline 463544 & Glenville & WV & $\begin{array}{l}\text { Agriculture } \\
\text { (distance to } \\
\text { urban less } \\
\text { than } 1 \text { mile) }\end{array}$ & 216.4 & 1890s present \\
\hline 465224 & Lewisburg & WV & Urban & 686.1 & 1900 s present \\
\hline
\end{tabular}


Table 3-1 Continue

\begin{tabular}{|c|c|c|c|c|c|c|}
\hline Station ID & Name & & State & Land cover & Elevation(m) & Data range \\
\hline 466867 & $\begin{array}{l}\text { Parsons } \\
\mathrm{NE}\end{array}$ & 1 & WV & Urban & 556.6 & 1900s present \\
\hline 467730 & Romney & & WV & $\begin{array}{l}\text { Forest } \\
\text { (distance to } \\
\text { urban less } \\
\text { than } 1 \text { mile) }\end{array}$ & 284.1 & 1890s present \\
\hline 468384 & Spencer & & WV & Urban & 287.4 & 1890s present \\
\hline 469436 & Weston & & WV & Urban & 311.8 & 1890s present \\
\hline
\end{tabular}


Table 3-2 Temperature and Precipitation Indices.

\begin{tabular}{|c|c|c|}
\hline Abbreviation & Term & Definition \\
\hline Tmean(TM) & Mean temperature & $\begin{array}{l}\text { Annual average mean } \\
\text { temperature in degree } \\
\text { Fahrenheit }\end{array}$ \\
\hline $\operatorname{Tmax}(\mathrm{TX})$ & Maximum temperature & $\begin{array}{l}\text { Annual average maximum } \\
\text { temperature in degree } \\
\text { Fahrenheit }\end{array}$ \\
\hline $\operatorname{Tmin}(\mathrm{TN})$ & Minimum temperature & $\begin{array}{l}\text { Annual average minimum } \\
\text { temperature in degree } \\
\text { Fahrenheit }\end{array}$ \\
\hline TRANGE & $\begin{array}{l}\text { Difference of Tmax and } \\
\text { Tmin }\end{array}$ & $\begin{array}{l}\text { Difference of annual } \\
\text { average maximum and } \\
\text { minimum temperature }\end{array}$ \\
\hline TX90(TX10) & Warm days (Cool days) & $\begin{array}{l}\text { Annual counts of days } \\
\text { when } \mathrm{TX}>90^{\text {th }} \quad\left(\mathrm{TX}<10^{\text {th }}\right) \\
\text { percentile }\end{array}$ \\
\hline TN90(TN10) & Warm nights (Cool nights) & $\begin{array}{l}\text { Annual counts of days } \\
\text { when } \mathrm{TN}>90^{\text {th }} \quad\left(\mathrm{TN}<10^{\text {th }}\right) \\
\text { percentile }\end{array}$ \\
\hline TXX(TNX) & $\begin{array}{l}\text { Maximum } \\
\text { maximum(minimum) } \\
\text { temperature }\end{array}$ & $\begin{array}{l}\text { Annual maximum } \\
\text { maximum(minimum) } \\
\text { temperature in degree } \\
\text { Fahrenheit }\end{array}$ \\
\hline TXN(TNN) & $\begin{array}{l}\text { Minimum } \\
\text { maximum(minimum) } \\
\text { temperature }\end{array}$ & $\begin{array}{l}\text { Annual minimum } \\
\text { maximum } \\
\text { temperature in degree } \\
\text { Fahrenheit }\end{array}$ \\
\hline CDD & Consecutive dry days & $\begin{array}{l}\text { Maximum number of } \\
\text { consecutive days with no } \\
\text { precipitation }\end{array}$ \\
\hline $\mathrm{PX}$ & $\begin{array}{l}\text { Maximum precipitation } \\
\text { intensity }\end{array}$ & $\begin{array}{l}\text { Maximum annual } \\
\text { precipitation intensity in } \\
\text { in/day }\end{array}$ \\
\hline P95 & Wet day precipitation & $\begin{array}{l}\text { Annual total } P R C P \text { when } \\
\text { PRCP }>95^{\text {th }} \text { percentile }\end{array}$ \\
\hline P95D & Wet days & $\begin{array}{l}\text { Annual counts of days } \\
\text { when } \\
\text { percentile }\end{array}$ \\
\hline
\end{tabular}




\section{Chapter 4 Results}

\subsection{Temperature Trends}

\subsubsection{Annual Trends}

Statistical significance of the trends was determined using the alpha $(\alpha)$ value of 0.05. The results for trends of annual temperatures are shown in Table 4.1. Fourteen out of twenty five stations had decreasing trends in annual mean temperature with 9 being statistically significant. The magnitude of the decreasing slopes ranged from -0.002 to $-0.028{ }^{\circ} \mathrm{F} / \mathrm{yr}$ for all the stations and -0.009 to $-0.028{ }^{\circ} \mathrm{F} / \mathrm{yr}$ for stations with p values less than 0.05. All stations in West Virginia experienced decreasing trends, and 6 of them were statistically significant. The average slope for the 6 stations was $-0.017^{\circ} \mathrm{F} / \mathrm{yr}$. Three significant decreasing trends were found in Virginia with average slope of $-0.02{ }^{\circ} \mathrm{F} / \mathrm{yr}$. The 5 stations in Maryland all occurred to have significant increasing trends for annual mean temperature. The average slope was $0.02{ }^{\circ} \mathrm{F} / \mathrm{yr}$. Increasing trends were also found in Pennsylvania but none were statistically significant.

Annual maximum temperature and annual minimum temperature exhibited similar trends as the annual average temperature. Sixteen decreasing trends were found with 8 being statistically significant. The slopes ranged from -0.001 to -0.042 ${ }^{\circ} \mathrm{F} / \mathrm{yr}$ for all the decreasing trends and the significant trends ranged from -0.013 to $-0.042^{\circ} \mathrm{F} / \mathrm{yr}$. Consistently, the 7 stations in West Virginia showed a decreasing trend as the annual mean temperature did. Four out of the six stations which showed statistically significant trends for annual mean temperature also had p values less than 0.05 for annual maximum temperature. Nevertheless, 3 significant decreasing trends were found in Virginia with average slope of $-0.017^{\circ} \mathrm{F} / \mathrm{yr}$. The average slope of significant increasing trends was $0.028{ }^{\circ} \mathrm{F} / \mathrm{yr}$, two of the stations were located in Maryland and one in Pennsylvania. There were total of four stations with an 
increasing trend in Maryland.

Twelve stations exhibited a decreasing trend in annual minimum temperature and 7 of them were significant. On the other hand, 7 statistically significant increasing trends were found. Except for one station, all West Virginia stations showed a decreasing trend ( 4 of them were significant), similar to annual mean temperature and annual maximum temperature. Range of the decreasing slopes in West Virginia was $-0.009--0.034{ }^{\circ} \mathrm{F} / \mathrm{yr}$ for all decreasing trends. Three significant decreasing trends were found in Virginia with an averaged slope of $-0.026{ }^{\circ} \mathrm{F} / \mathrm{yr}$. All the Maryland stations showed an increasing trend and 3 of them were significant (average slope was $\left.0.033{ }^{\circ} \mathrm{F} / \mathrm{yr}\right)$. One significant increasing trend $\left(0.02{ }^{\circ} \mathrm{F} / \mathrm{yr}\right)$ was found in Virginia, and 3 increasing trends (two slopes being $0.012{ }^{\circ} \mathrm{F} / \mathrm{yr}$ and 1 being $\left.0.014^{\circ} \mathrm{F} / \mathrm{yr}\right)$ in Pennsylvania. The remaining trends were not significant.

The trends for the differences between annual maximum temperature and annual minimum temperature also varied among differently stations (Table 4.2). The number of decreasing trends and increasing trends both were found at nearly half of the stations (13 decreasing trends and 10 increasing trends). Nine out of the 13 decreasing trends were significant and 6 out of the 10 increasing trends were significant. Three (3) stations in West Virginia showed significant increasing trends $\left(0.011{ }^{\circ} \mathrm{F} / \mathrm{yr}, 0.011{ }^{\circ} \mathrm{F} / \mathrm{yr}\right.$, and $\left.0.018{ }^{\circ} \mathrm{F} / \mathrm{yr}\right)$ and two showed significant decreasing trends $\left(-0.031^{\circ} \mathrm{F} / \mathrm{yr}\right.$ and $\left.-0.037^{\circ} \mathrm{F} / \mathrm{yr}\right)$. There were 3 significant decreasing trends $\left(-0.021{ }^{\circ} \mathrm{F} / \mathrm{yr},-0.018{ }^{\circ} \mathrm{F} / \mathrm{yr}\right.$, and $\left.-0.016{ }^{\circ} \mathrm{F} / \mathrm{yr}\right)$ and 1 significant increasing trend $(0.013$ ${ }^{\circ} \mathrm{F} / \mathrm{yr}$ ) in Pennsylvania. One (1) station in Virginia showed a significant decreasing trend $\left(-0.028{ }^{\circ} \mathrm{F} / \mathrm{yr}\right)$ and 2 increasing trends $\left(0.013^{\circ} \mathrm{F} / \mathrm{yr}\right.$ and $\left.0.016{ }^{\circ} \mathrm{F} / \mathrm{yr}\right)$. Three (3) stations in Maryland showed a significant decreasing trend $\left(-0.033{ }^{\circ} \mathrm{F} / \mathrm{yr},-0.028{ }^{\circ} \mathrm{F} / \mathrm{yr}\right.$, and $\left.-0.026^{\circ} \mathrm{F} / \mathrm{yr}\right)$ and 1 increasing trend $\left(0.057^{\circ} \mathrm{F} / \mathrm{yr}\right)$.

Tables 4.3, 4.4, 4.5 and 4.6 listed the results for extreme temperature events. Seventeen stations showed decreasing trend for TX90 (warm days) with 11 of them being statistically significant. All the stations in Virginia had a decreasing trend and 4 of them were significant $(-0.10 \mathrm{~d} / \mathrm{yr},-0.11 \mathrm{~d} / \mathrm{yr},-0.22 \mathrm{~d} / \mathrm{yr}$, and $-0.14 \mathrm{~d} / \mathrm{yr})$. Except for one station, the remainder stations in West Virginia also exhibited a decreasing 
trend for TX90. The magnitude of the slopes was larger than the stations in Virginia with the highest value of $-0.37 \mathrm{~d} / \mathrm{yr}$ and the lowest value of $-0.12 \mathrm{~d} / \mathrm{yr}$. Two significant decreasing trends were also observed at Pennsylvania stations (-0.077 d/yr and $-0.2 \mathrm{~d} / \mathrm{yr}$ ). Alternatively, 2 significant increasing trends were detected in Maryland. The values for the slope were $0.199 \mathrm{~d} / \mathrm{yr}$ and $0.087 \mathrm{~d} / \mathrm{yr}$ respectively.

Among the 8 significant trends found for TX10 (cool days), 4 of them were increasing trends and 3 decreasing trends. Those stations spread out the whole region. Although all of the 7 stations in West Virginia showed an increasing trend, only 2 of them were significant $(0.114 \mathrm{~d} / \mathrm{yr}$ and $0.128 \mathrm{~d} / \mathrm{yr})$. One (1) significant increasing trend was spotted in Pennsylvania (0.1 d/yr) and 1 in Virginia (0.109 d/yr). No trend was found for 3 stations in Pennsylvania and 1 significant decreasing trend with a slope of $-0.098 \mathrm{~d} / \mathrm{yr}$. Two (2) remaining significant decreasing trends were found in Maryland (-0.284 d/yr and $-0.197 \mathrm{~d} / \mathrm{yr})$. The total number decreasing trends identified was 7 regardless of the statistical significance. The number of the increasing trends was two times of the decreasing ones.

Trends for TN90 (warm nights) and TN10 (cool nights) also varied from stations to stations. The number of stations showed a decreasing trend was 13 which exceeded the number of increasing trends by 5 for warm nights. Six (6) out of 7 stations in West Virginia showed a decreasing trend but only 1 of them was statistically significant $(-0.091 \mathrm{~d} / \mathrm{yr})$. Three (3) stations in Virginia showed significant a decreasing trend $(-0.111 \mathrm{~d} / \mathrm{yr},-0.165 \mathrm{~d} / \mathrm{yr}$, and $-0.067 \mathrm{~d} / \mathrm{yr})$ and 1 in Maryland (-0.164 d/yr) which made a total of 6 significant decreasing trends among the 25 stations. The single station had a statistically significant increasing trend in West Virginia (0.098 d/yr). The only two significant trends found in Pennsylvania were increasing trends $(0.067 \mathrm{~d} / \mathrm{yr}$ and $0.095 \mathrm{~d} / \mathrm{yr})$. The 4 remaining significant increasing trends all had a p value less than 0.001. One (1) station was located in Virginia (0.172 d/yr) and 3 were located in Maryland $(0.273 \mathrm{~d} / \mathrm{yr}, 0.138 \mathrm{~d} / \mathrm{yr}$, and $0.160 \mathrm{~d} / \mathrm{yr})$.

Results for TN10 were slightly different from those for TN90. Both 11 decreasing trends and 11 increasing trends were detected. Half of the trends were 
significant. All stations in Maryland experienced a decreasing trend and 4 of them were significant. The average slope was $-0.115 \mathrm{~d} / \mathrm{yr}$ for the 4 stations. Pennsylvania had 1 station with a significant decreasing trend $(-0.083 \mathrm{~d} / \mathrm{yr})$. Regardless of the station that showed no trend, all West Virginia stations showed an increasing trend and 2 were statistically significant $(0.125 \mathrm{~d} / \mathrm{yr}$ and $0.094 \mathrm{~d} / \mathrm{yr})$. The slopes for the significant increasing trends were $0.084 \mathrm{~d} / \mathrm{yr}$ in Pennsylvania and 0.108 $\mathrm{d} / \mathrm{yr}$ and $0.130 \mathrm{~d} / \mathrm{yr}$ for stations in Virginia.

In addition to the frequency of extreme temperature events, the magnitude was also studied. Nearly half of the stations showed no trend for all the four parameters (TXX, TNX, TXN, and TNN). Eight (8) significant decreasing trends were found for TNX ( 3 in WV, 1 in PA, 3 in VA, 2 in MD). The average slope of the decreasing trends was $-0.028^{\circ} \mathrm{F} / \mathrm{yr}$ and $0.03^{\circ} \mathrm{F} / \mathrm{yr}$ for the increasing trends. All TXX trends were decreasing. The average slope for the 11 significant decreasing trends was $-0.025{ }^{\circ} \mathrm{F} / \mathrm{yr}$. The significant trends for TNN were all increasing ( 3 in Pennsylvania, 2 in Virginia, and 1 in Maryland) and the average slope was $0.055^{\circ} \mathrm{F} / \mathrm{yr}$. Only 2 significant trends were found for TXN, 1 was decreasing and the other increasing. The station with a decreasing trend located in West Virginia had slope of $-0.042^{\circ} \mathrm{F} / \mathrm{yr}$. The station with increasing trend was located Maryland $\left(0.049^{\circ} \mathrm{F} / \mathrm{yr}\right)$.

\subsubsection{Seasonal Trends}

Winter (December to February) and summer (June to August) were picked to study the seasonal trend for all parameters.

Most stations showed consistency in the seasonal trends and annual trends of annual mean temperature, annual maximum temperature and annual minimum temperature (Tables 4.7 and 4.8). However, some stations showed mixed trends. At station Warren, in Pennsylvania, annual mean temperature exhibited opposite trends for winter season (positive, not significant) and summer season $\left(-0.009{ }^{\circ} \mathrm{F} / \mathrm{yr}\right.$, significant). Two stations in West Virginia (Romeny and Spencer) showed discrepancy between the seasonal trends and annual trends for annual maximum 
temperature. The station at Romeny (ID 467730) had a significant decreasing trend $\left(-0.013{ }^{\circ} \mathrm{F} / \mathrm{yr}\right)$ for summer but a non-significant increasing trend for winter was detected. The climate station at Spencer (ID 468384) had a significant decreasing trend $\left(-0.065{ }^{\circ} \mathrm{F} / \mathrm{yr}\right)$ for summer season was and a significant increasing trend $(0.037$ ${ }^{\circ} \mathrm{F} / \mathrm{yr}$ ) for the winter season. Two incompatible trends were also discovered for annual minimum temperature. Both significant decreasing trends were found for station at Woodstock (ID 449263, $-0.096{ }^{\circ} \mathrm{F} / \mathrm{yr}$ ) and Princess Anne (ID 187330, -0.017 $\left.{ }^{\circ} \mathrm{F} / \mathrm{yr}\right)$ for the summer season and significant increasing trends $\left(0.076{ }^{\circ} \mathrm{F} / \mathrm{yr}\right.$ and 0.017 ${ }^{\circ} \mathrm{F} / \mathrm{yr}$ ) for the winter season.

Except for three stations, trends for the differences between annual maximum temperature and annual minimum temperature were similar for the seasonal trends and annual trends (Table 4.9). Two stations (Glenville ID463544 and Spencer ID 468384) showed significant decreasing trends for the summer season $\left(-0.021^{\circ} \mathrm{F} / \mathrm{yr}\right.$ and $\left.-0.059^{\circ} \mathrm{F} / \mathrm{yr}\right)$ but significant increasing trends for the winter season $\left(0.016{ }^{\circ} \mathrm{F} / \mathrm{yr}\right.$ and $0.046{ }^{\circ} \mathrm{F} / \mathrm{yr}$ ). At station (Woodstock, ID 449263), a significant increasing trend occurred in summer $\left(0.094^{\circ} \mathrm{F} / \mathrm{yr}\right)$ but a significant decreasing trend occurred in winter $\left(-0.068{ }^{\circ} \mathrm{F} / \mathrm{yr}\right)$

The criterion of greater than the 95th percentile or less than 95th Percentile of individual season instead of the whole year was used to define extreme temperature events at individual climate stations for summer and winter seasons to study severe conditions. Tables 4.10 4.13 showed the results for the two seasons. Seven (7) significant decreasing trends were found for TX90 (warm nights) for summer season and 7 significant increasing trends were found for winter season. Three (3) out of the 7 stations with a significant decreasing trend for TX90 during summer season were located in West Virginia (-0.067 d/yr, $-0.056 \mathrm{~d} / \mathrm{yr}$, and $-0.053 \mathrm{~d} / \mathrm{yr}), 1$ station was in Pennsylvania (-0.067 d/yr), and 3 were in Virginia (-0.053 d/yr, $-0.036 \mathrm{~d} / \mathrm{yr}$, and $-0.057 \mathrm{~d} / \mathrm{yr})$. One (1) out of the 7 stations showed a significant increasing trend for TX90 during winter season was located in West Virginia $(0.024 \mathrm{~d} / \mathrm{yr}), 3$ in Pennsylvania (0.028 d/yr, $0.034 \mathrm{~d} / \mathrm{yr}$, and $0.029 \mathrm{~d} / \mathrm{yr}), 1$ in Virginia $(0.032 \mathrm{~d} / \mathrm{yr})$ and 1 in Maryland $(0.042 \mathrm{~d} / \mathrm{yr})$. Overall $63 \%$ of the stations showed a negative trend for 
warm nights during summer season and only $12 \%$ showed a positive trend with one being statistically significant. Exclude all the stations where no trends were found, during the winter season, all the trends were positive for TX90. The average negative slope was $-0.04 \mathrm{~d} / \mathrm{yr}$ for the summer season and the average positive slope was $0.025 \mathrm{~d} / \mathrm{yr}$ for he winter sason.

Ten stations showed no trends for TX10 (cool days) for the summer season and 8 showed no trends for the winter season. A total of 6 increasing trends were detected with only 1 being significant $(0.029 \mathrm{~d} / \mathrm{yr})$ and 8 decreasing trends were detected with 5 being significant for summer. All the stations in Maryland showed a negative trend for summer and 4 of them were statistically significant. The average slope of the decreasing trend was $0.037 \mathrm{~d} / \mathrm{yr}$. On the other hand, 5 decreasing trends were detected with 2 being significant $(-0.038 \mathrm{~d} / \mathrm{yr}$ and $-0.069 \mathrm{~d} / \mathrm{yr})$ and 9 increasing trends were detected with 3 being significant $(0.03 \mathrm{~d} / \mathrm{yr}, 0.03 \mathrm{~d} / \mathrm{yr}$ and $0.047 \mathrm{~d} / \mathrm{yr})$ for winter.

Ten decreasing trends were found for TN90 (warm nights) for summer time and 8 of them were significant - 3 in West Virginia (-0.04 d/yr, $-0.026 \mathrm{~d} / \mathrm{yr}$, and -0.025 $\mathrm{d} / \mathrm{yr}), 1$ in Pennsylvania $(-0.043 \mathrm{~d} / \mathrm{yr}), 3$ in Virginia $(-0.036 \mathrm{~d} / \mathrm{yr},-0.038 \mathrm{~d} / \mathrm{yr}$, and $-0.019 \mathrm{~d} / \mathrm{yr})$ and 1 in Maryland $(-0.028 \mathrm{~d} / \mathrm{yr})$. A total of 6 significant increasing trends were found. Pennsylvania and Virginia each had one station and Maryland had four. The average slope of the increasing trends was $0.056 \mathrm{~d} / \mathrm{yr}$. Eight (8) negative trends ( 5 significant) and 6 positive trends ( 4 significant) were found for the winter season. The average negative slope was $0.029 \mathrm{~d} / \mathrm{yr}$ and the average positive slope was $0.032 \mathrm{~d} / \mathrm{yr}$. Fourteen decreasing trends were found for TN10 (cool nights) during summer time and 11 of them were significant. All the stations in Pennsylvania and Maryland (except for one) showed a decreasing trend. Only 4 increasing trends were found with 2 being significant. Ten decreasing trends (3 significant) and 5 ricreasing rends (none sgnificant) were found fr TN10 for winter. 


\subsubsection{Homogenous Test}

The $\chi^{2}$ homogeneous test showed significant heterogeneous trends for the 25 (24) stations for all parameters. This suggested that a homogeneous regional trend cannot be formed given the individual trends.

The stations were divided into three groups (low, medium and high) according to their elevation with each group covering a third of the elevation range of the climate stations. Figure 4.1 shows that the slopes of TX10 (cool days) at lower elevation stations tended to be negative and positive at higher elevations. Kruskal-Wallis test indicated significant statistical differences among the three groups $(\mathrm{K}=10.13, \mathrm{p}=0.006)$. Similar results were found for the summer $(\mathrm{K}=5.012, \mathrm{p}=$ 0.082, Figure 4.2) and winter seasons $(\mathrm{K}=5.687, \mathrm{p}=0.058$, Figure 4.3). Decreasing distributions from low elevation stations to high elevation stations were found for minimum annual maximum temperature $(K=6.906, p=0.032$, Figures 4.4$)$. Graphic view showed decreasing trend from low elevation to high elevation for both annual trends and seasonal trends for maximum temperature (Figure 4.5 4.7). However, only winter season showed statistically difference $(K=7.835, p=0.02)$. Similar conclusion was drawn for TX90 (Figure 4.8 4.10). Trends for winter season for parameter TX90 were all greater or equal to zero, and the magnitude tend to decreasing from low elevation to high elevation $(K=7.536, p=0.023)$.

\subsection{Precipitation Trends}

\subsubsection{Annual Trends}

Most of the stations (21 out 25) showed an increasing trend for wet day precipitation and half of them were statistically significant (Table 4.14). There was 1 significant positive trend in West Virginia; the magnitude of the slope was 0.039 in/yr. Four stations in Pennsylvania showed significant positive trend, and the slopes were $0.026 \mathrm{in} / \mathrm{yr}, 0.029 \mathrm{in} / \mathrm{yr}, 0.033 \mathrm{in} / \mathrm{yr}$, and $0.024 \mathrm{in} / \mathrm{yr}$. The remaining 5 
significant trends, 2 of them were located in Virginia (0.042 in/yr and $0.025 \mathrm{in} / \mathrm{yr}$ ) and 3 of them were located in Maryland (0.031 in/yr, $0.035 \mathrm{in} / \mathrm{yr}$, and $0.102 \mathrm{in} / \mathrm{yr})$. One (1) significant negative trend (-0.087 in/yr) was detected in West Virginia.

More than half of the stations showed no trend for the number of days with precipitation greater than $95^{\text {th }}$ percentile (Table 4.14). Nine (9) positive trends were found. A total of 7 significant positive trends included 1 in West Virginia (0.025 d/yr), 3 in Pennsylvania (0.018 d/yr and $0.022 \mathrm{~d} / \mathrm{yr})$, and 2 in Virginia (0.015 d/yr and $0.009 \mathrm{~d} / \mathrm{yr})$ and 1 in Maryland (0.049 d/yr).

Table 4.15 shows the results for severe dry days and severe precipitation intensity. Thirteen out of 25 trends were negative for consecutive dry days (CDD). There were 5 significant negative trends in West Virginia, and the slopes were -0.076 $\mathrm{d} / \mathrm{yr},-0.029 \mathrm{~d} / \mathrm{yr},-0.088 \mathrm{~d} / \mathrm{yr},-0.058 \mathrm{~d} / \mathrm{yr}$, and $-0.060 \mathrm{~d} / \mathrm{yr}$. Three stations in Pennsylvania experienced significant decreasing trends with the slopes being -0.054 $\mathrm{d} / \mathrm{yr},-0.025 \mathrm{~d} / \mathrm{yr}$ and $-0.015 \mathrm{~d} / \mathrm{yr}$. The remaining significant trends were located in Virginia (-0.075 d/yr and $-0.047 \mathrm{~d} / \mathrm{yr})$. Beside the stations where no trend was found, all the stations in Maryland experienced increasing trends. The magnitude of the one significant trend was $0.031 \mathrm{~d} / \mathrm{yr}$.

Eight significant trends were found for maximum precipitation intensity, mostly decreasing. Seven stations in West Virginia showed a decreasing trend and 2 of them were statistically significant $(-0.003 \mathrm{in} / \mathrm{d} / \mathrm{yr}$ and $-0.012 \mathrm{in} / \mathrm{d} / \mathrm{yr})$. The remaining station in West Virginia showed a significant increasing trend with slope of $0.005 \mathrm{in} / \mathrm{d} / \mathrm{yr}$. The other 4 stations had a significant decreasing trend with 1 in Pennsylvania (-0.003 in/d/yr) and 3 in Virginia (-0.004 in/d/yr, $-0.004 \mathrm{in} / \mathrm{d} / \mathrm{yr}$ and $-0.003 \mathrm{in} / \mathrm{d} / \mathrm{yr}$ ). Including the 1 station located in West Virginia, 3 showed significant increasing trends. Both of the 2 trends were located in Maryland (0.006 in/d/yr and $0.011 \mathrm{n} / \mathrm{d} / \mathrm{yr})$.

\subsubsection{Seasonal Trends}

Trends for maximum annual intensity showed moderate discrepancy between 
annual trends and seasonal trends. Only two stations showed a difference. Negative slope was detected for station Glenville, WV (ID 463544) during winter but positive slope was detected during summer. Negative slope was detected for station Franklin, PA (ID 363028) for winter but no trend was found for summer. Several stations accouter the condition that trends of CDD were detected in one season but not the other. Four stations had significant increasing trends for summer but no trends were detected for winter. Four stations had significant decreasing trends for winter season but no trends were detected for summer season.

The criteria for P95 and P95D were defined individually for each season to study severe conditions. Only 1 significant trend was found during the summer season for P95 and 3 during the winter season (Table 4.18). The significant trend in summer had a decreasing slope of -0.03 in/yr. The 3 significant slopes were detected in winter with 1 decreasing trend (-0.03 in/yr) and 2 increasing trends (0.008 in/yr and $0.012 \mathrm{in} / \mathrm{yr}$ ). No trend was found for P95D during both seasons at any station.

\subsubsection{Homogenous Test}

The $\chi^{2}$ homogeneous test showed significant heterogeneous trends among the 25 stations for all parameters. This suggested that a homogeneous regional trend cannot be formed given the individual trends.

After dividing the station into three groups, results showed the trends tend to decreasing from low elevation stations to high elevations for P95 and PX (Figures 4.11 4.16).

Figure 4.11 shows that the slopes of annual precipitation amount exceeding $95^{\text {th }}$ percentile at lower elevation stations tended to be positive and negative at higher elevations. Kruskal-Wallis test indicated significant statistical differences among the three groups $(\mathrm{K}=14.17, \mathrm{p}<0.001)$. Similar results were found for the summer $(\mathrm{K}=$ 7.465, $\mathrm{p}=0.024$, Figure 4.12). The difference for winter season was not statistically significant. Similar decreasing distributions from low elevation stations to high elevation stations were found for annual maximum precipitation intensity ( $K=10.617$, 
$\mathrm{p}=0.005$, Figures 4.14). Although graphic view showed differences among the three groups, Kruska-Wallis test results showed no significant differences between the groups for summer seasonal maximum precipitation intensity $(K=4.946, p=0.084$, Figure 4.15), and winter seasonal maximum precipitation intensity ( $\mathrm{K}=3.162$, $\mathrm{p}=0.206$, Figure 4.16). Only the medium elevation group showed discrepancy with the other two with median value being zero ( $K=9.540$, $p=0.008$, Figure 4.17). 
Table 4-1 Slopes and $\mathrm{P}$ values for annual temperature. Significant trends are indicated in bold characters $(\mathrm{P}<0.05)$. Italic stands for increasing trend and normal format stands for decreasing trends.

\begin{tabular}{|c|c|c|c|c|c|c|}
\hline & \multicolumn{2}{|c|}{ Tmean } & \multicolumn{2}{|c|}{ Tmax } & \multicolumn{2}{|c|}{ Tmin } \\
\hline & Slope $\left({ }^{\circ} \mathrm{F} / \mathrm{yr}\right)$ & $\mathrm{P}$ & Slope $\left({ }^{\circ} \mathrm{F} / \mathrm{yr}\right)$ & $\mathrm{P}$ & Slope $\left({ }^{\circ} \mathrm{F} / \mathrm{yr}\right)$ & $\mathrm{P}$ \\
\hline \multicolumn{7}{|l|}{ WV } \\
\hline 460580 & -0.028 & $<0.001$ & -0.042 & $<0.001$ & -0.013 & 0.034 \\
\hline 461220 & -0.005 & 0.249 & 0.005 & 0.363 & -0.013 & 0.006 \\
\hline 463544 & -0.016 & 0.006 & -0.023 & 0.015 & -0.014 & 0.004 \\
\hline 465224 & -0.008 & 0.06 & -0.007 & 0.228 & -0.009 & 0.064 \\
\hline 466867 & -0.014 & 0.005 & -0.033 & $<0.001$ & 0.005 & 0.367 \\
\hline 467730 & -0.009 & 0.043 & -0.004 & 0.442 & -0.009 & 0.042 \\
\hline 468384 & -0.015 & 0.007 & -0.013 & 0.024 & -0.011 & 0.131 \\
\hline 469436 & -0.022 & 0.003 & -0.016 & 0.036 & -0.034 & $<0.001$ \\
\hline \multicolumn{7}{|l|}{ PA } \\
\hline 363028 & No trend & & -0.006 & 0.219 & 0.012 & 0.004 \\
\hline 366233 & 0.01 & 0.064 & 0.005 & 0.407 & 0.012 & 0.021 \\
\hline 367477 & -0.011 & 0.059 & -0.02 & 0.006 & -0.005 & 0.429 \\
\hline 368445 & 0.006 & 0.108 & 0.009 & 0.057 & 0.007 & 0.125 \\
\hline 368905 & 0.005 & 0.177 & 0.011 & 0.017 & -0.001 & 0.806 \\
\hline 369298 & 0.007 & 0.105 & -0.001 & 0.746 & 0.014 & 0.005 \\
\hline \multicolumn{7}{|l|}{ VA } \\
\hline 441209 & -0.002 & 0.646 & -0.004 & 0.364 & No trend & \\
\hline 442208 & 0.004 & 0.253 & -0.014 & 0.002 & 0.02 & $<0.001$ \\
\hline 442245 & -0.022 & $<0.001$ & -0.02 & 0.002 & -0.028 & $<0.001$ \\
\hline 447338 & -0.017 & 0.003 & -0.01 & 0.101 & -0.021 & 0.001 \\
\hline 448062 & -0.023 & $<0.001$ & -0.018 & $<0.001$ & -0.029 & $<0.001$ \\
\hline 449263 & -0.002 & 0.65 & 0.002 & 0.668 & -0.002 & 0.601 \\
\hline \multicolumn{7}{|l|}{$\mathrm{MD}$} \\
\hline 185111 & 0.024 & $<0.001$ & 0.006 & 0.168 & 0.041 & $<0.001$ \\
\hline 186620 & 0.012 & 0.006 & -0.004 & 0.482 & 0.026 & $<0.001$ \\
\hline 187330 & 0.029 & $<0.001$ & 0.055 & $<0.001$ & 0.002 & 0.617 \\
\hline 188000 & 0.017 & 0.001 & 0.004 & 0.523 & 0.032 & $<0.001$ \\
\hline 188405 & 0.014 & 0.013 & 0.019 & 0.004 & 0.01 & 0.092 \\
\hline
\end{tabular}


Table 4-2 Slopes and $\mathrm{P}$ values for the difference between annual maximum and annual minimum temperature. Significant trends are indicated in bold characters $(\mathrm{P}<0.05)$. Italic stands for increasing trend and normal format stands for decreasing trends.

\begin{tabular}{|c|c|c|}
\hline & \multicolumn{2}{|c|}{ TRANGE } \\
\hline & Slope $\left({ }^{\circ} \mathrm{F} / \mathrm{yr}\right)$ & $\mathrm{P}$ \\
\hline \multicolumn{3}{|l|}{ WV } \\
\hline 460580 & -0.031 & 0.001 \\
\hline 461220 & 0.011 & 0.017 \\
\hline 463544 & -0.003 & 0.622 \\
\hline 465224 & No trend & \\
\hline 466867 & -0.037 & $<0.001$ \\
\hline 467730 & 0.011 & 0.048 \\
\hline 468384 & -0.001 & 0.925 \\
\hline \multicolumn{3}{|l|}{469436} \\
\hline \multicolumn{3}{|l|}{$\mathrm{PA}$} \\
\hline 363028 & -0.021 & $<0.001$ \\
\hline 366233 & -0.002 & 0.566 \\
\hline 367477 & -0.018 & 0.017 \\
\hline 368445 & 0.002 & 0.515 \\
\hline 368905 & 0.013 & 0.001 \\
\hline 369298 & -0.016 & 0.003 \\
\hline \multicolumn{3}{|l|}{ VA } \\
\hline 441209 & -0.003 & 0.427 \\
\hline 442208 & -0.028 & $<0.001$ \\
\hline 442245 & 0.008 & 0.153 \\
\hline 447338 & 0.013 & 0.027 \\
\hline 448062 & 0.016 & 0.032 \\
\hline 449263 & 0.005 & 0.362 \\
\hline \multicolumn{3}{|l|}{ MD } \\
\hline 185111 & -0.033 & $<0.001$ \\
\hline 186620 & -0.028 & $<0.001$ \\
\hline 187330 & 0.057 & $<0.001$ \\
\hline 188000 & -0.026 & $<0.001$ \\
\hline 188405 & 0.006 & 0.151 \\
\hline
\end{tabular}


Table 4-3 Slopes and P values for warm days and cool days. Significant trends are indicated in bold characters $(\mathrm{P}<0.05)$. Italic stands for increasing trend and normal format stands for decreasing trends.

\begin{tabular}{|c|c|c|c|c|}
\hline & \multicolumn{2}{|c|}{ TX90(Warm Days) } & \multicolumn{2}{|c|}{ TX10(Cool Days) } \\
\hline & Slope(d/yr) & $\mathrm{P}$ & Slope(d/yr) & $\mathrm{P}$ \\
\hline \multicolumn{5}{|c|}{ WV Stations } \\
\hline 460580 & -0.367 & $<0.001$ & 0.114 & 0.017 \\
\hline 461220 & 0.016 & 0.666 & 0.034 & 0.265 \\
\hline 463544 & -0.253 & $<0.001$ & 0.017 & 0.593 \\
\hline 465224 & -0.031 & 0.427 & 0.06 & 0.106 \\
\hline 466867 & -0.25 & $<0.001$ & 0.128 & 0.001 \\
\hline 467730 & -0.124 & 0.002 & 0.016 & 0.652 \\
\hline 468384 & -0.348 & $<0.001$ & 0.016 & 0.572 \\
\hline \multicolumn{5}{|l|}{469436} \\
\hline \multicolumn{5}{|c|}{ PA Stations } \\
\hline 363028 & -0.077 & 0.029 & No trend & \\
\hline 366233 & -0.057 & 0.275 & No trend & \\
\hline 367477 & -0.2 & 0.002 & 0.1 & 0.014 \\
\hline 368445 & 0.024 & 0.474 & -0.036 & 0.186 \\
\hline 368905 & No trend & & -0.098 & 0.004 \\
\hline 369298 & 0.014 & 0.697 & No trend & \\
\hline \multicolumn{5}{|c|}{ VA Stations } \\
\hline 441209 & -0.028 & 0.484 & 0.061 & 0.052 \\
\hline 442208 & -0.1 & 0.024 & 0.043 & 0.192 \\
\hline 442245 & -0.111 & 0.021 & 0.109 & 0.017 \\
\hline 447338 & -0.074 & 0.143 & 0.059 & 0.112 \\
\hline 448062 & -0.222 & $<0.001$ & 0.048 & 0.097 \\
\hline 449263 & -0.143 & 0.006 & -0.023 & 0.550 \\
\hline \multicolumn{5}{|c|}{ MD Stations } \\
\hline 185111 & 0.067 & 0.080 & -0.042 & 0.201 \\
\hline 186620 & -0.089 & 0.058 & 0.039 & 0.187 \\
\hline 187330 & 0.199 & $<0.001$ & -0.284 & $<0.001$ \\
\hline 188000 & -0.026 & 0.544 & -0.064 & 0.124 \\
\hline 188405 & 0.087 & 0.003 & -0.197 & $<0.001$ \\
\hline
\end{tabular}


Table 4-4 Slopes and P values for warm nights and cool nights. Significant trends are indicated in bold characters $(\mathrm{P}<0.05)$. Italic stands for increasing trend and normal format stands for decreasing trends.

\begin{tabular}{|c|c|c|c|c|}
\hline & \multicolumn{2}{|c|}{ TN90(Warm Nights) } & \multicolumn{2}{|c|}{ TN10(Cool Nights) } \\
\hline & Slope(d/yr) & $\mathrm{P}$ & Slope(d/yr) & $\mathrm{P}$ \\
\hline \multicolumn{5}{|c|}{ WV Stations } \\
\hline 460580 & -0.074 & 0.056 & 0.125 & $<0.001$ \\
\hline 461220 & No trend & & 0.094 & 0.004 \\
\hline 463544 & -0.091 & 0.006 & 0.047 & 0.168 \\
\hline 465224 & -0.039 & 0.295 & 0.059 & 0.079 \\
\hline 466867 & 0.098 & 0.006 & No trend & \\
\hline 467730 & -0.014 & 0.645 & 0.053 & 0.150 \\
\hline 468384 & -0.044 & 0.243 & 0.061 & 0.075 \\
\hline \multicolumn{5}{|l|}{469436} \\
\hline \multicolumn{5}{|c|}{ PA Stations } \\
\hline 363028 & 0.022 & 0.396 & -0.051 & 0.157 \\
\hline 366233 & 0.063 & 0.061 & -0.038 & 0.328 \\
\hline 367477 & -0.048 & 0.194 & 0.084 & 0.048 \\
\hline 368445 & 0.067 & 0.033 & -0.031 & 0.332 \\
\hline 368905 & -0.012 & 0.551 & -0.028 & 0.409 \\
\hline 369298 & 0.095 & 0.003 & -0.030 & 0.370 \\
\hline \multicolumn{5}{|c|}{ VA Stations } \\
\hline 441209 & No trend & & No trend & \\
\hline 442208 & 0.172 & $<0.001$ & -0.083 & 0.016 \\
\hline 442245 & -0.054 & 0.285 & 0.108 & 0.011 \\
\hline 447338 & -0.111 & 0.009 & 0.057 & 0.092 \\
\hline 448062 & -0.165 & $<0.001$ & 0.130 & $<0.001$ \\
\hline 449263 & -0.067 & 0.038 & 0.012 & 0.671 \\
\hline \multicolumn{5}{|c|}{ MD Stations } \\
\hline 185111 & 0.273 & $<0.001$ & -0.162 & $<0.001$ \\
\hline 186620 & 0.138 & $<0.001$ & -0.031 & 0.235 \\
\hline 187330 & -0.164 & $<0.001$ & -0.090 & 0.012 \\
\hline 188000 & 0.160 & $<0.001$ & -0.128 & 0.001 \\
\hline 188405 & -0.050 & 0.079 & -0.080 & 0.005 \\
\hline
\end{tabular}


Table 4-5 Slopes and $\mathrm{P}$ values for maximum annual maximum temperature and annual minimum temperature. Significant trends are indicated in bold characters $(\mathrm{P}<0.05)$. Italic stands for increasing trend and normal format stands for decreasing trends.

\begin{tabular}{|c|c|c|c|c|}
\hline & \multicolumn{2}{|c|}{ TNX } & \multicolumn{2}{|c|}{ TXX } \\
\hline & Slope $\left({ }^{\circ} \mathrm{F} / \mathrm{yr}\right)$ & $\mathrm{P}$ & Slope $\left({ }^{\circ} \mathrm{F} / \mathrm{yr}\right)$ & $\mathrm{P}$ \\
\hline \multicolumn{5}{|l|}{ WV } \\
\hline 460580 & -0.024 & 0.001 & -0.025 & 0.01 \\
\hline 461220 & No trend & & No trend & \\
\hline 463544 & No trend & & -0.021 & 0.024 \\
\hline 465224 & No trend & & -0.013 & 0.029 \\
\hline 466867 & No trend & & -0.034 & $<0.001$ \\
\hline 467730 & -0.043 & $<0.001$ & -0.012 & 0.078 \\
\hline 468384 & No trend & & No trend & \\
\hline \multicolumn{5}{|l|}{469436} \\
\hline \multicolumn{5}{|l|}{$\mathrm{PA}$} \\
\hline 363028 & No trend & & -0.024 & 0.006 \\
\hline 366233 & No trend & & -0.022 & 0.013 \\
\hline 367477 & -0.029 & $<0.001$ & -0.05 & $<0.001$ \\
\hline 368445 & No trend & & -0.011 & 0.037 \\
\hline 368905 & No trend & & No trend & \\
\hline 369298 & No trend & & No trend & \\
\hline \multicolumn{5}{|l|}{ VA } \\
\hline 441209 & No trend & & -0.02 & 0.006 \\
\hline 442208 & No trend & & No trend & \\
\hline 442245 & -0.017 & 0.013 & -0.029 & 0.002 \\
\hline 447338 & -0.029 & $<0.001$ & -0.01 & 0.075 \\
\hline 448062 & No trend & & -0.024 & 0.003 \\
\hline 449263 & -0.025 & $<0.001$ & No trend & \\
\hline \multicolumn{5}{|l|}{ MD } \\
\hline 185111 & 0.04 & $<0.001$ & No trend & \\
\hline 186620 & 0.01 & 0.052 & No trend & \\
\hline 187330 & No trend & & No trend & \\
\hline 188000 & 0.02 & $<0.001$ & -0.011 & 0.065 \\
\hline 188405 & No trend & & No trend & \\
\hline
\end{tabular}


Table 4-6 Slopes and P values for minimum annual maximum temperature and annual minimum temperature. Significant trends are indicated in bold characters $(\mathrm{P}<0.05)$. Italic stands for increasing trend and normal format stands for decreasing trends.

\begin{tabular}{|c|c|c|c|c|}
\hline & \multicolumn{2}{|c|}{ TNN } & \multicolumn{2}{|c|}{ TXN } \\
\hline & Slope $\left({ }^{\circ} \mathrm{F} / \mathrm{yr}\right)$ & $\mathrm{P}$ & Slope $\left({ }^{\circ} \mathrm{F} / \mathrm{yr}\right)$ & $\mathrm{P}$ \\
\hline \multicolumn{5}{|l|}{ WV } \\
\hline 460580 & No trend & & -0.028 & 0.179 \\
\hline 461220 & No trend & & No trend & \\
\hline 463544 & 0.038 & 0.088 & 0.013 & 0.348 \\
\hline 465224 & No trend & & -0.042 & 0.018 \\
\hline 466867 & -0.032 & 0.08 & -0.029 & 0.133 \\
\hline 467730 & No trend & & -0.023 & 0.129 \\
\hline 468384 & 0.021 & 0.289 & 0.02 & 0.274 \\
\hline \multicolumn{5}{|l|}{469436} \\
\hline \multicolumn{5}{|l|}{$\mathrm{PA}$} \\
\hline 363028 & 0.048 & 0.016 & -0.013 & 0.288 \\
\hline 366233 & 0.034 & 0.096 & No trend & \\
\hline 367477 & No trend & & -0.02 & 0.289 \\
\hline 368445 & 0.037 & 0.01 & No trend & \\
\hline 368905 & 0.034 & 0.063 & 0.026 & 0.121 \\
\hline 369298 & 0.063 & 0.001 & No trend & \\
\hline \multicolumn{5}{|l|}{ VA } \\
\hline 441209 & No trend & & -0.024 & 0.155 \\
\hline 442208 & 0.054 & 0.007 & No trend & \\
\hline 442245 & No trend & & -0.027 & 0.141 \\
\hline 447338 & No trend & & No trend & \\
\hline 448062 & No trend & & No trend & \\
\hline 449263 & 0.08 & $<0.001$ & 0.022 & 0.203 \\
\hline \multicolumn{5}{|l|}{ MD } \\
\hline 185111 & 0.047 & 0.014 & 0.018 & 0.194 \\
\hline 186620 & 0.04 & 0.107 & No trend & \\
\hline 187330 & No trend & & 0.049 & 0.001 \\
\hline 188000 & 0.023 & 0.183 & No trend & \\
\hline 188405 & 0.022 & 0.104 & 0.03 & 0.056 \\
\hline
\end{tabular}


Table 4-7 Slopes and $\mathrm{P}$ values for annual temperature for the summer season. Significant trends are indicated in bold characters $(\mathrm{P}<0.05)$. Italic stands for increasing trend and normal format stands for decreasing trends.

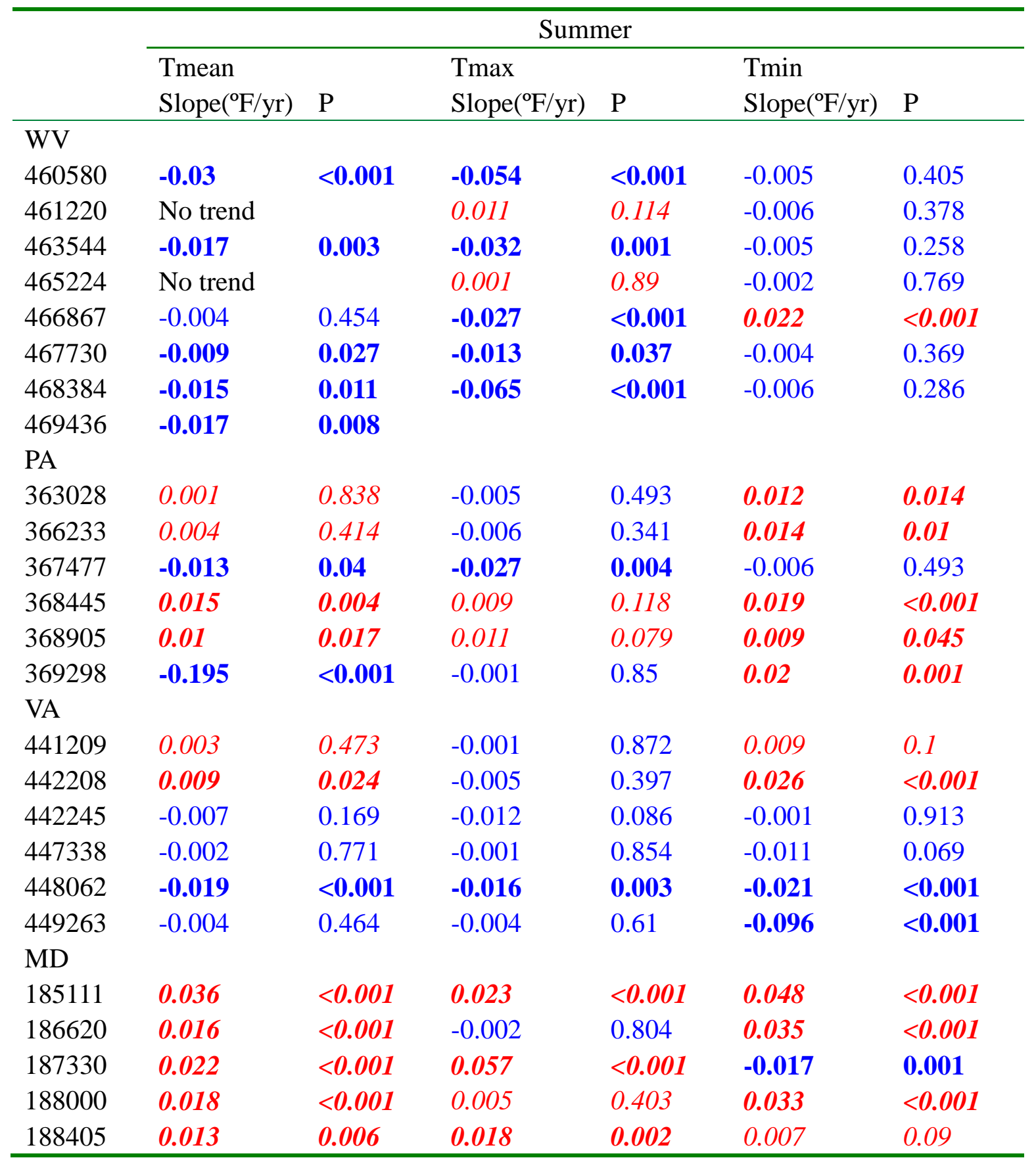


Table 4-8 Slopes and $\mathrm{P}$ values for annual temperature for the winter season. Significant trends are indicated in bold characters $(\mathrm{P}<0.05)$. Italic stands for increasing trend and normal format stands for decreasing trends.

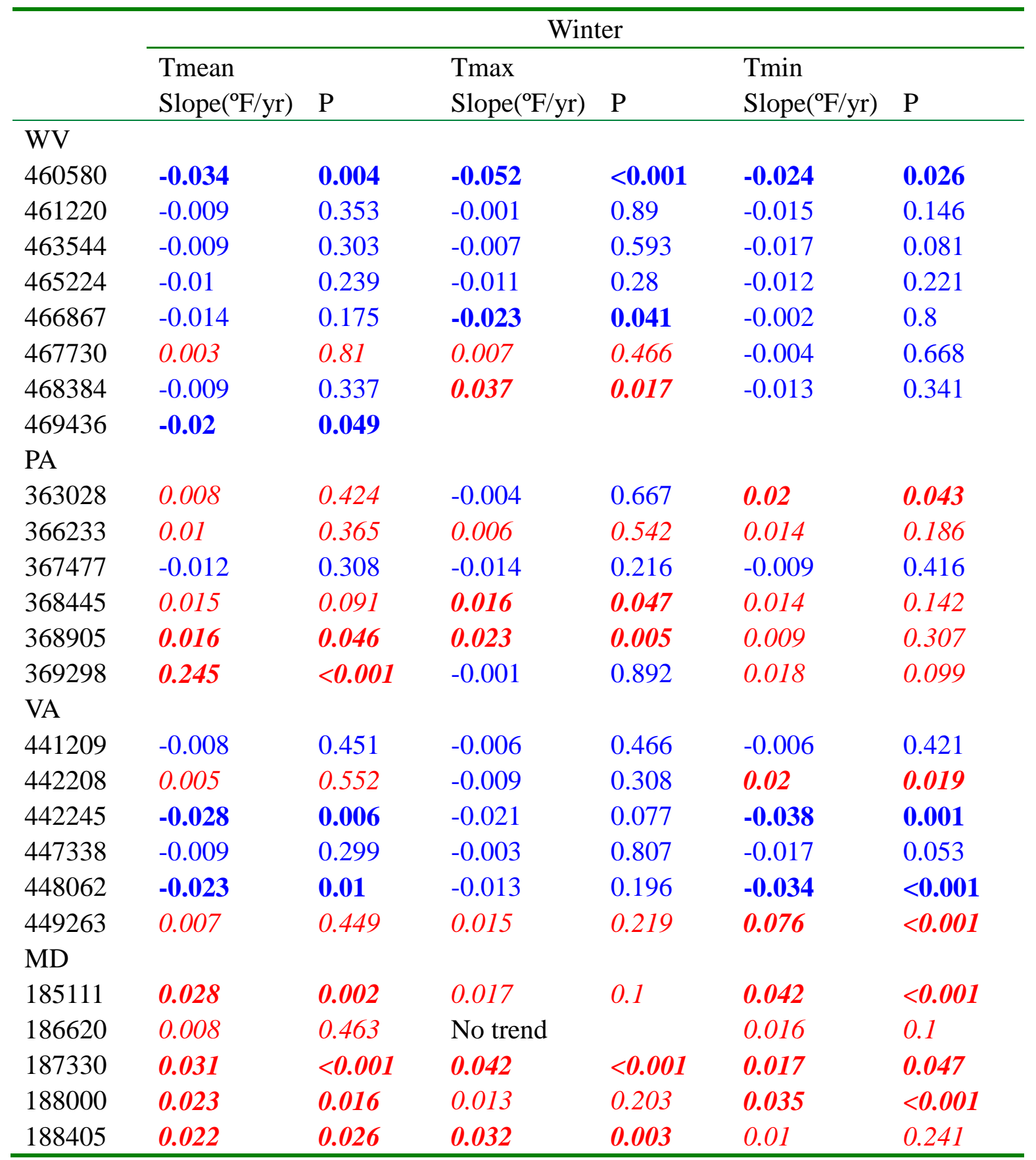


Table 4-9 Slopes and P values for annual temperature for summer and winter season. Significant trends are indicated in bold characters $(\mathrm{P}<0.05)$. Italic stands for increasing trend and normal format stands for decreasing trends.

\begin{tabular}{|c|c|c|c|c|}
\hline & \multicolumn{4}{|c|}{ TRANGE } \\
\hline & \multicolumn{2}{|c|}{ Winter } & \multicolumn{2}{|c|}{ Summer } \\
\hline & Slope $\left({ }^{\circ} \mathrm{F} / \mathrm{yr}\right)$ & $\mathrm{P}$ & Slope $\left({ }^{\circ} \mathrm{F} / \mathrm{yr}\right)$ & $\mathrm{P}$ \\
\hline \multicolumn{5}{|l|}{ WV } \\
\hline 460580 & -0.017 & 0.073 & -0.052 & $<0.001$ \\
\hline 461220 & 0.01 & 0.076 & 0.005 & 0.523 \\
\hline 463544 & 0.016 & 0.05 & -0.021 & 0.013 \\
\hline 465224 & 0.001 & 0.846 & 0.001 & 0.903 \\
\hline 466867 & -0.023 & $<0.001$ & -0.046 & $<0.001$ \\
\hline 467730 & 0.009 & 0.189 & -0.004 & 0.563 \\
\hline 468384 & 0.046 & 0.001 & -0.059 & $<0.001$ \\
\hline \multicolumn{5}{|l|}{469436} \\
\hline \multicolumn{5}{|l|}{$\mathrm{PA}$} \\
\hline 363028 & -0.024 & $<0.001$ & -0.017 & 0.013 \\
\hline 366233 & -0.01 & 0.042 & -0.018 & 0.006 \\
\hline 367477 & -0.009 & 0.283 & -0.03 & 0.007 \\
\hline 368449 & 0.002 & 0.58 & -0.008 & 0.109 \\
\hline 368905 & 0.013 & 0.004 & 0.003 & 0.656 \\
\hline 369298 & -0.018 & 0.008 & -0.017 & 0.01 \\
\hline \multicolumn{5}{|l|}{ VA } \\
\hline 441209 & 0.002 & 0.721 & -0.007 & 0.226 \\
\hline 442208 & -0.033 & $<0.001$ & -0.029 & $<0.001$ \\
\hline 442245 & 0.019 & 0.003 & -0.011 & 0.208 \\
\hline 447338 & 0.018 & 0.01 & 0.016 & 0.074 \\
\hline 448062 & 0.031 & $<0.001$ & 0.002 & 0.742 \\
\hline 449263 & -0.068 & $<0.001$ & 0.094 & $<0.001$ \\
\hline \multicolumn{5}{|l|}{ MD } \\
\hline 185111 & -0.026 & $<0.001$ & -0.024 & $<0.001$ \\
\hline 186620 & -0.018 & 0.001 & -0.036 & $<0.001$ \\
\hline 187330 & 0.024 & $<0.001$ & 0.074 & $<0.001$ \\
\hline 188000 & -0.02 & $<0.001$ & -0.028 & $<0.001$ \\
\hline 188405 & 0.014 & 0.012 & 0.007 & 0.104 \\
\hline
\end{tabular}


Table 4-10 Slopes and P values for TX90 (warm days) and TX10 (cool days) during the summer season. Significant trends are indicated in bold characters $(\mathrm{P}<0.05)$. Italic stands for increasing trend and normal format stands for decreasing trends.

\begin{tabular}{|c|c|c|c|c|}
\hline & \multicolumn{4}{|c|}{ Summer } \\
\hline & \multicolumn{2}{|c|}{ TX90(Warm Days) } & \multicolumn{2}{|c|}{ TX10(Cool Days) } \\
\hline & Slope(d/yr) & $\mathrm{P}$ & Slope(d/yr) & $\mathrm{P}$ \\
\hline \multicolumn{5}{|l|}{ WV } \\
\hline 460580 & -0.067 & 0.006 & 0.065 & $<0.001$ \\
\hline 461220 & No trend & & -0.013 & 0.224 \\
\hline 463544 & -0.056 & 0.035 & 0.029 & 0.026 \\
\hline 465224 & -0.015 & 0.369 & No trend & \\
\hline 466867 & -0.053 & 0.004 & 0.02 & 0.121 \\
\hline 467730 & -0.029 & 0.108 & 0.011 & 0.212 \\
\hline 468384 & -0.036 & 0.13 & No trend & \\
\hline \multicolumn{5}{|l|}{469436} \\
\hline \multicolumn{5}{|l|}{ PA } \\
\hline 363028 & -0.012 & 0.345 & No trend & \\
\hline 366233 & -0.037 & 0.071 & No trend & \\
\hline 367477 & -0.067 & 0.002 & 0.017 & 0.226 \\
\hline 368445 & No trend & & No trend & \\
\hline 368905 & No trend & & -0.026 & 0.028 \\
\hline 369298 & No trend & & No trend & \\
\hline \multicolumn{5}{|l|}{ VA } \\
\hline 441209 & -0.023 & 0.155 & No trend & \\
\hline 442208 & No trend & & No trend & \\
\hline 442245 & -0.053 & 0.026 & No trend & \\
\hline 447338 & -0.036 & 0.026 & No trend & \\
\hline 448062 & -0.057 & 0.002 & 0.017 & 0.128 \\
\hline 449263 & -0.022 & 0.181 & -0.018 & 0.138 \\
\hline \multicolumn{5}{|l|}{$\mathrm{MD}$} \\
\hline 185111 & 0.013 & 0.299 & -0.033 & 0.003 \\
\hline 186620 & -0.022 & 0.248 & -0.012 & 0.151 \\
\hline 187330 & 0.063 & 0.004 & -0.113 & $<0.001$ \\
\hline 188000 & -0.013 & 0.372 & -0.037 & 0.005 \\
\hline 188405 & No trend & & -0.049 & $<0.001$ \\
\hline
\end{tabular}


Table 4-11 Slopes and P values for TX90 (warm days) and TX10 (cool days) during the winter season. Significant trends are indicated in bold characters $(\mathrm{P}<0.05)$. Italic stands for increasing trend and normal format stands for decreasing trends.

\begin{tabular}{|c|c|c|c|c|}
\hline & \multicolumn{4}{|c|}{ Winter } \\
\hline & \multicolumn{2}{|c|}{ TX90(Warm Days) } & \multicolumn{2}{|c|}{ TX10(Cool Days) } \\
\hline & Slope(d/yr) & $\mathrm{P}$ & Slope(d/yr) & $\mathrm{P}$ \\
\hline \multicolumn{5}{|l|}{ WV } \\
\hline 460580 & No trend & & 0.022 & 0.144 \\
\hline 461220 & 0.024 & 0.024 & No trend & \\
\hline 463544 & 0.01 & 0.375 & No trend & \\
\hline 465224 & No trend & & 0.03 & 0.036 \\
\hline 466867 & No trend & & 0.03 & 0.026 \\
\hline 467730 & 0.023 & 0.121 & & \\
\hline 468384 & 0.031 & 0.064 & -0.02 & 0.213 \\
\hline \multicolumn{5}{|l|}{469436} \\
\hline \multicolumn{5}{|l|}{ PA } \\
\hline 363028 & No trend & & No trend & \\
\hline 366233 & 0.014 & 0.292 & 0.013 & 0.359 \\
\hline 367477 & No trend & & 0.033 & 0.111 \\
\hline 368445 & 0.028 & 0.032 & No trend & \\
\hline 368905 & 0.034 & 0.008 & -0.038 & 0.01 \\
\hline 369298 & 0.029 & 0.024 & No trend & \\
\hline \multicolumn{5}{|l|}{ VA } \\
\hline 441209 & No trend & & 0.021 & 0.09 \\
\hline 442208 & No trend & & No trend & \\
\hline 442245 & No trend & & 0.047 & 0.028 \\
\hline 447338 & 0.016 & 0.257 & 0.019 & 0.151 \\
\hline 448062 & No trend & & 0.011 & 0.351 \\
\hline 449263 & 0.032 & 0.04 & -0.029 & 0.07 \\
\hline \multicolumn{5}{|l|}{ MD } \\
\hline 185111 & 0.035 & 0.016 & No trend & \\
\hline 186620 & 0.02 & 0.179 & No trend & \\
\hline 187330 & 0.019 & 0.086 & -0.069 & $<0.001$ \\
\hline 188000 & 0.027 & 0.065 & No trend & \\
\hline 188405 & 0.042 & 0.012 & -0.032 & 0.054 \\
\hline
\end{tabular}


Table 4-12 Slopes and P values for TN90 (warm nights) and TN10 (cool nights) during the summer season. Significant trends are indicated in bold characters $(\mathrm{P}<0.05)$. Italic stands for increasing trend and normal format stands for decreasing trends.

\begin{tabular}{|c|c|c|c|c|}
\hline & \multicolumn{4}{|c|}{ Summer } \\
\hline & \multicolumn{2}{|c|}{ TN90(Warm Nights) } & \multicolumn{2}{|c|}{ TN10(Cool Nights) } \\
\hline & Slope(d/yr) & $\mathrm{P}$ & Slope(d/yr) & $\mathrm{P}$ \\
\hline \multicolumn{5}{|l|}{ WV } \\
\hline 460580 & -0.04 & 0.012 & -0.016 & 0.218 \\
\hline 461220 & -0.012 & 0.345 & 0.013 & 0.344 \\
\hline 463544 & -0.014 & 0.173 & No trend & \\
\hline 465224 & No trend & & No trend & \\
\hline 466867 & 0.016 & 0.053 & -0.051 & 0.001 \\
\hline 467730 & -0.026 & 0.041 & No trend & \\
\hline 468384 & -0.025 & 0.046 & No trend & \\
\hline \multicolumn{5}{|l|}{469436} \\
\hline \multicolumn{5}{|l|}{ PA } \\
\hline 363028 & No trend & & -0.055 & $<0.001$ \\
\hline 366233 & No trend & & -0.026 & 0.055 \\
\hline 367477 & -0.043 & 0.036 & -0.028 & 0.094 \\
\hline 368445 & No trend & & -0.043 & $<0.001$ \\
\hline 368905 & No trend & & -0.037 & $<0.001$ \\
\hline 369298 & 0.039 & 0.005 & -0.056 & $<0.001$ \\
\hline \multicolumn{5}{|l|}{ VA } \\
\hline 441209 & No trend & & -0.026 & 0.044 \\
\hline 442208 & 0.042 & 0.009 & -0.05 & $<0.001$ \\
\hline 442245 & No trend & & No trend & \\
\hline 447338 & -0.036 & 0.015 & No trend & \\
\hline 448062 & -0.038 & 0.002 & 0.018 & 0.152 \\
\hline 449263 & -0.091 & $<0.001$ & 0.077 & $<0.001$ \\
\hline \multicolumn{5}{|l|}{ MD } \\
\hline 185111 & 0.1 & $<0.001$ & -0.103 & $<0.001$ \\
\hline 186620 & 0.071 & $<0.001$ & -0.069 & $<0.001$ \\
\hline 187330 & -0.028 & 0.044 & 0.047 & 0.002 \\
\hline 188000 & 0.065 & $<0.001$ & -0.091 & $<0.001$ \\
\hline 188405 & 0.019 & 0.031 & -0.019 & 0.111 \\
\hline
\end{tabular}


Table 4-13 Slopes and P values for TN90 (warm nights) and TN10 (cool nights) during the winter season. Significant trends are indicated in bold characters $(\mathrm{P}<0.05)$. Italic stands for increasing trend and normal format stands for decreasing trends.

\begin{tabular}{|c|c|c|c|c|}
\hline & \multicolumn{4}{|c|}{ Winter } \\
\hline & \multicolumn{2}{|c|}{ TN90(Warm Nights) } & \multicolumn{2}{|c|}{ TN10(Cool Nights) } \\
\hline & Slope(d/yr) & $\mathrm{P}$ & Slope(d/yr) & $\mathrm{P}$ \\
\hline \multicolumn{5}{|l|}{ WV } \\
\hline 460580 & -0.018 & 0.117 & 0.015 & 0.283 \\
\hline 461220 & No trend & & No trend & \\
\hline 463544 & -0.036 & 0.001 & No trend & \\
\hline 465224 & -0.012 & 0.316 & No trend & \\
\hline 466867 & No trend & & No trend & \\
\hline 467730 & No trend & & No trend & \\
\hline 468384 & -0.011 & 0.312 & 0.011 & 0.379 \\
\hline \multicolumn{5}{|l|}{469436} \\
\hline \multicolumn{5}{|l|}{$\mathrm{PA}$} \\
\hline 363028 & 0.017 & 0.052 & -0.005 & 0.446 \\
\hline 366233 & No trend & & -0.012 & 0.351 \\
\hline 367477 & No trend & & 0.028 & 0.148 \\
\hline 368445 & 0.01 & 0.287 & No trend & \\
\hline 368905 & No trend & & No trend & \\
\hline 369298 & No trend & & -0.02 & 0.142 \\
\hline \multicolumn{5}{|l|}{ VA } \\
\hline 441209 & -0.021 & 0.047 & No trend & \\
\hline 442208 & No trend & & -0.048 & 0.002 \\
\hline 442245 & -0.069 & $<0.001$ & No trend & \\
\hline 447338 & -0.025 & 0.022 & No trend & \\
\hline 448062 & -0.042 & 0.001 & 0.034 & 0.097 \\
\hline 449263 & 0.053 & 0.003 & -0.091 & $<0.001$ \\
\hline \multicolumn{5}{|l|}{$\mathrm{MD}$} \\
\hline 185111 & 0.041 & 0.001 & -0.057 & 0.004 \\
\hline 186620 & No trend & & -0.017 & 0.145 \\
\hline 187330 & No trend & & -0.014 & 0.316 \\
\hline 188000 & 0.043 & 0.003 & -0.035 & 0.075 \\
\hline 188405 & 0.029 & 0.045 & -0.03 & 0.062 \\
\hline
\end{tabular}


Table 4-14 Slopes and P values for wet day precipitation and wet days. Significant trends are indicated in bold characters $(\mathrm{P}<0.05)$. Italic stands for increasing trend and normal format stands for decreasing trends.

\begin{tabular}{|c|c|c|c|c|}
\hline & \multicolumn{2}{|c|}{ P95 } & \multicolumn{2}{|c|}{ P95D } \\
\hline & Slope(in/yr) & $\mathrm{P}$ & Slope(d/yr) & $\mathrm{P}$ \\
\hline \multicolumn{5}{|c|}{ WV Stations } \\
\hline 460580 & -0.021 & 0.223 & No trend & \\
\hline 461220 & 0.006 & 0.63 & No trend & \\
\hline 463544 & 0.013 & 0.32 & No trend & \\
\hline 465224 & 0.003 & 0.8 & No trend & \\
\hline 466867 & -0.087 & $<0.001$ & -0.041 & 0.001 \\
\hline 467730 & 0.003 & 0.754 & No trend & \\
\hline 468384 & 0.022 & 0.145 & 0.013 & 0.081 \\
\hline 469436 & 0.039 & 0.011 & 0.025 & 0.007 \\
\hline \multicolumn{5}{|c|}{ PA Stations } \\
\hline 363028 & 0.026 & 0.024 & 0.013 & 0.059 \\
\hline 366233 & 0.029 & 0.02 & 0.018 & 0.026 \\
\hline 367477 & 0.033 & 0.016 & 0.022 & 0.01 \\
\hline 368445 & 0.01 & 0.376 & No trend & \\
\hline 368905 & 0.024 & 0.016 & 0.015 & 0.017 \\
\hline 369298 & 0.007 & 0.557 & No trend & \\
\hline \multicolumn{5}{|c|}{ VA Stations } \\
\hline 441209 & -0.02 & 0.124 & No trend & \\
\hline 442208 & 0.005 & 0.633 & No trend & \\
\hline 442245 & 0.042 & 0.004 & 0.015 & 0.011 \\
\hline 447338 & 0.011 & 0.43 & No trend & \\
\hline 448062 & No trend & & No trend & \\
\hline 449263 & 0.025 & 0.03 & 0.009 & 0.047 \\
\hline \multicolumn{5}{|c|}{ MD Stations } \\
\hline 185111 & 0.024 & 0.075 & No trend & \\
\hline 186620 & 0.005 & 0.652 & No trend & \\
\hline 187330 & 0.031 & 0.043 & No trend & \\
\hline 188000 & 0.035 & 0.046 & No trend & \\
\hline 188405 & 0.102 & $<0.001$ & 0.049 & $<0.001$ \\
\hline
\end{tabular}


Table 4-15 Slopes and $\mathrm{P}$ values maximum number of consecutive days with no precipitation and maximum annual precipitation intensity in in/day. Significant trends are indicated in bold characters $(\mathrm{P}<0.05)$. Italic stands for increasing trend and normal format stands for decreasing trends.

\begin{tabular}{|c|c|c|c|c|}
\hline & \multicolumn{2}{|c|}{ Drought } & \multicolumn{2}{|c|}{ Intensity } \\
\hline & Slope(days/yr) & $\mathrm{P}$ & Slope(in/day/yr) & $\mathrm{P}$ \\
\hline \multicolumn{5}{|c|}{ WV Stations } \\
\hline 460580 & -0.076 & $<0.001$ & -0.002 & 0.092 \\
\hline 461220 & -0.029 & 0.018 & -0.002 & 0.096 \\
\hline 463544 & -0.019 & 0.055 & -0.001 & 0.516 \\
\hline 465224 & No trend & & -0.003 & 0.031 \\
\hline 466867 & -0.088 & $<0.001$ & -0.012 & $<0.001$ \\
\hline 467730 & -0.058 & $<0.001$ & -0.001 & 0.681 \\
\hline 468384 & -0.06 & $<0.001$ & -0.003 & 0.062 \\
\hline 469436 & No trend & & 0.005 & 0.001 \\
\hline \multicolumn{5}{|c|}{ PA Stations } \\
\hline 363028 & -0.054 & $<0.001$ & No trend & \\
\hline 366233 & -0.019 & 0.082 & 0.001 & 0.417 \\
\hline 367477 & -0.025 & 0.02 & -0.003 & 0.066 \\
\hline 368445 & No trend & & 0.001 & 0.3 \\
\hline 368905 & No trend & & -0.001 & 0.482 \\
\hline 369298 & -0.015 & 0.044 & -0.003 & 0.026 \\
\hline \multicolumn{5}{|c|}{ VA Stations } \\
\hline 441209 & -0.075 & $<0.001$ & -0.004 & 0.011 \\
\hline 442208 & -0.011 & 0.262 & -0.004 & $<0.001$ \\
\hline 442245 & 0.026 & 0.053 & 0.002 & 0.215 \\
\hline 447338 & -0.047 & 0.001 & -0.003 & 0.05 \\
\hline 448062 & 0.017 & 0.131 & -0.004 & 0.017 \\
\hline 449263 & 0.018 & 0.207 & No trend & \\
\hline \multicolumn{5}{|c|}{ MD Stations } \\
\hline 185111 & 0.012 & 0.297 & 0.001 & 0.645 \\
\hline 186620 & No trend & & -0.001 & 0.437 \\
\hline 187330 & 0.025 & 0.063 & 0.006 & 0.001 \\
\hline 188000 & 0.031 & 0.026 & 0.001 & 0.525 \\
\hline 188405 & 0.011 & 0.319 & 0.011 & $<0.001$ \\
\hline
\end{tabular}


Table 4-16 Slopes and $\mathrm{P}$ values maximum number of consecutive days with no precipitation and maximum annual precipitation intensity in in/day during summer season. Significant trends are indicated in bold characters $(\mathrm{P}<0.05)$. Italic stands for increasing trend and normal format stands for decreasing trends.

\begin{tabular}{|c|c|c|c|c|}
\hline & \multicolumn{3}{|c|}{ Summer } & \multirow[b]{3}{*}{$\mathrm{P}$} \\
\hline & \multirow{2}{*}{$\begin{array}{l}\text { Drought } \\
\text { Slope(days/yr) }\end{array}$} & \multirow[b]{2}{*}{$\mathrm{P}$} & \multirow{2}{*}{$\begin{array}{l}\text { Intensity } \\
\text { Slope(in/day/yr) }\end{array}$} & \\
\hline & & & & \\
\hline \multicolumn{5}{|l|}{ WV } \\
\hline 460580 & -0.023 & 0.019 & -0.002 & 0.21 \\
\hline 461220 & -0.015 & 0.141 & -0.003 & 0.003 \\
\hline 463544 & No trend & & 0.001 & 0.647 \\
\hline 465224 & 0.017 & 0.037 & -0.001 & 0.485 \\
\hline 466867 & -0.057 & $<0.001$ & -0.009 & $<0.001$ \\
\hline 467730 & -0.026 & 0.008 & -0.001 & 0.322 \\
\hline 468384 & -0.03 & $<0.001$ & -0.002 & 0.166 \\
\hline 469436 & No trend & & 0.003 & 0.048 \\
\hline \multicolumn{5}{|l|}{$\mathrm{PA}$} \\
\hline 363028 & -0.019 & 0.031 & No trend & \\
\hline 366233 & No trend & & No trend & \\
\hline 367477 & No trend & & -0.002 & 0.352 \\
\hline 368445 & No trend & & 0.002 & 0.085 \\
\hline 368905 & No trend & & No trend & \\
\hline 369298 & No trend & & -0.001 & 0.299 \\
\hline \multicolumn{5}{|l|}{ VA } \\
\hline 441209 & No trend & & -0.001 & 0.726 \\
\hline 442208 & 0.019 & 0.006 & -0.001 & 0.313 \\
\hline 442245 & 0.028 & 0.012 & 0.001 & 0.522 \\
\hline 447338 & No trend & & -0.002 & 0.259 \\
\hline 448062 & 0.031 & 0.003 & 0.001 & 0.549 \\
\hline 449263 & 0.01 & 0.165 & -0.001 & 0.589 \\
\hline \multicolumn{5}{|l|}{ MD } \\
\hline 185111 & 0.019 & 0.05 & 0.001 & 0.635 \\
\hline 186620 & No trend & & No trend & \\
\hline 187330 & 0.024 & 0.006 & 0.005 & 0.007 \\
\hline 188000 & No trend & & 0.001 & 0.603 \\
\hline 188405 & 0.034 & 0.005 & 0.004 & 0.129 \\
\hline
\end{tabular}


Table 4-17 Slopes and $\mathrm{P}$ values maximum number of consecutive days with no precipitation and maximum annual precipitation intensity in in/day during winter season. Significant trends are indicated in bold characters $(\mathrm{P}<0.05)$. Italic stands for increasing trend and normal format stands for decreasing trends.

\begin{tabular}{|c|c|c|c|c|}
\hline & \multicolumn{3}{|c|}{ Winter } & \multirow[b]{3}{*}{$\mathrm{P}$} \\
\hline & \multirow{2}{*}{$\begin{array}{l}\text { Drought } \\
\text { Slope(days/yr) }\end{array}$} & \multirow[b]{2}{*}{$\mathrm{P}$} & \multirow{2}{*}{$\begin{array}{l}\text { Intensity } \\
\text { Slope(in/day/yr) }\end{array}$} & \\
\hline & & & & \\
\hline \multicolumn{5}{|l|}{ WV } \\
\hline 460580 & -0.038 & $<0.001$ & -0.001 & 0.388 \\
\hline 461220 & -0.032 & $<0.001$ & -0.002 & 0.029 \\
\hline 463544 & -0.012 & 0.026 & -0.002 & 0.038 \\
\hline 465224 & -0.014 & 0.086 & -0.001 & 0.249 \\
\hline 466867 & -0.058 & $<0.001$ & -0.012 & $<0.001$ \\
\hline 467730 & -0.031 & 0.011 & -0.002 & 0.092 \\
\hline 468384 & No trend & & -0.002 & 0.022 \\
\hline 469436 & No trend & & No trend & \\
\hline \multicolumn{5}{|l|}{$\mathrm{PA}$} \\
\hline 363028 & No trend & & -0.002 & $<0.001$ \\
\hline 366233 & No trend & & No trend & \\
\hline 367477 & No trend & & -0.002 & 0.037 \\
\hline 368445 & -0.014 & 0.001 & -0.001 & 0.114 \\
\hline 368905 & No trend & & No trend & \\
\hline 369298 & -0.019 & $<0.001$ & -0.001 & 0.208 \\
\hline \multicolumn{5}{|l|}{ VA } \\
\hline 441209 & -0.025 & 0.002 & -0.003 & 0.001 \\
\hline 442208 & No trend & & -0.001 & 0.281 \\
\hline 442245 & No trend & & 0.001 & 0.642 \\
\hline 447338 & -0.014 & 0.125 & -0.003 & 0.059 \\
\hline 448062 & 0.012 & 0.228 & No trend & \\
\hline 449263 & 0.013 & 0.274 & No trend & \\
\hline \multicolumn{5}{|l|}{$\mathrm{MD}$} \\
\hline 185111 & No trend & & No trend & \\
\hline 186620 & No trend & & -0.001 & 0.241 \\
\hline 187330 & 0.034 & 0.002 & 0.004 & $<0.001$ \\
\hline 188000 & No trend & & No trend & \\
\hline 188405 & No trend & & 0.005 & $<0.001$ \\
\hline
\end{tabular}


Table 4-18 Slopes and $\mathrm{P}$ values for wet day precipitation during summer and winter season. Significant trends are indicated in bold characters $(\mathrm{P}<0.05)$. Italic stands for increasing trend and normal format stands for decreasing trends.

\begin{tabular}{|c|c|c|c|c|}
\hline & \multicolumn{4}{|c|}{ P95 } \\
\hline & \multicolumn{2}{|c|}{ Summer } & \multicolumn{2}{|c|}{ Winter } \\
\hline & Slope(in/yr) & $\mathrm{P}$ & Slope(in/yr) & $\mathrm{P}$ \\
\hline \multicolumn{5}{|l|}{ WV } \\
\hline 460580 & -0.008 & 0.431 & -0.007 & 0.147 \\
\hline 461220 & -0.009 & 0.243 & 0.01 & 0.059 \\
\hline 463544 & 0.004 & 0.460 & -0.006 & 0.102 \\
\hline 465224 & 0.003 & 0.492 & 0.001 & 0.472 \\
\hline 466867 & -0.02 & 0.01 & -0.03 & $<0.001$ \\
\hline 467730 & -0.001 & 0.830 & -0.002 & 0.539 \\
\hline 468384 & -0.004 & 0.422 & -0.003 & 0.41 \\
\hline 469436 & 0.003 & 0.743 & 0.002 & 0.654 \\
\hline \multicolumn{5}{|l|}{$\mathrm{PA}$} \\
\hline 363028 & 0.003 & 0.433 & No trend & \\
\hline 366233 & -0.001 & 0.867 & 0.001 & 0.505 \\
\hline 367477 & 0.005 & 0.248 & 0.004 & 0.322 \\
\hline 368445 & 0.001 & 0.719 & 0.002 & 0.402 \\
\hline 368905 & -0.002 & 0.647 & No trend & \\
\hline 369298 & 0.008 & 0.120 & No trend & \\
\hline \multicolumn{5}{|l|}{ VA } \\
\hline 441209 & -0.001 & 0.723 & -0.002 & 0.594 \\
\hline 442208 & -0.003 & 0.561 & -0.001 & 0.431 \\
\hline 442245 & -0.002 & 0.651 & -0.001 & 0.775 \\
\hline 447338 & 0.003 & 0.722 & -0.002 & 0.351 \\
\hline 448062 & -0.001 & 0.723 & No trend & \\
\hline 449263 & 0.004 & 0.296 & 0.003 & 0.475 \\
\hline \multicolumn{5}{|l|}{$\mathrm{MD}$} \\
\hline 185111 & 0.001 & 0.875 & 0.002 & 0.522 \\
\hline 186620 & 0.002 & 0.673 & -0.009 & 0.075 \\
\hline 187330 & 0.007 & 0.224 & 0.008 & 0.015 \\
\hline 188000 & 0.01 & 0.172 & 0.013 & 0.055 \\
\hline 188405 & 0.018 & 0.058 & 0.012 & 0.048 \\
\hline
\end{tabular}




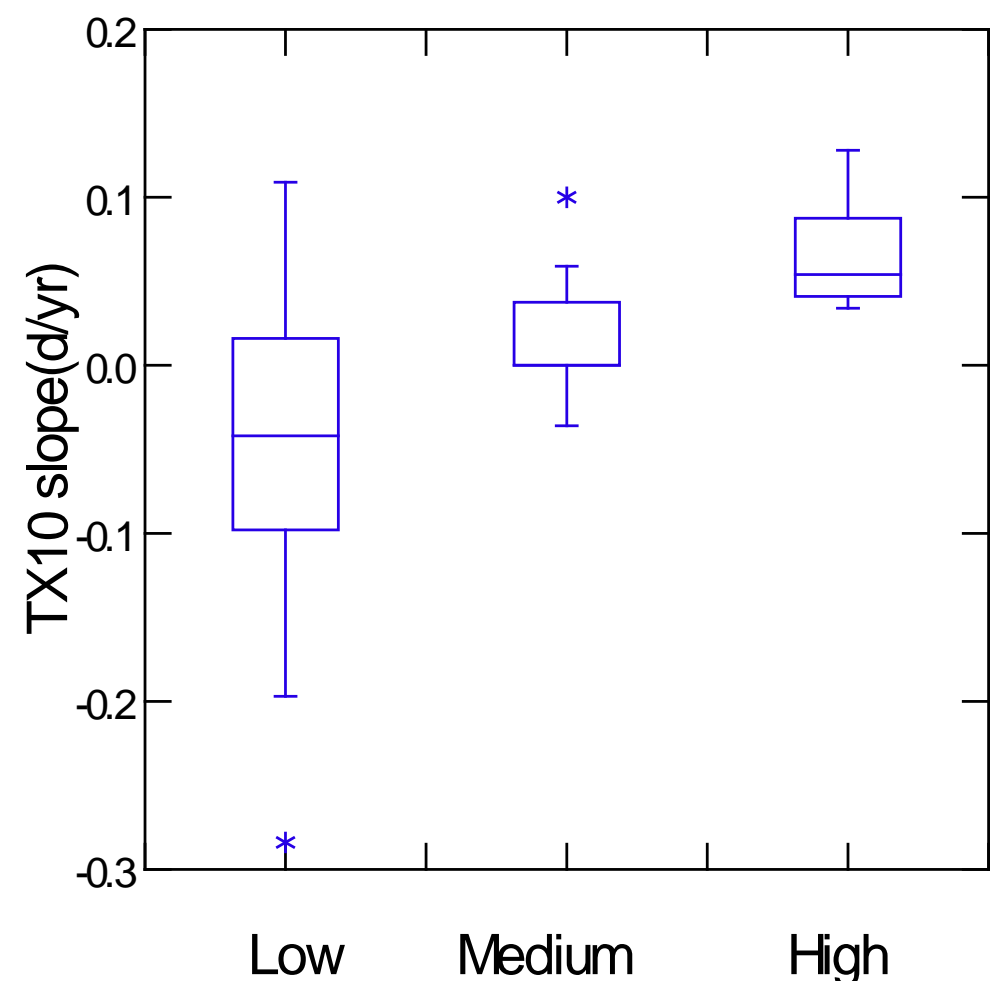

Figure 4-1 Slopes of TX10 (cool days) in different elevation groups. 


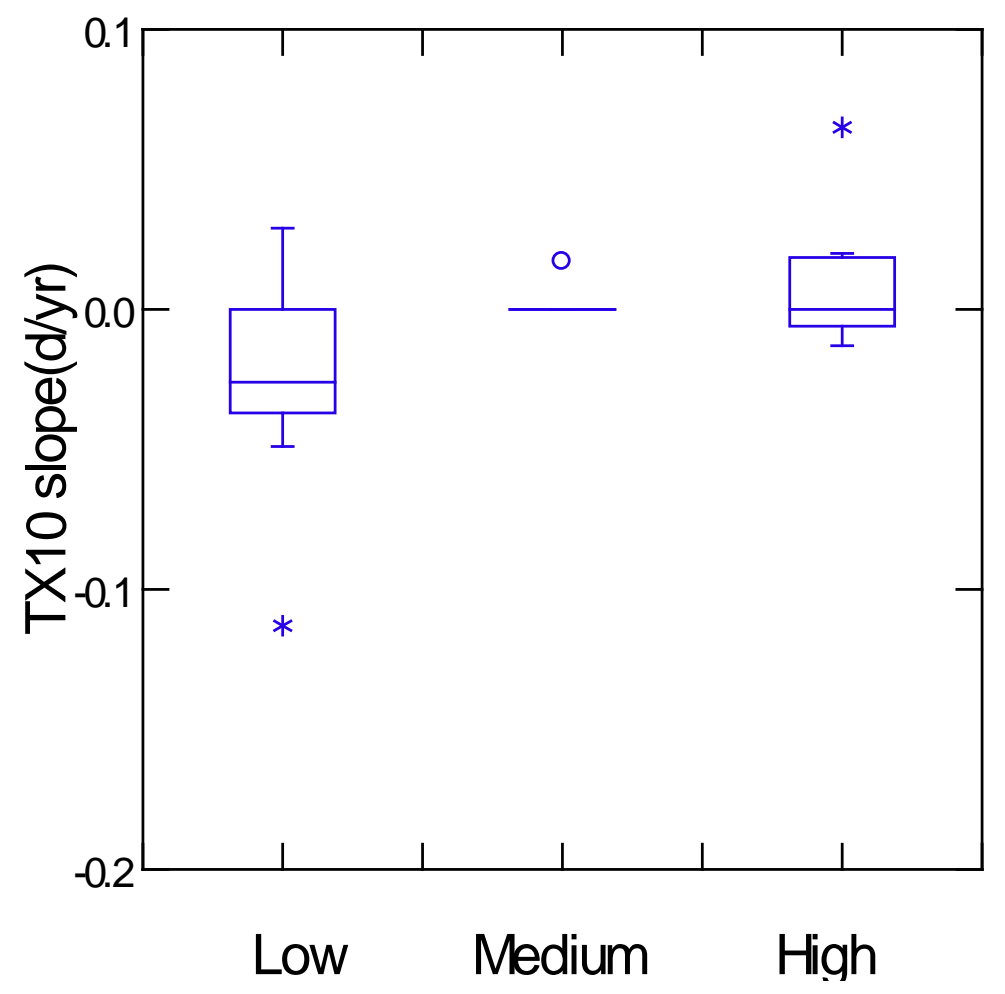

Figure 4-2 Slopes of TX10 (cool days) during summer season in different elevation groups. 


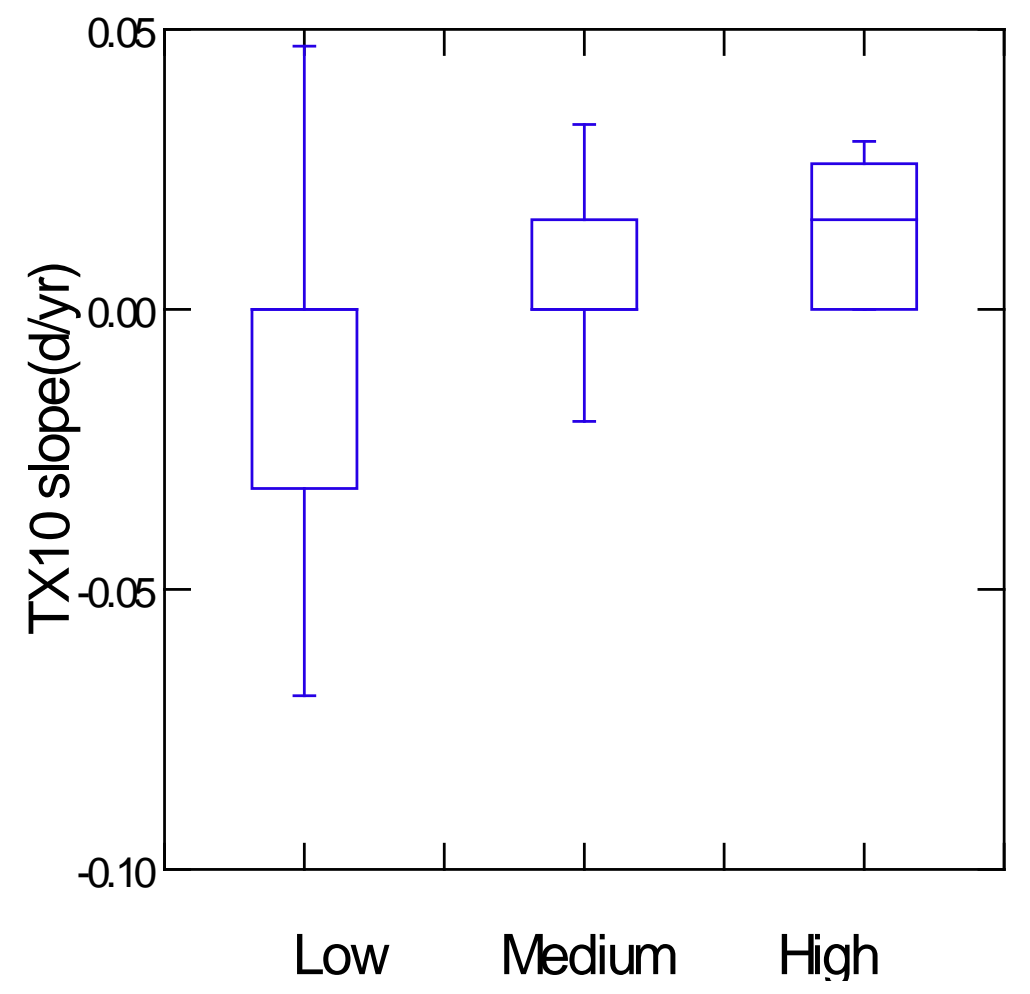

Figure 4-3 Slopes of TX10 (cool days) during winter season in different elevation groups. 


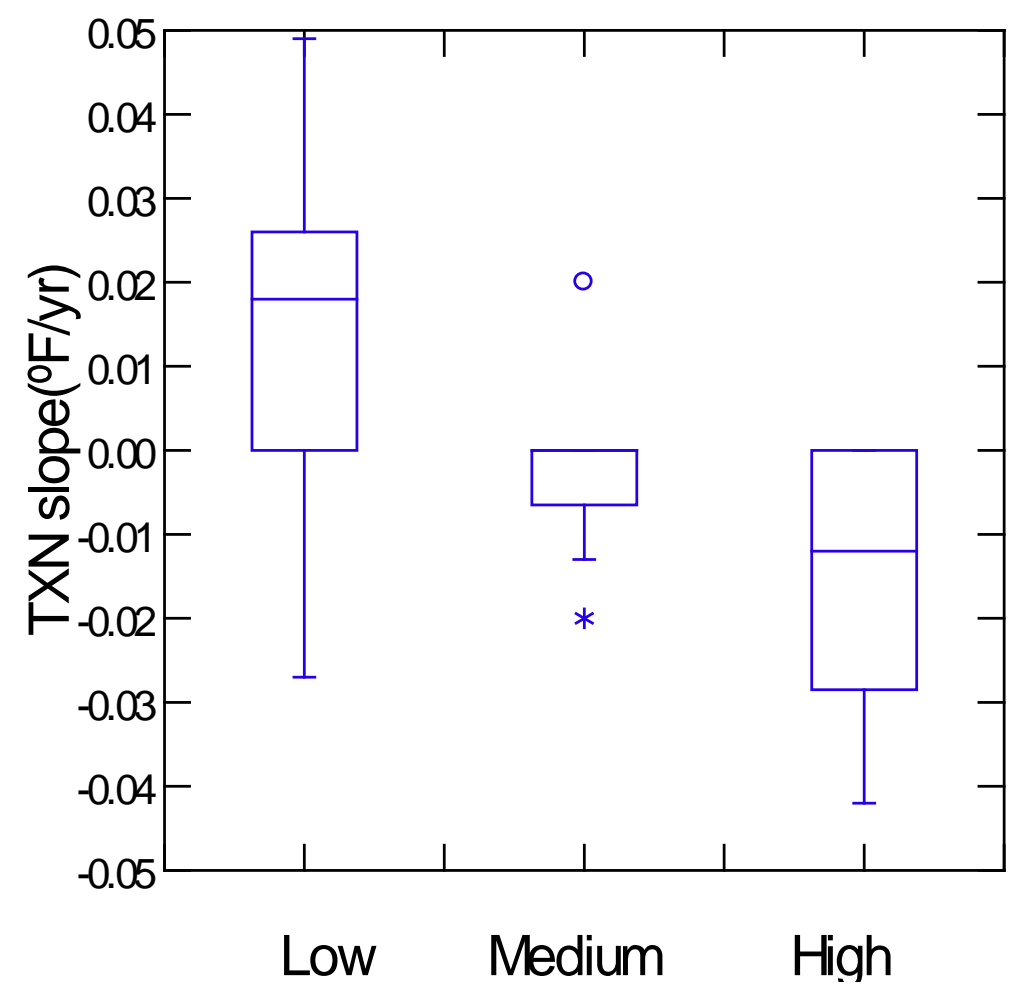

Figure 4-4 Slopes of TXN (minimum annual maximum temperature) in different elevation groups. 


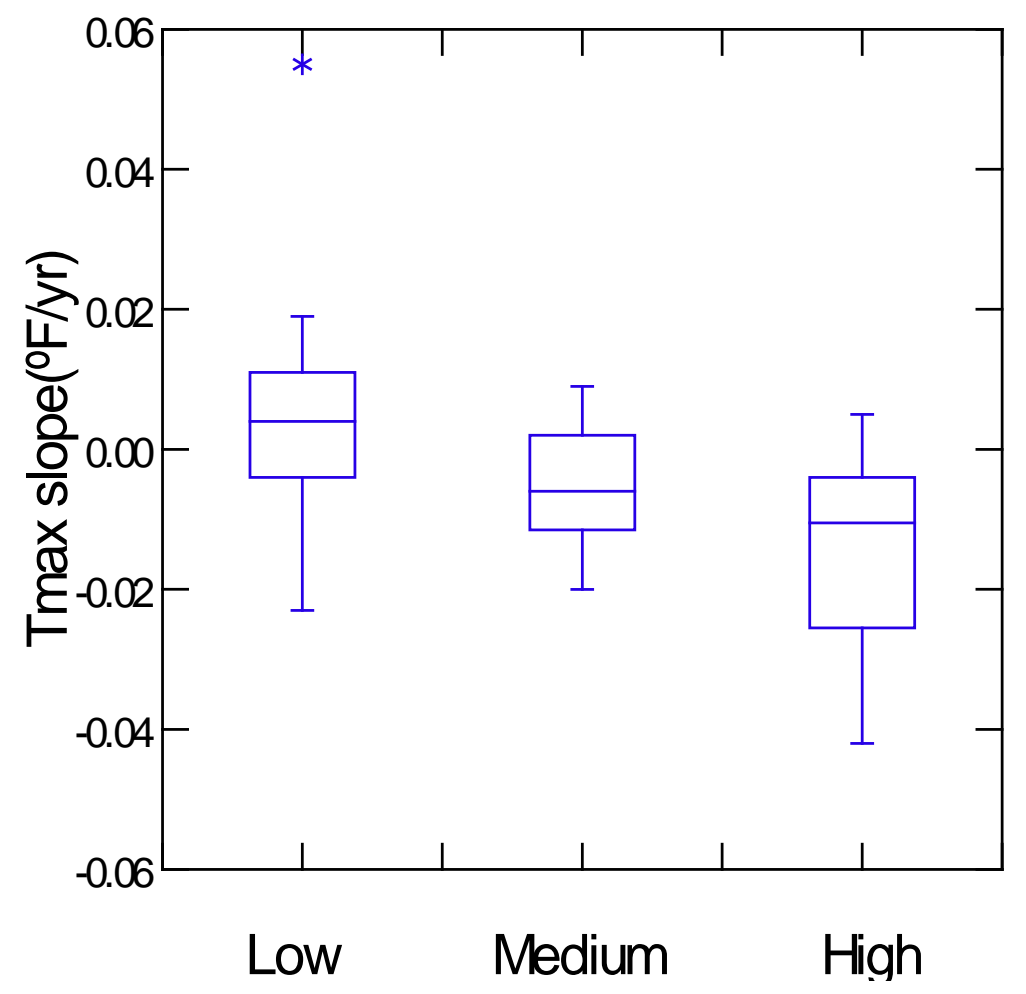

Figure 4-5 Slopes of TXN in different elevation groups. 


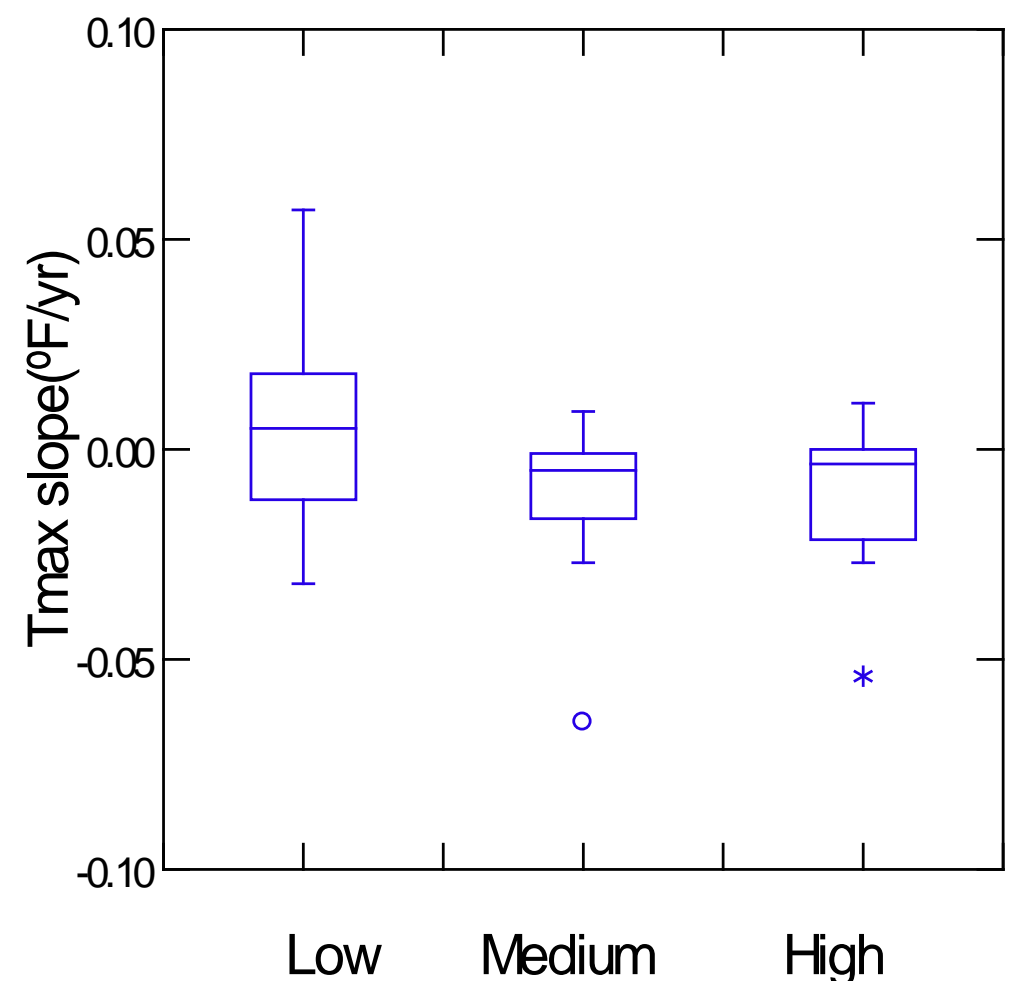

Figure 4-6 Slopes of annual maximum temperature during summer season in different elevation groups. 


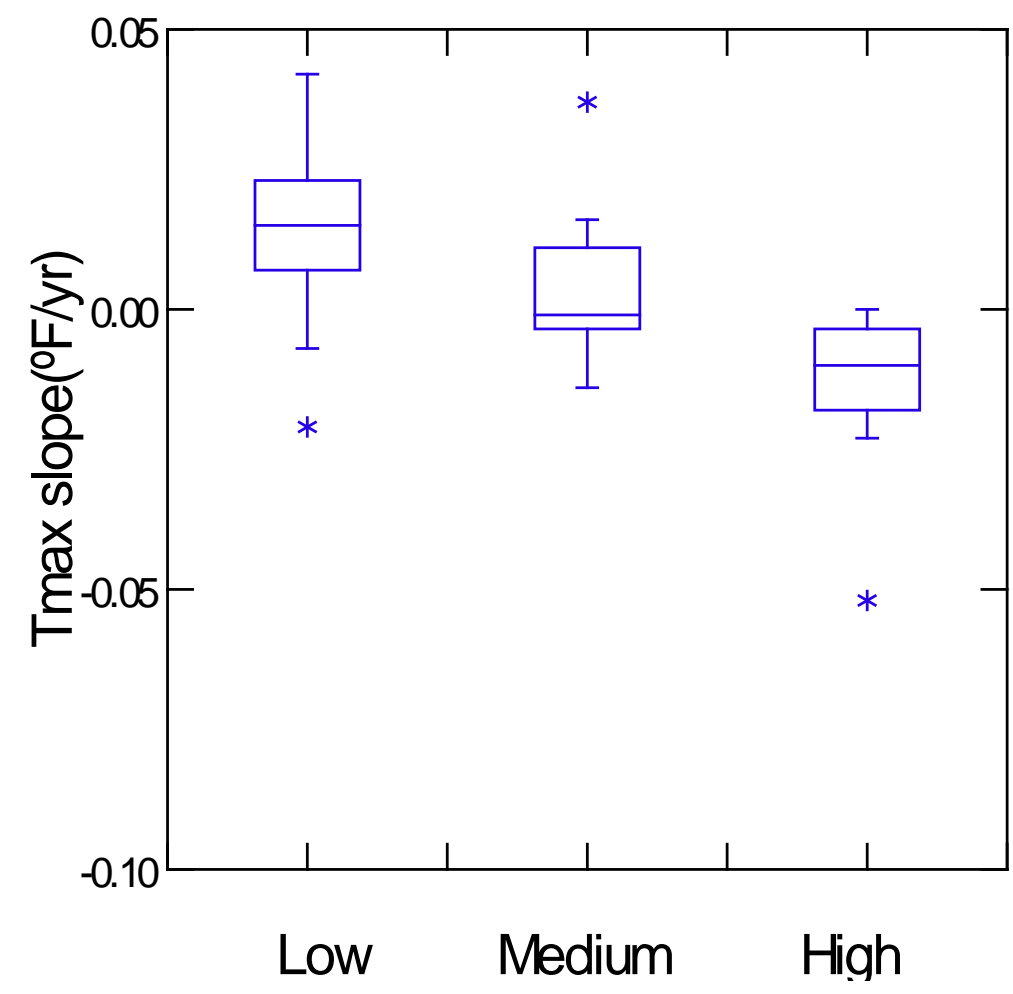

Figure 4-7 Slopes of annual maximum temperature during winter season in different elevation groups. 


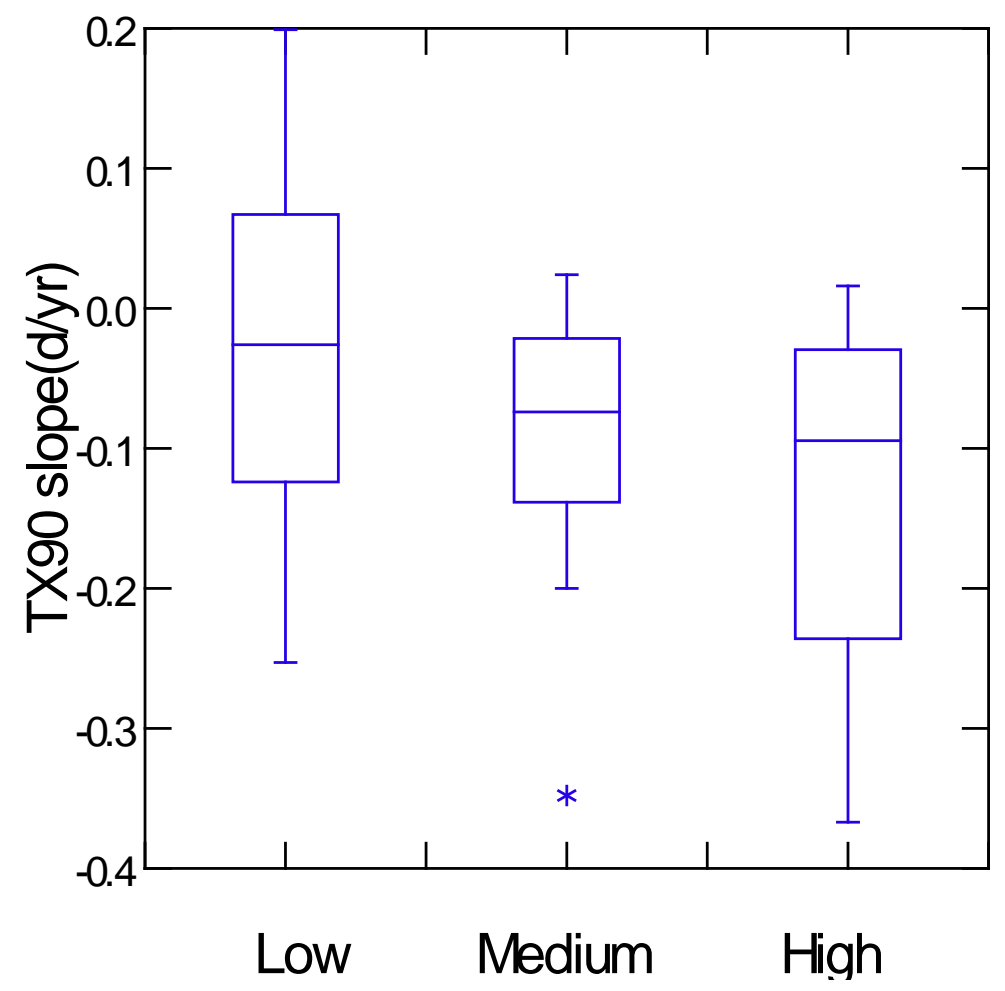

Figure 4-8 Slopes of TX90 (Warm days) in different elevation groups. 


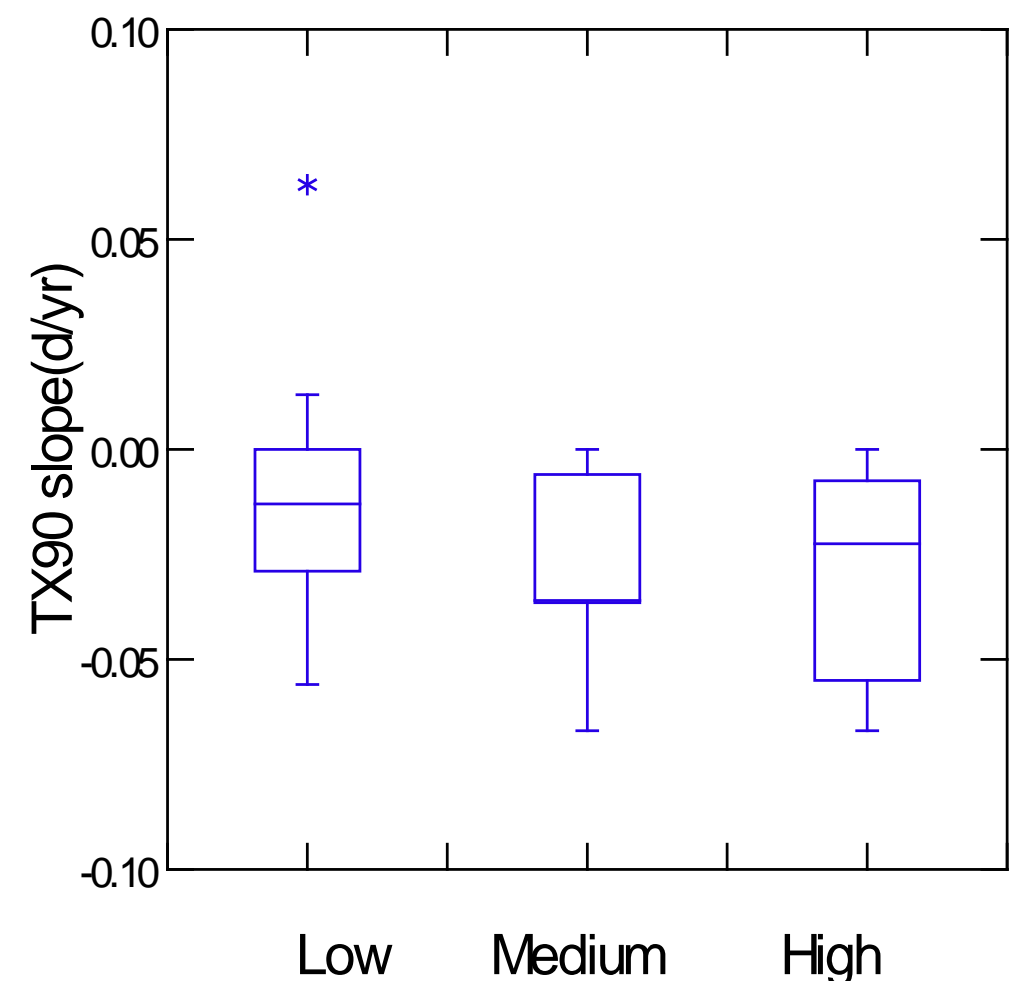

Figure 4-9 Slopes of TX90 (Warm days) during summer season in different elevation groups. 


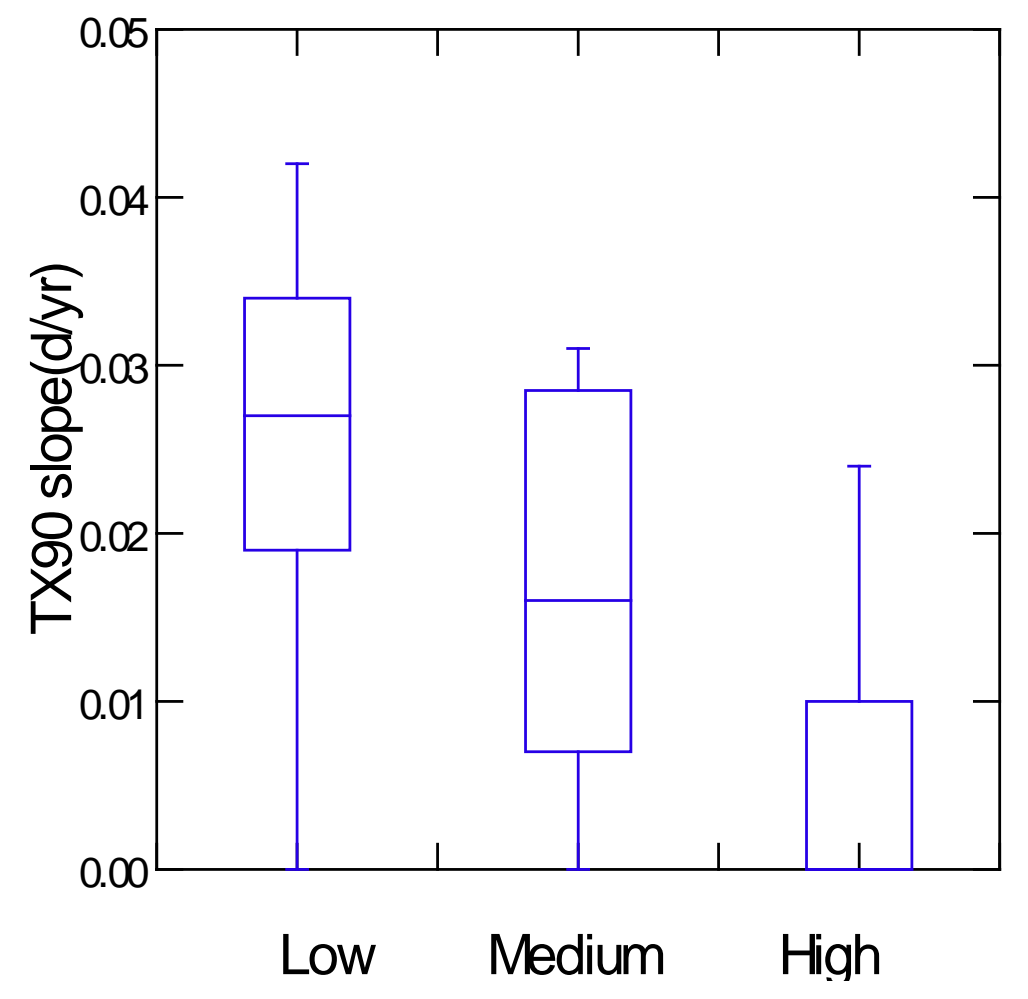

Figure 4-10 Slopes of TX90 (Warm days) during winter season in different elevation groups. 


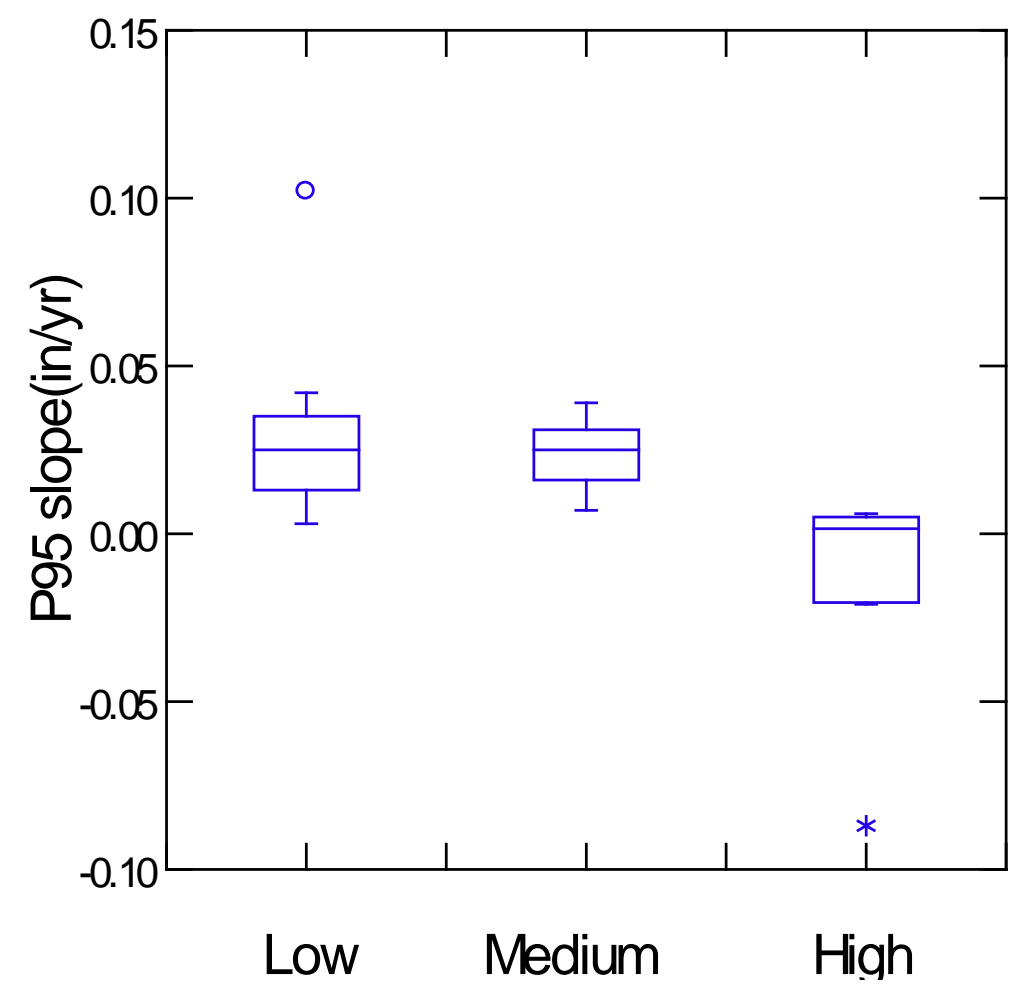

Figure 4-11 Slopes of P95 (Annual total precipitation exceeding $95^{\text {th }}$ percentile) in different elevation groups. 


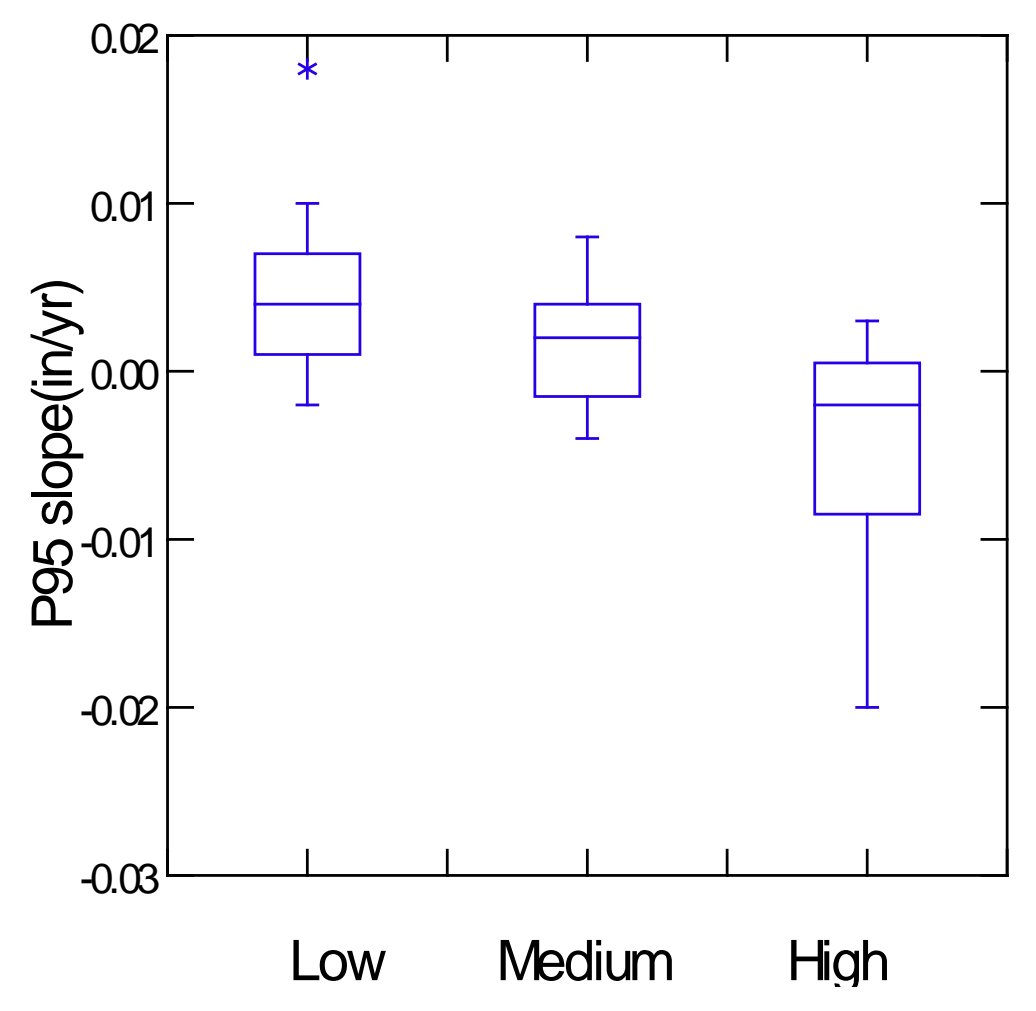

Figure 4-12 Slopes of P95 (Annual total precipitation exceeding $95^{\text {th }}$ percentile) during summer season in different elevation groups. 


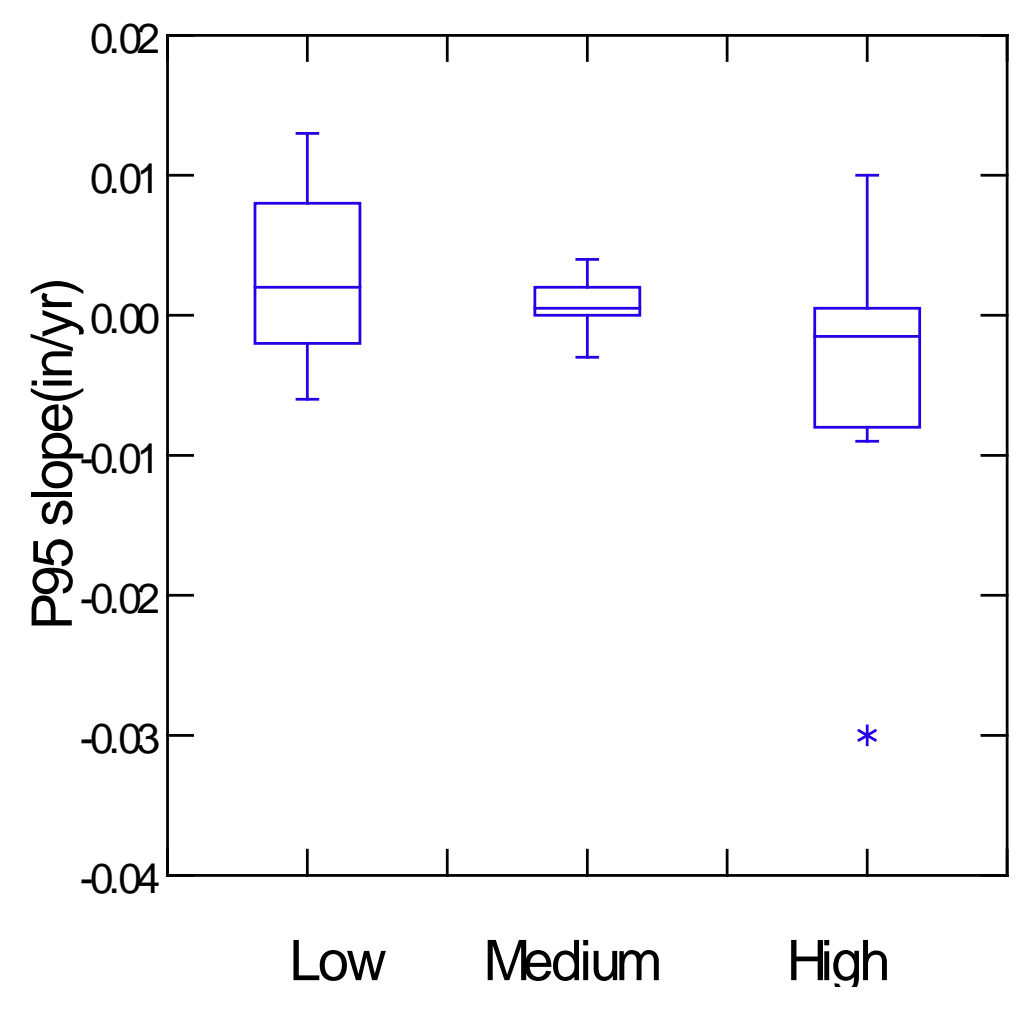

Figure 4-13 Slopes of P95 (Annual total precipitation exceeding $95^{\text {th }}$ percentile) during winter season in different elevation groups. 


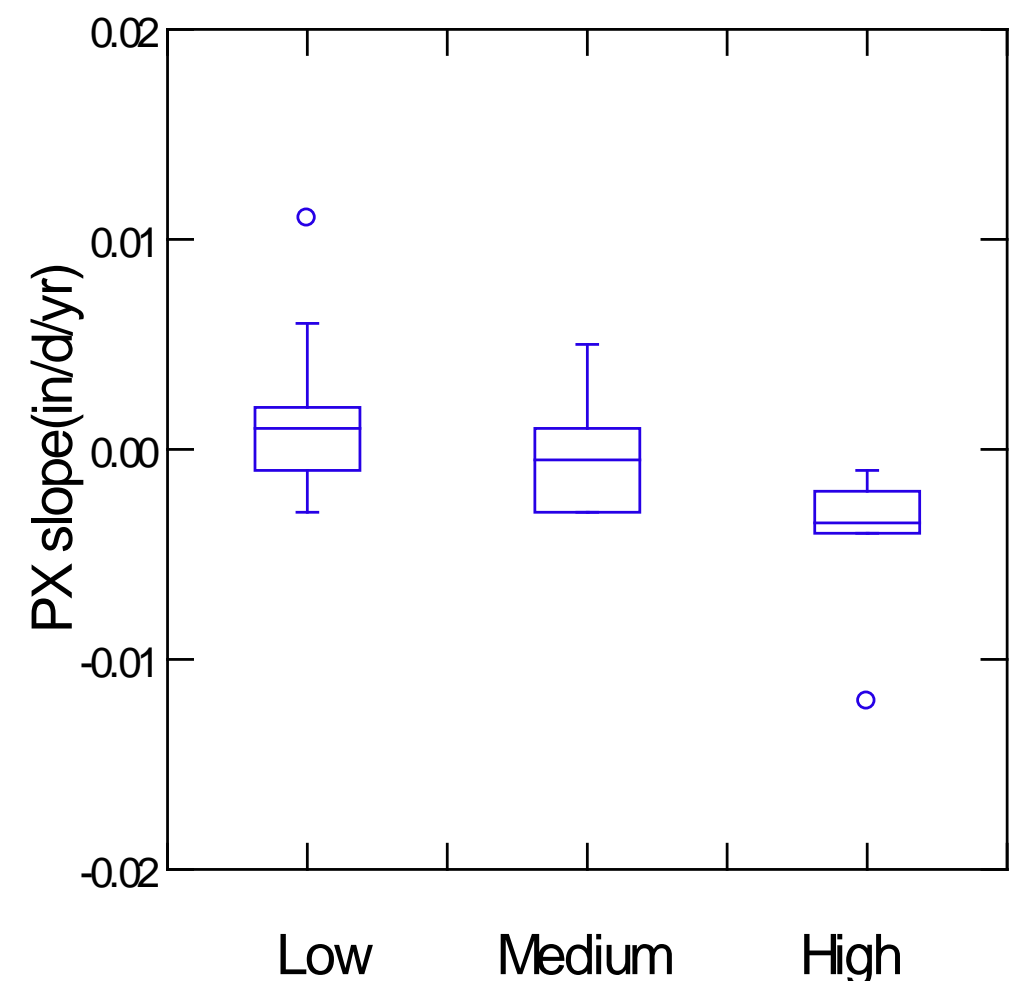

Figure 4-14 Slopes of PX (maximum precipitation intensity) in different elevation groups. 


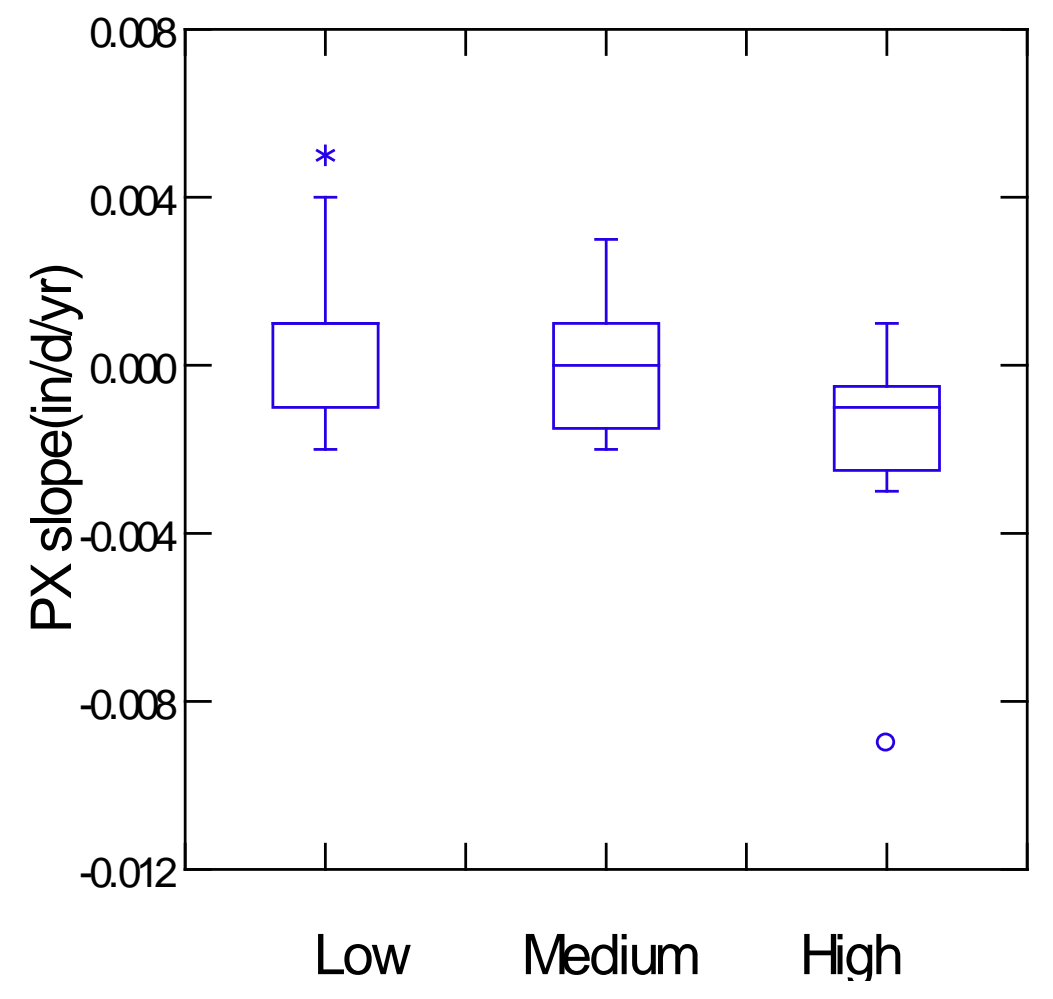

Figure 4-15 Slopes of PX (maximum precipitation intensity) during summer season in different elevation groups. 


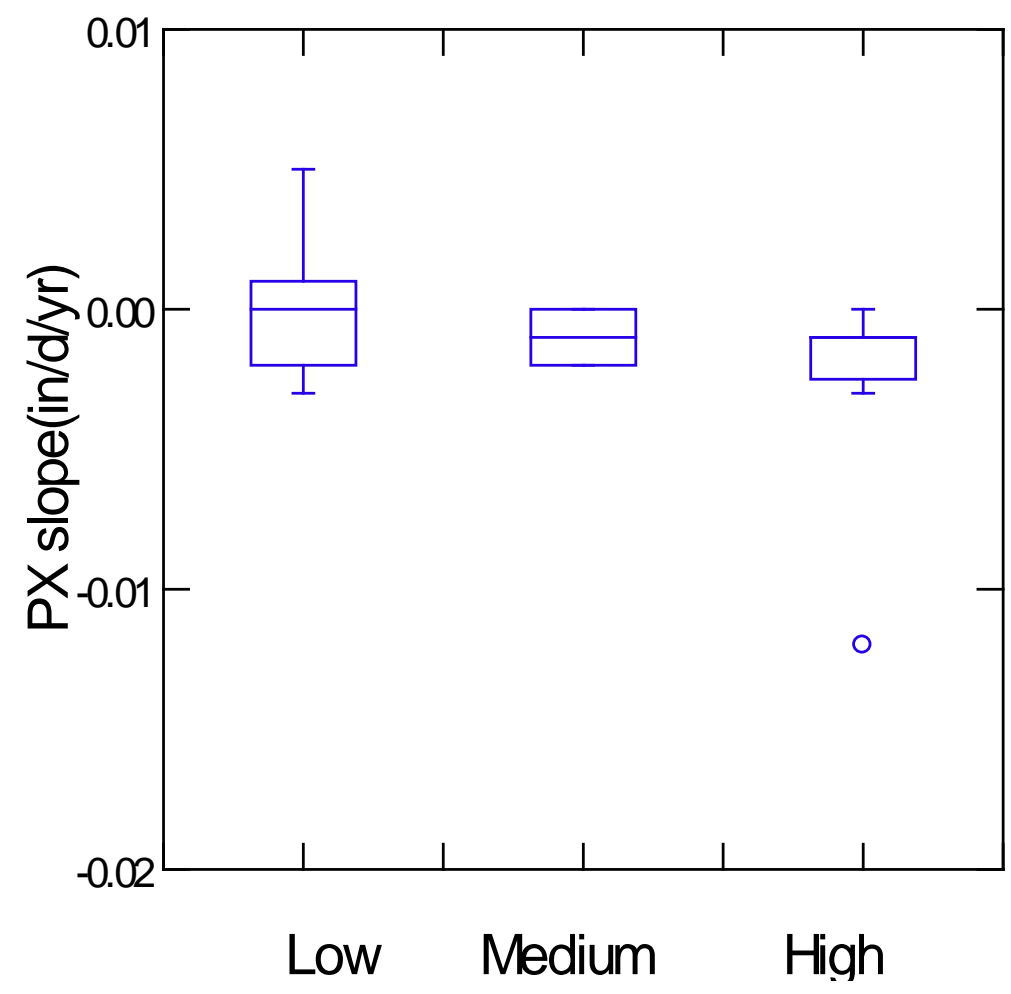

Figure 4-16 Slopes of PX (maximum precipitation intensity) during winter season in different elevation groups. 


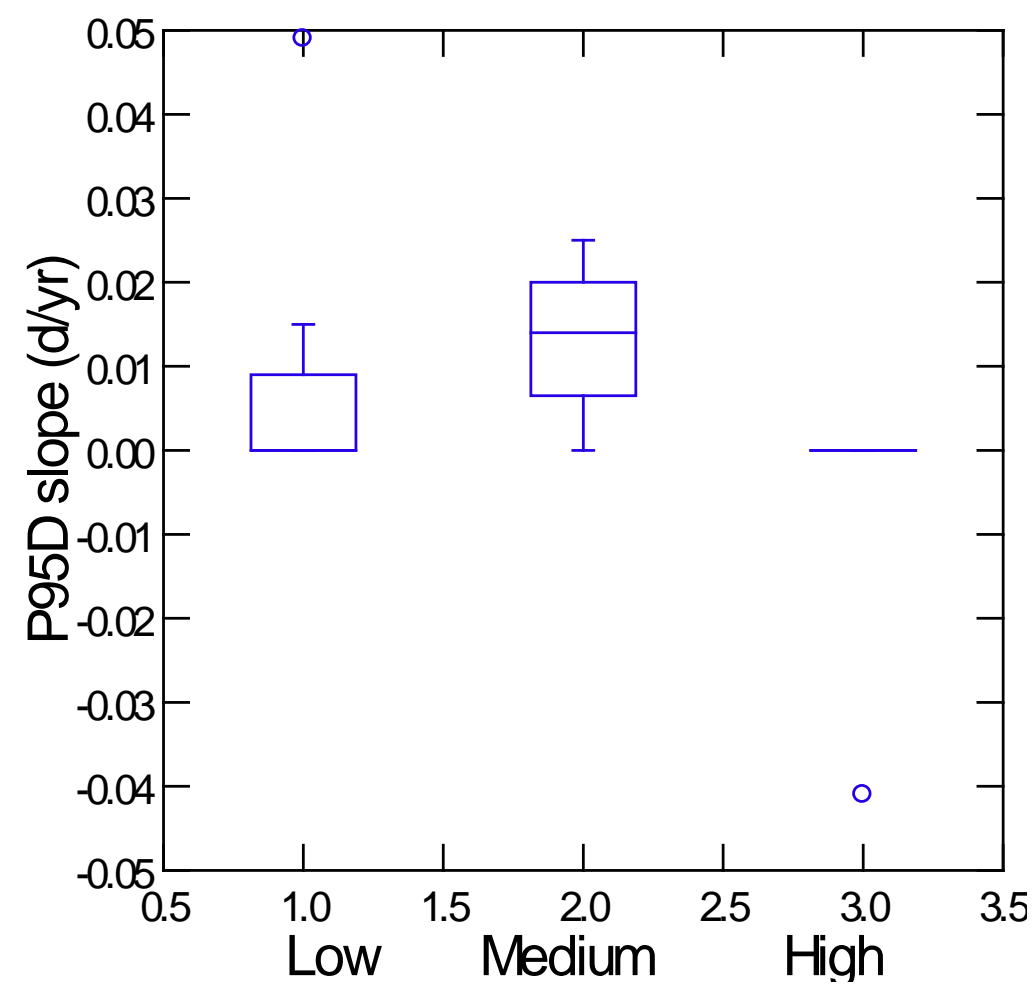

Figure 4-17 Slopes of P95D (numbers of days with precipitation exceeding $95^{\text {th }}$ percentile) during in different elevation groups. 
a.

Station 185111

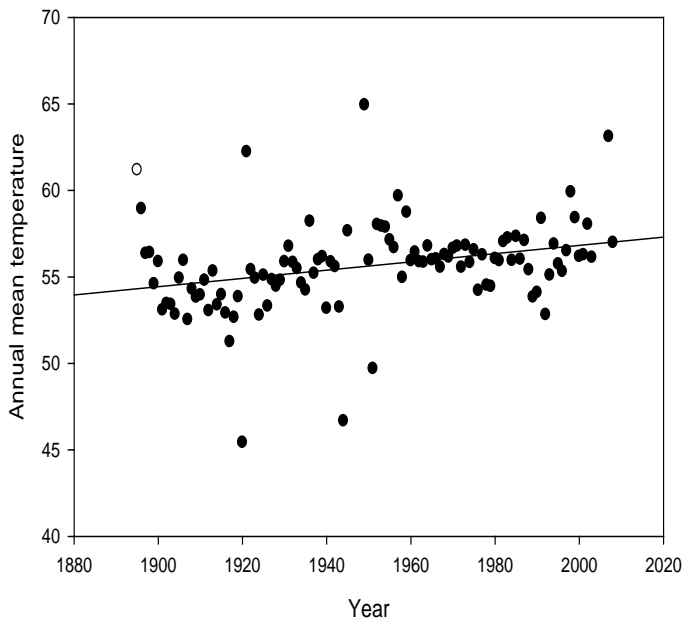

C.

Station 185111

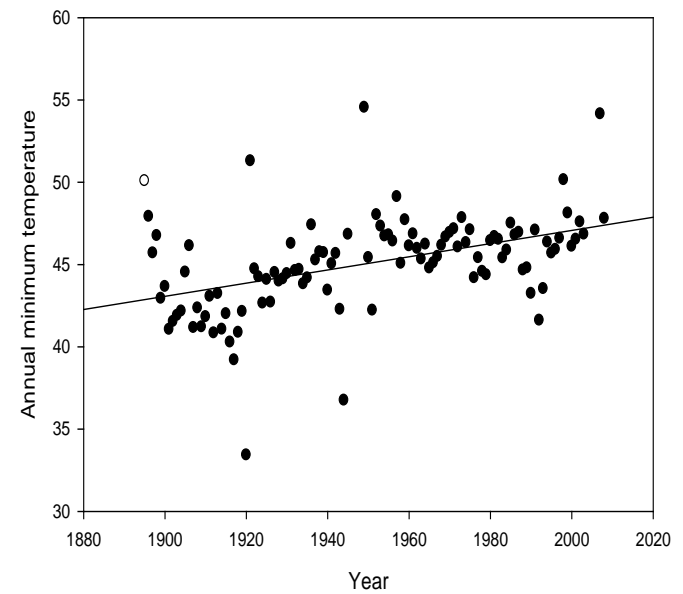

b.

Station 185111

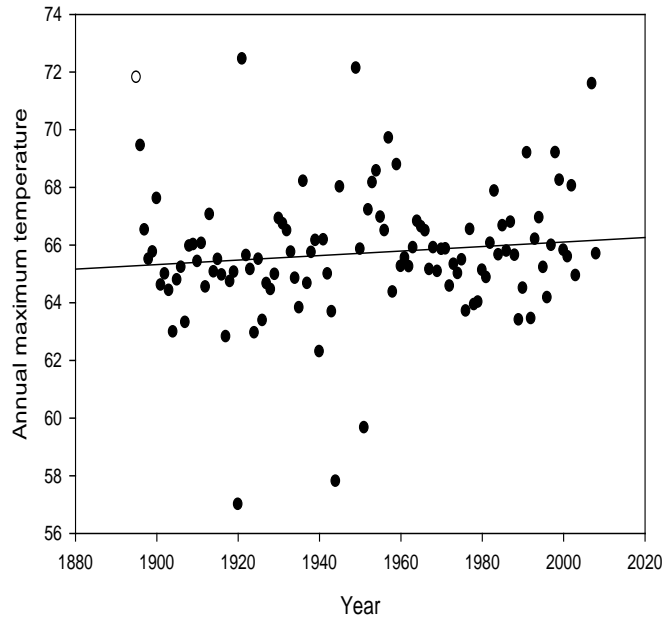

d.

Station 185111

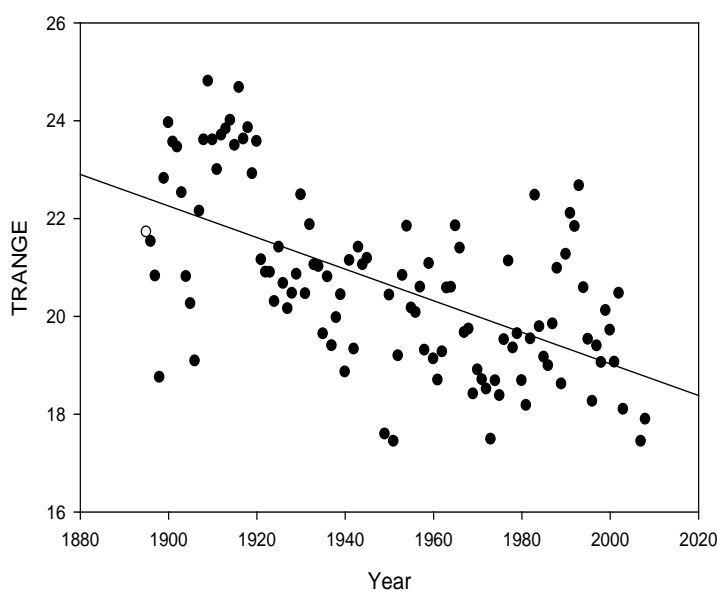

Figure 4-18 Graphic view of trends for station 185111, a. annual mean temperature, b. annual maximum temperature, c. annual minimum temperature $d . T_{\text {RANGE }}$ 
a.

Station 185111

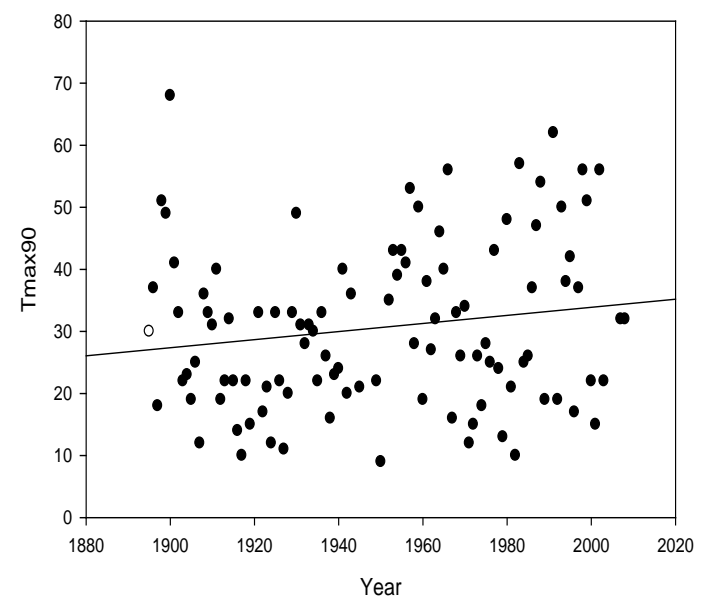

C.

Station 185111

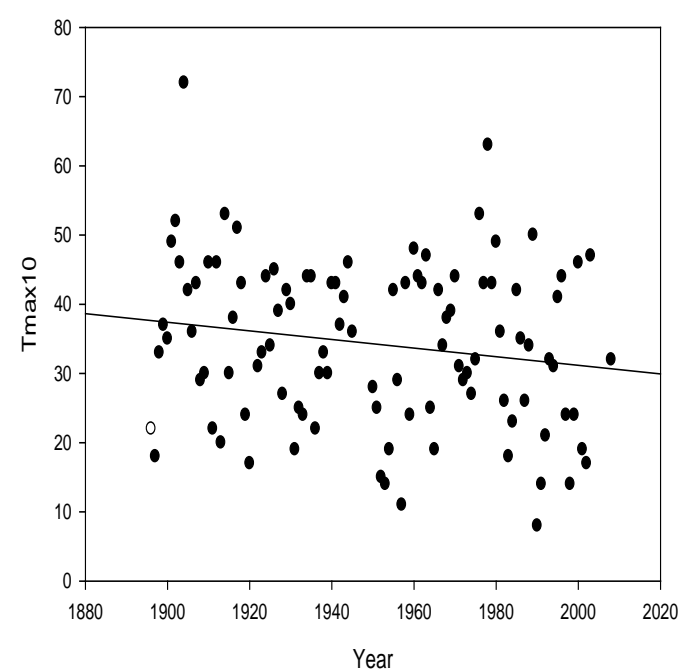

b.

Station 185111

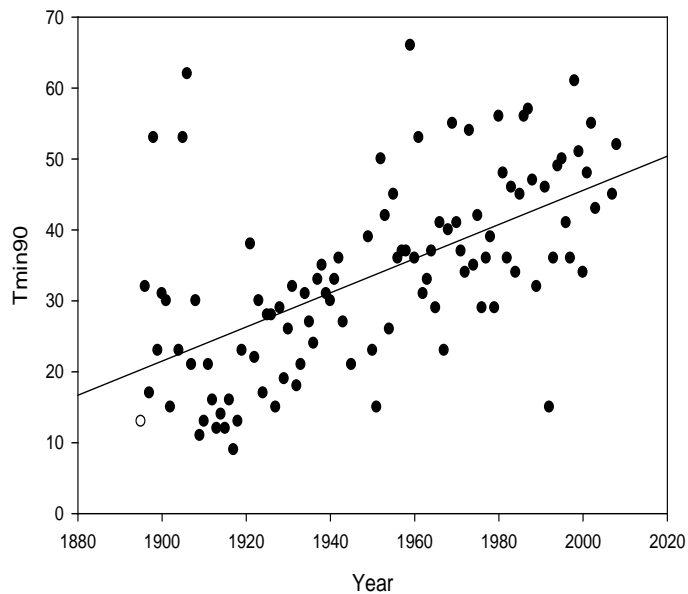

d.

Stationa 185111

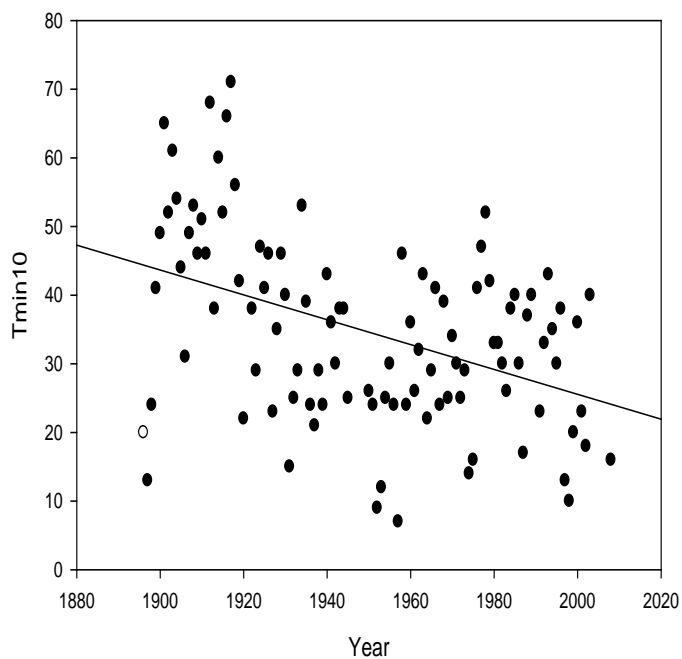

Figure 4-19 Graphic view of trends for station 185111, a. Tmax90, b. Tmin90, c. Tmax10 d. Tmin10. 
a.

Station 185111

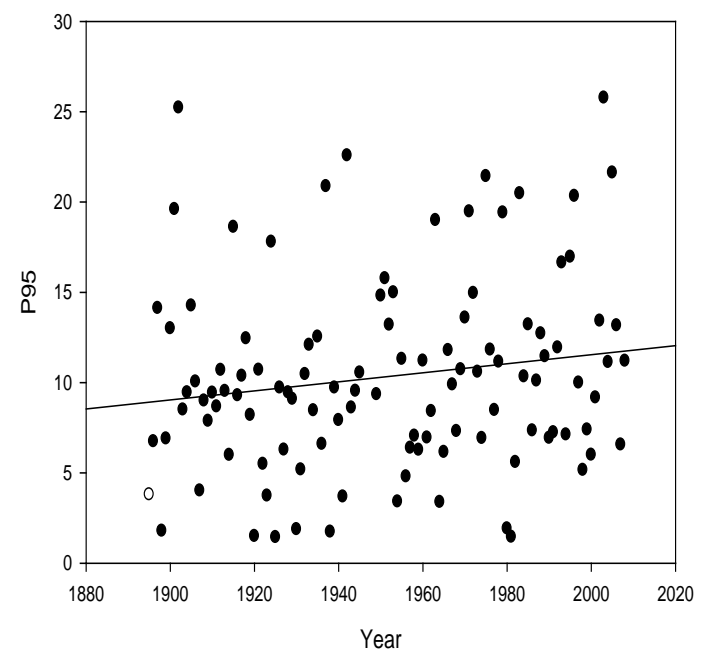

c.

Station 185111

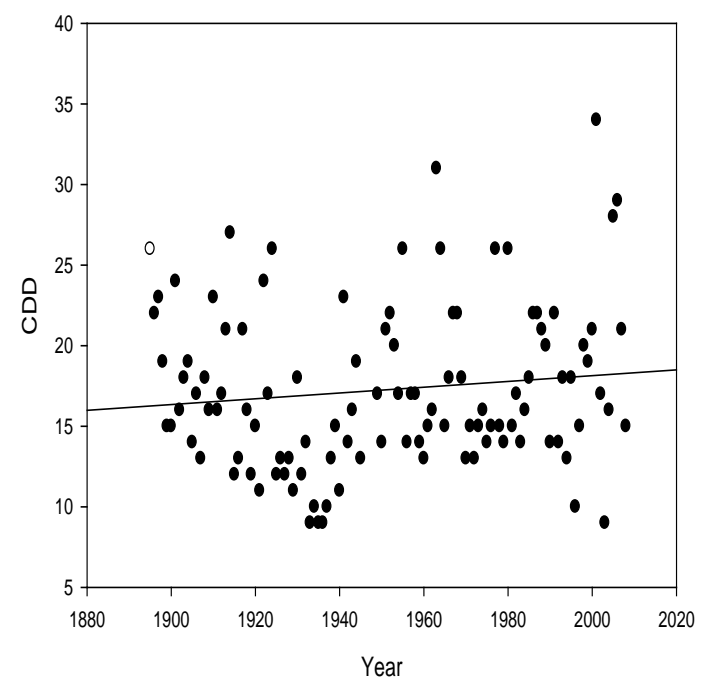

b.

Station 185111

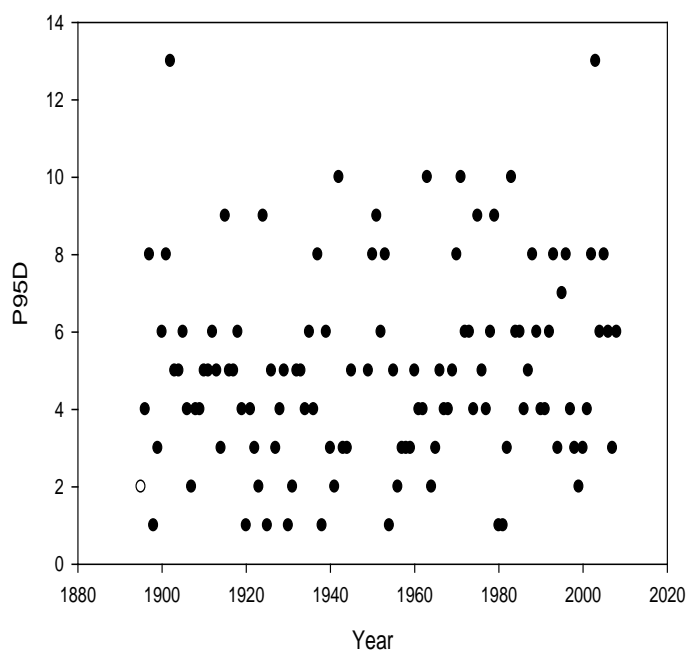

d.

Station 185111

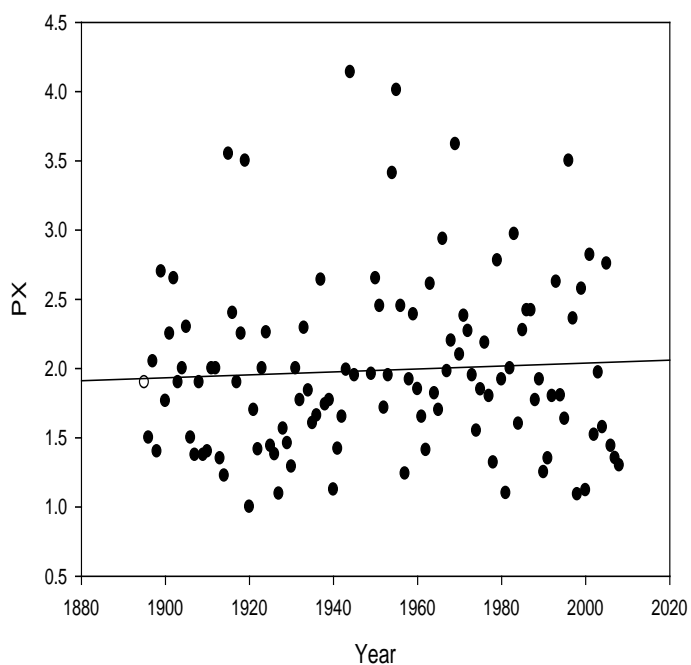

Figure 4-20 Graphic view of trends for station 185111, a. P95, b. P95D, c. CDD d. PX. 
a.

Station 185111

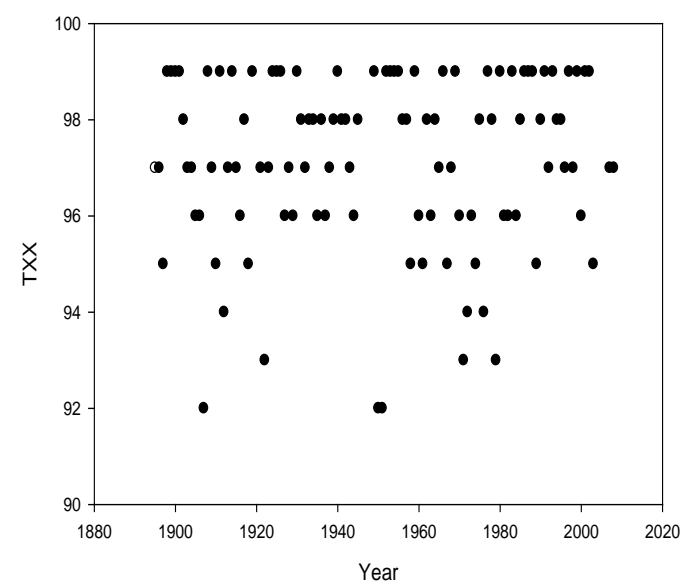

C.

Station 185111

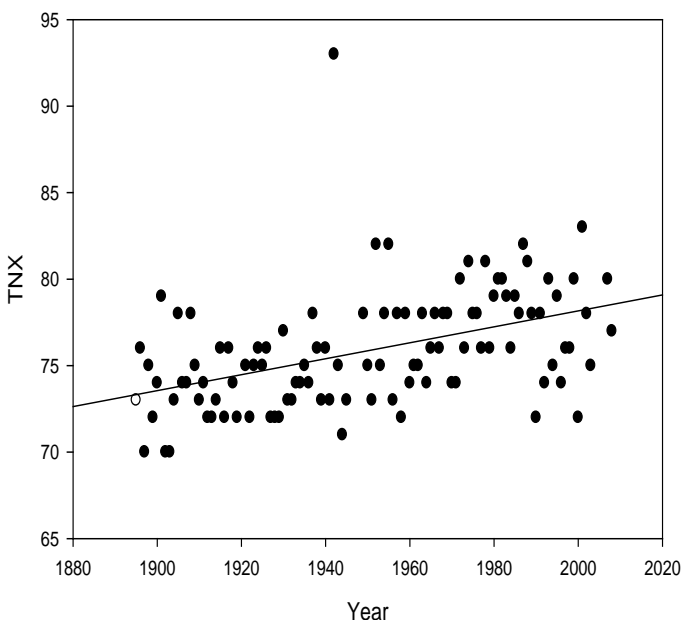

b.

Station 185111

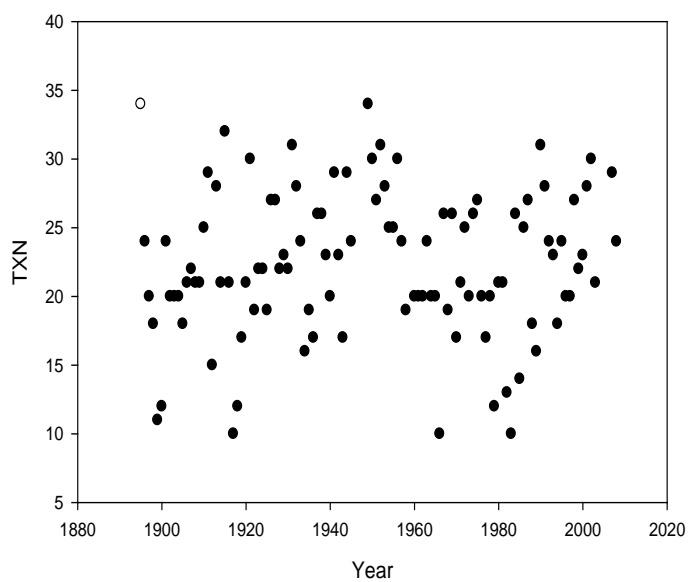

d.

Station 185111

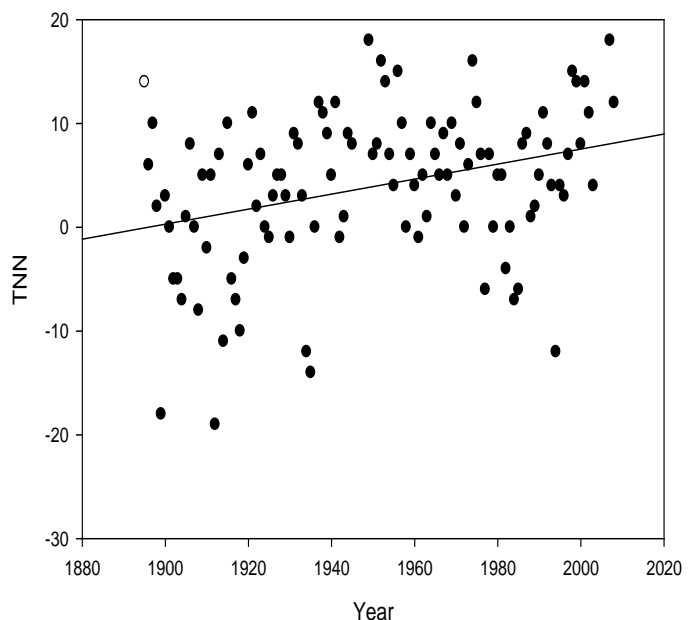

Figure 4-21 Graphic view of trends for station 185111, a. TXX, b. TXN, c. TNX d. TNN. 


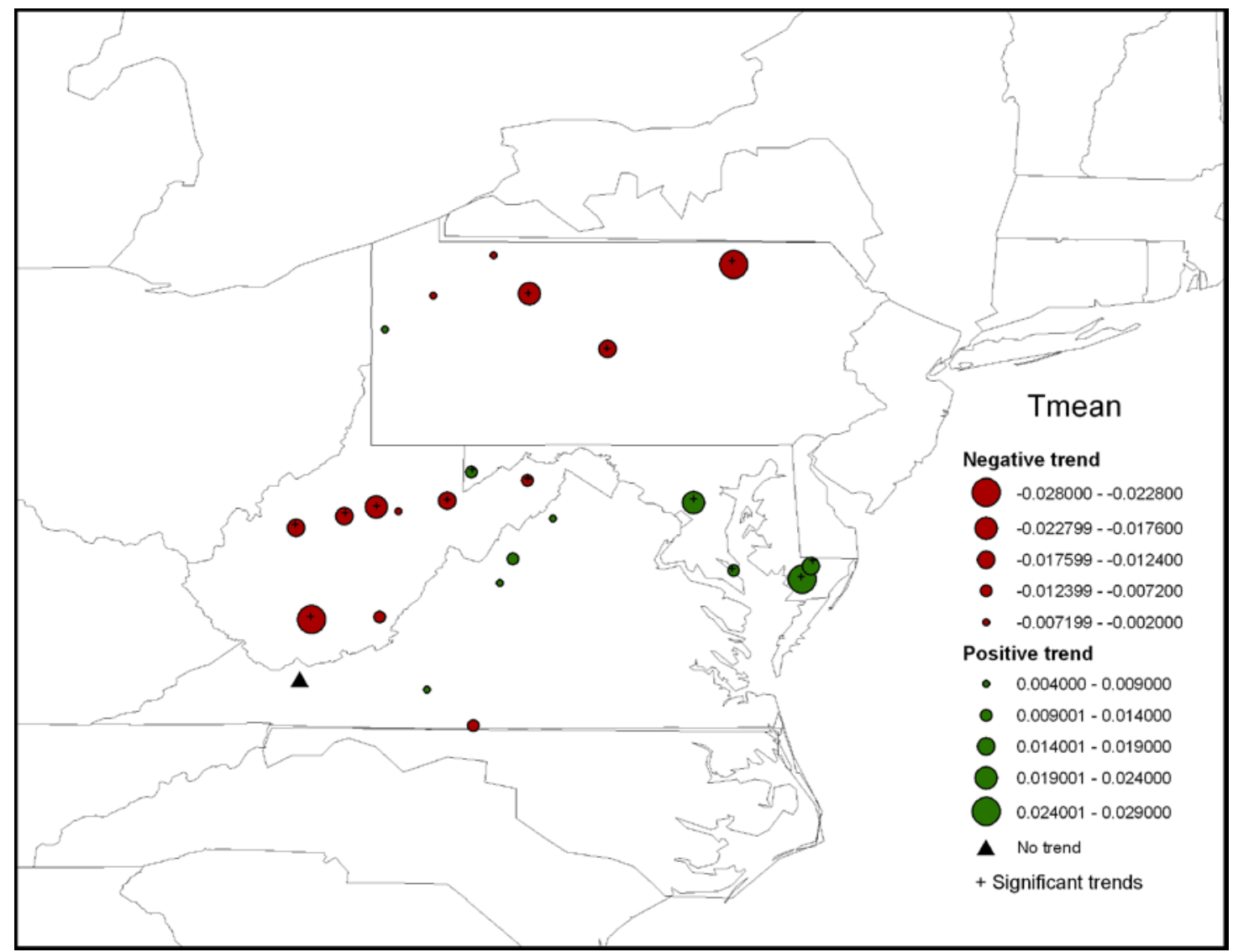

Figure 4-22 Spatial distribution of trends for annual mean temperature. 


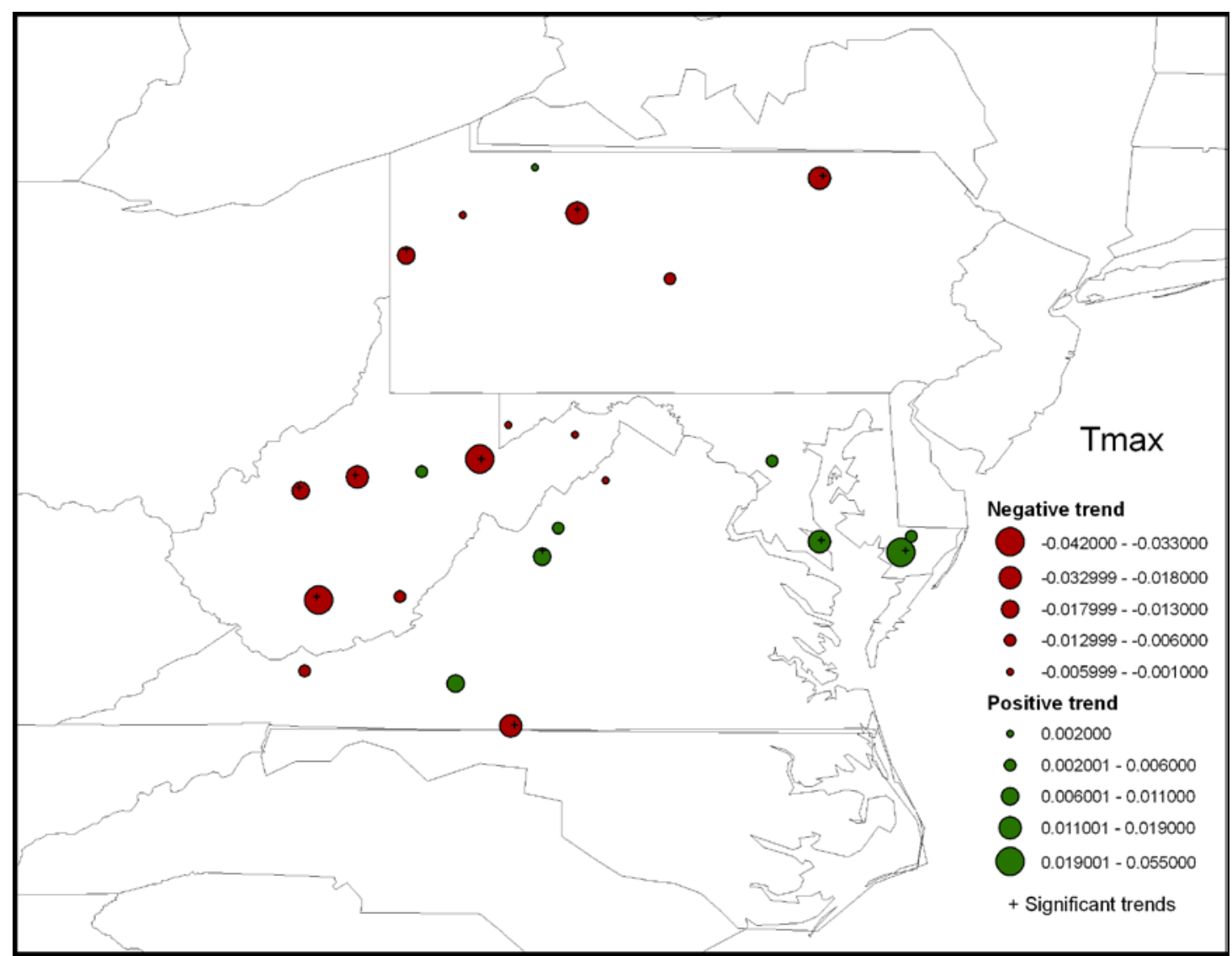

Figure 4-23 Spatial distribution of trends for annual maximum temperature. 


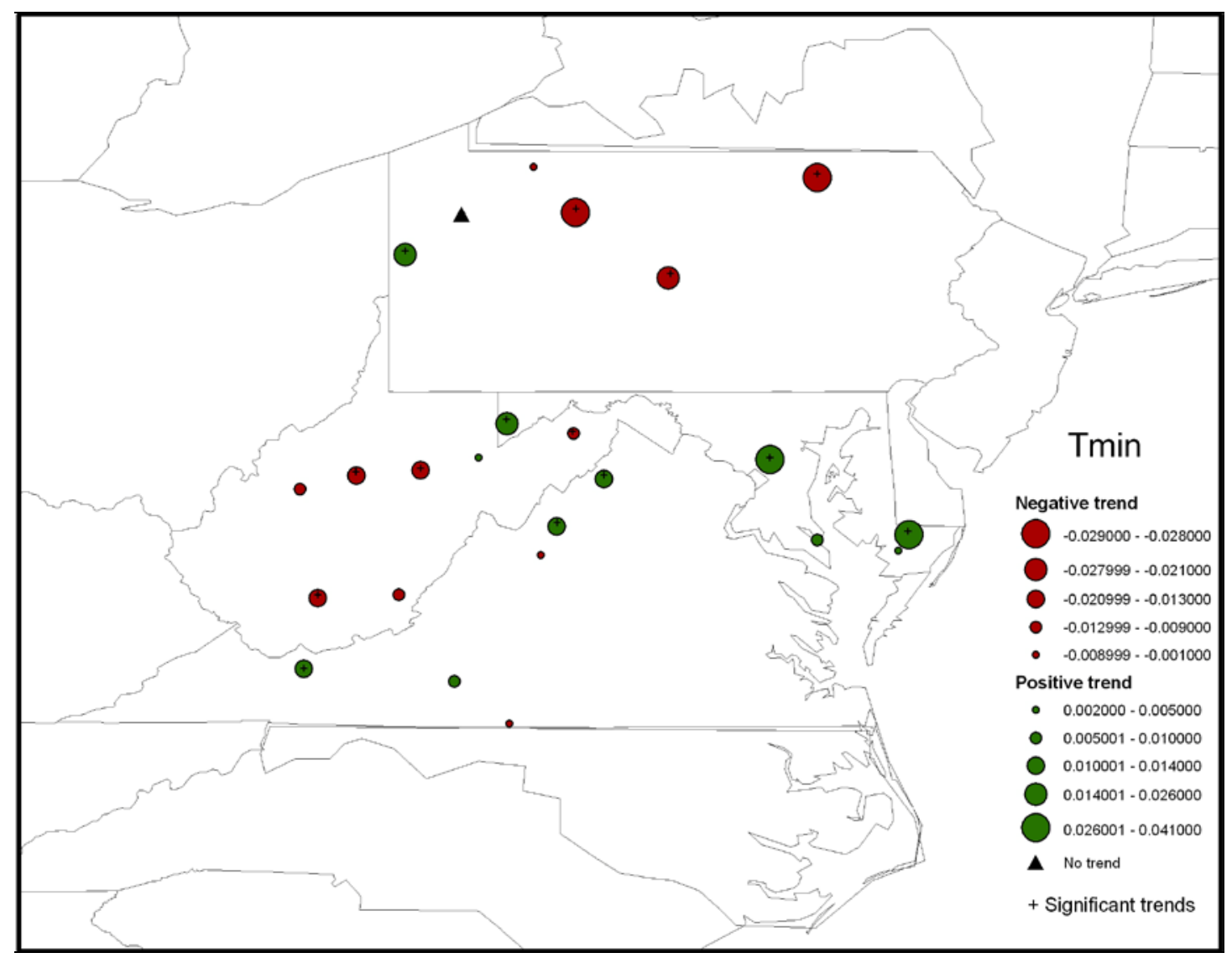

Figure 4-24 Spatial distribution of trends for annual minimum temperature. 


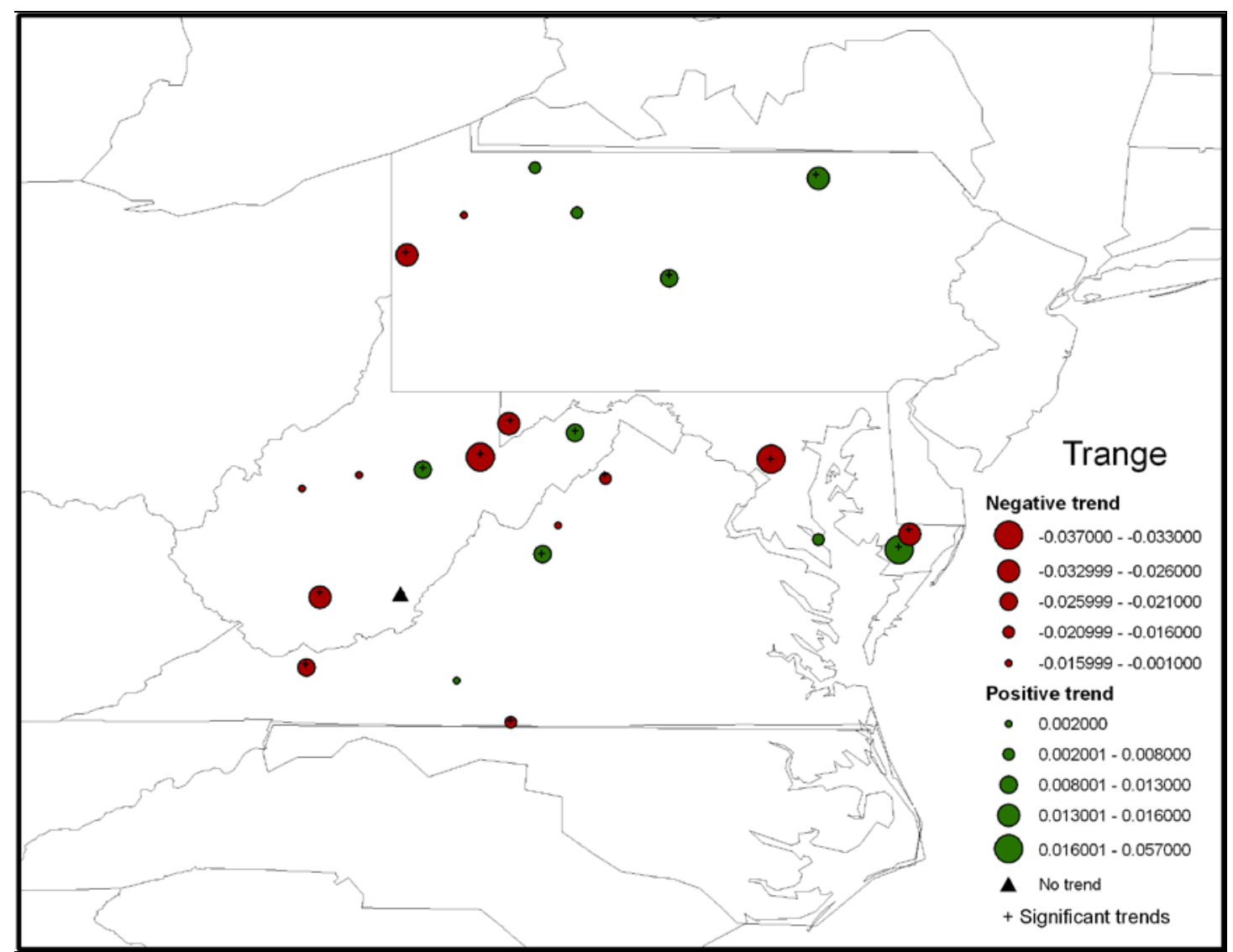

Figure 4-25 Spatial distribution of trends for binaural temperature range. 


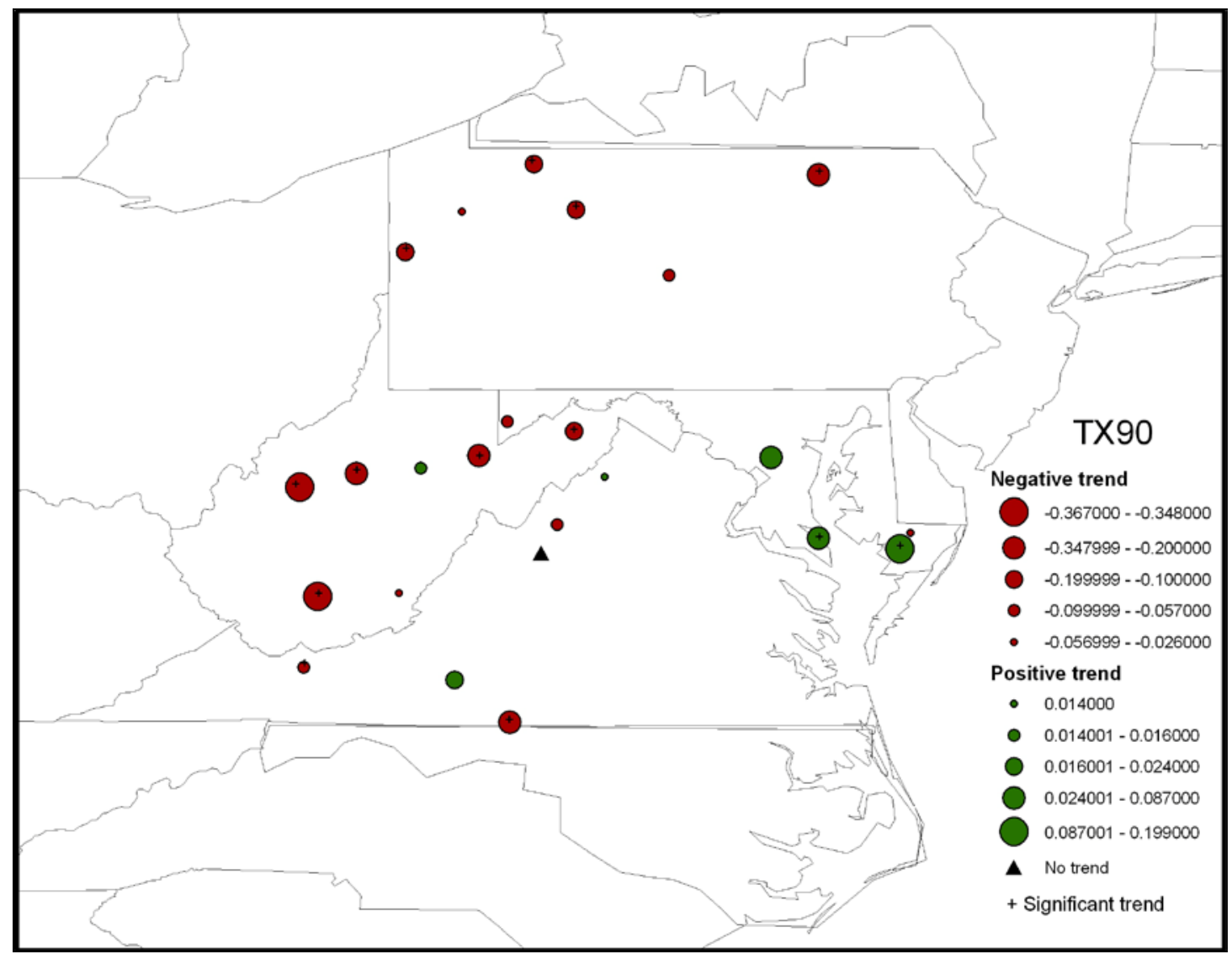

Figure 4-26 Spatial distribution of trends for TX90 (warm days). 


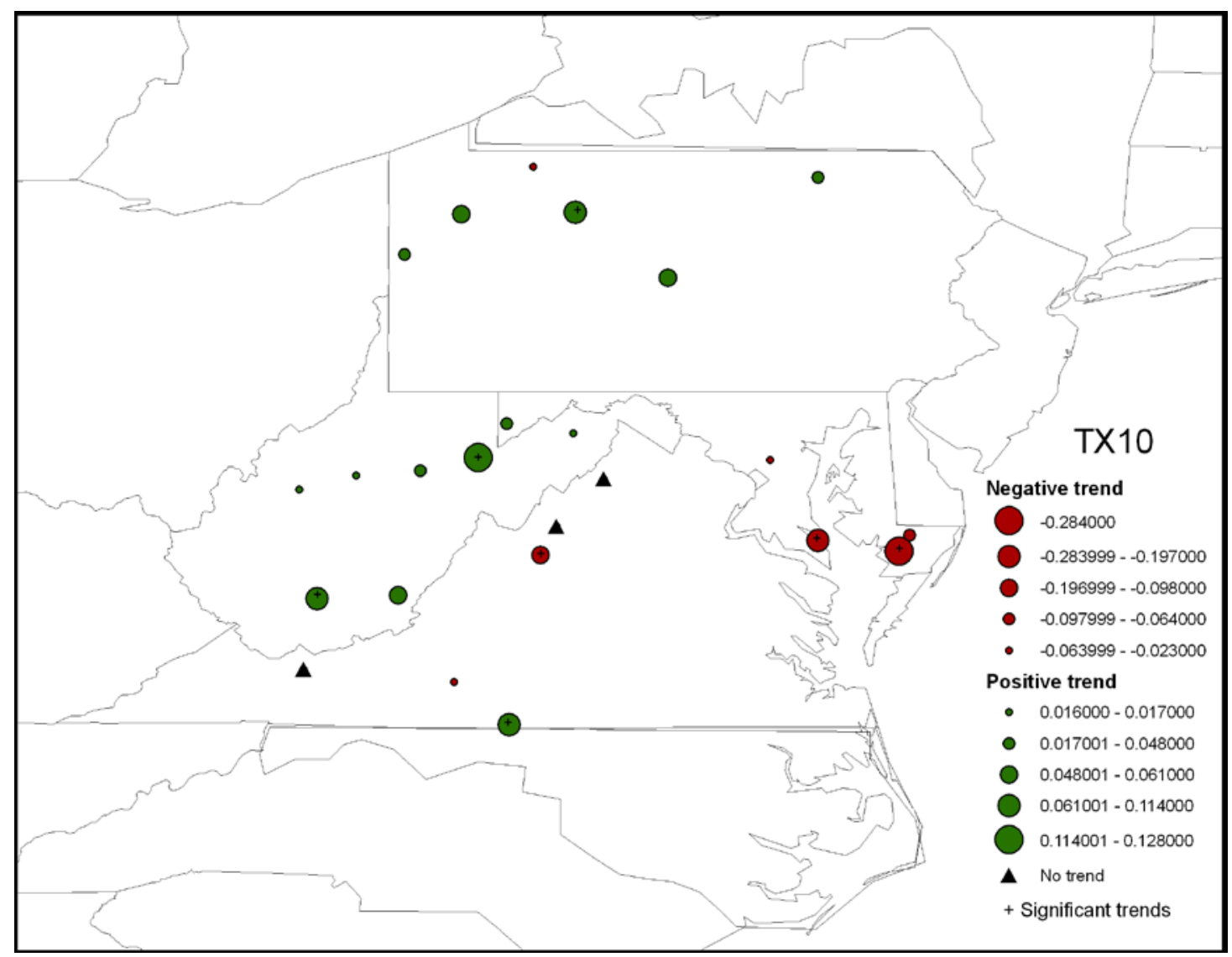

Figure 4-27 Spatial distribution of trends for TX10 (cool days). 


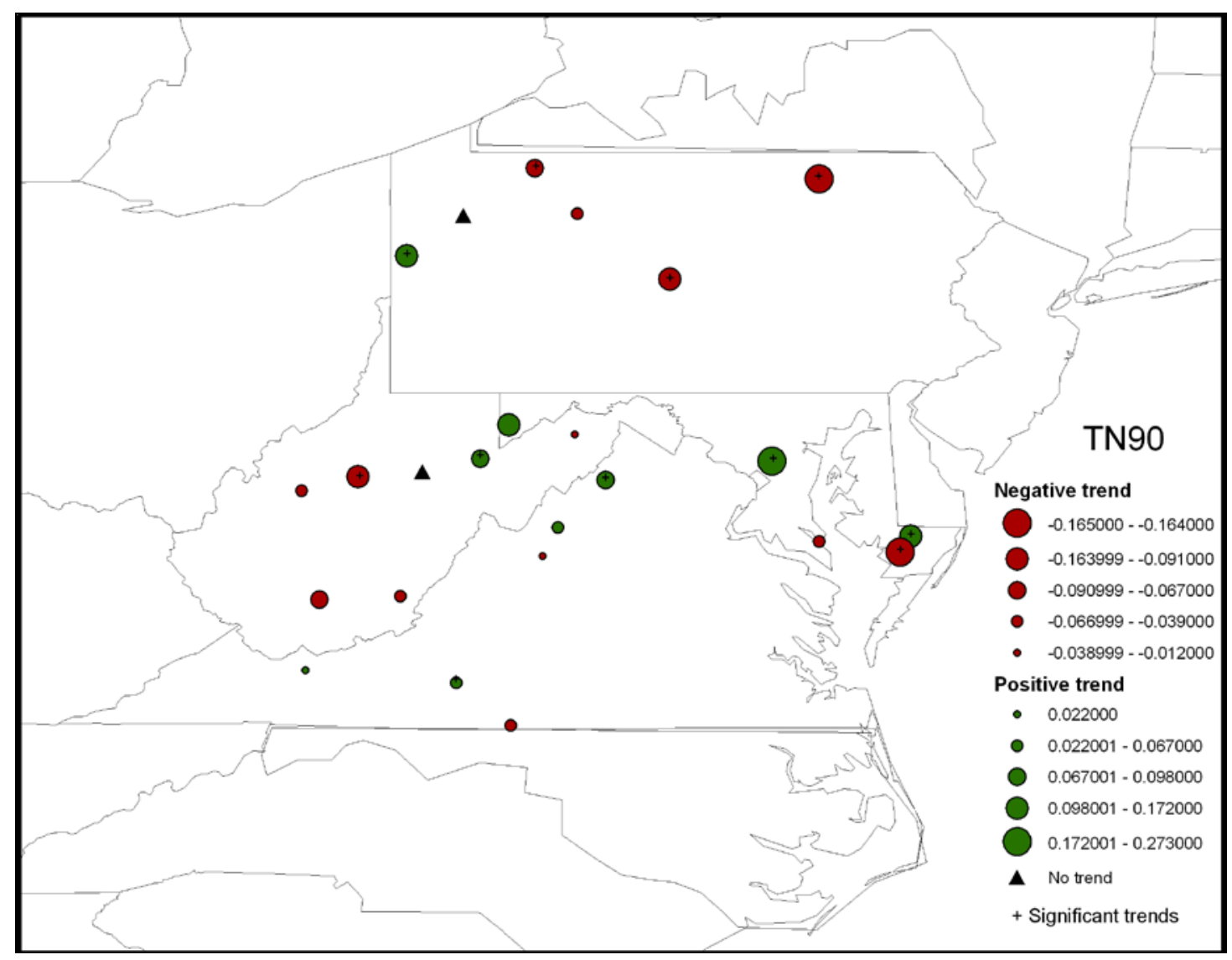

Figure 4-28 Spatial distribution of trends for TN90 (warm nights). 


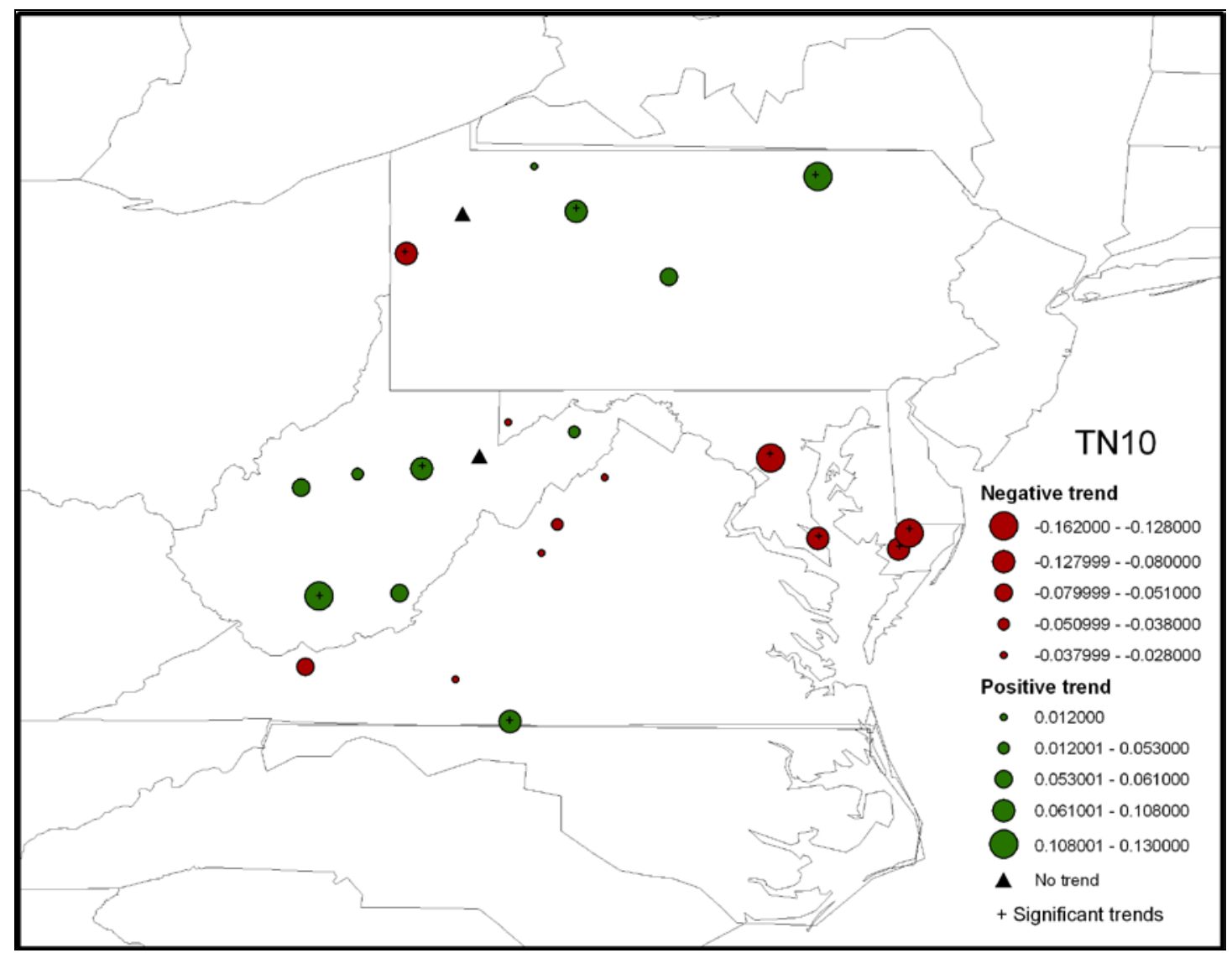

Figure 4-29 Spatial distribution of trends for TN10 (cool nights). 


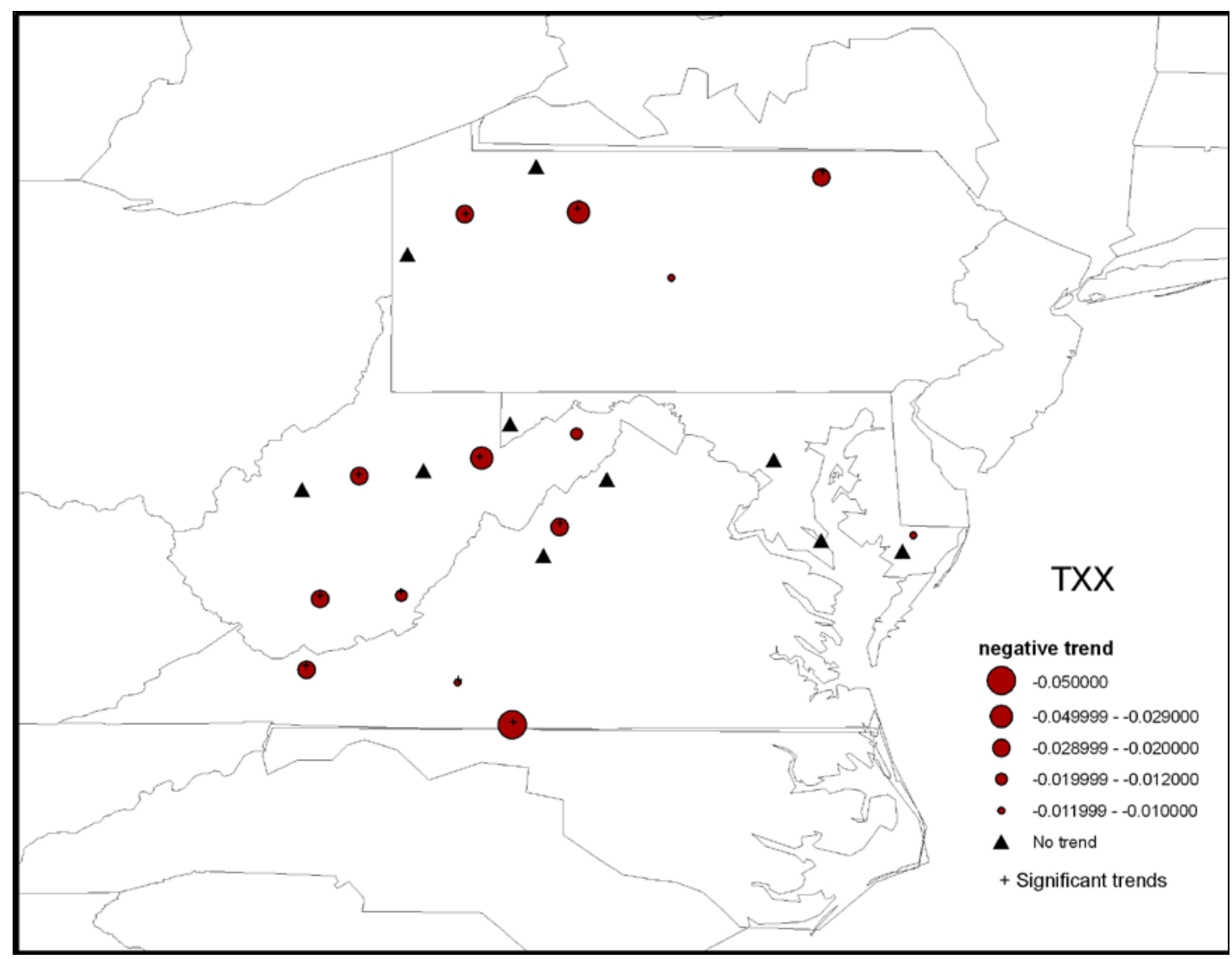

Figure 4-30 Spatial distribution of trends for maximum annual maximum temperature. 


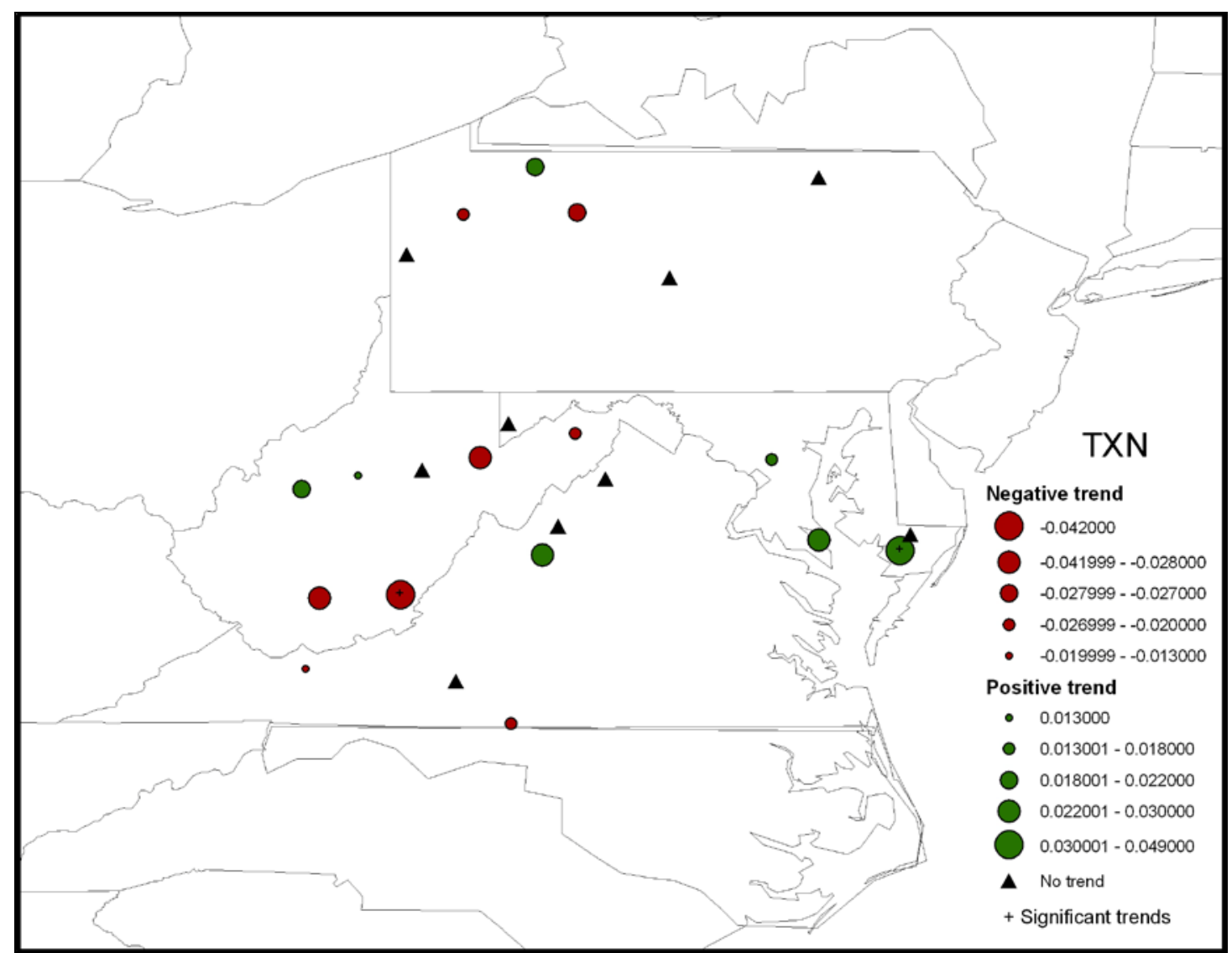

Figure 4-31 Spatial distribution of trends for minimum annual maximum temperature. 


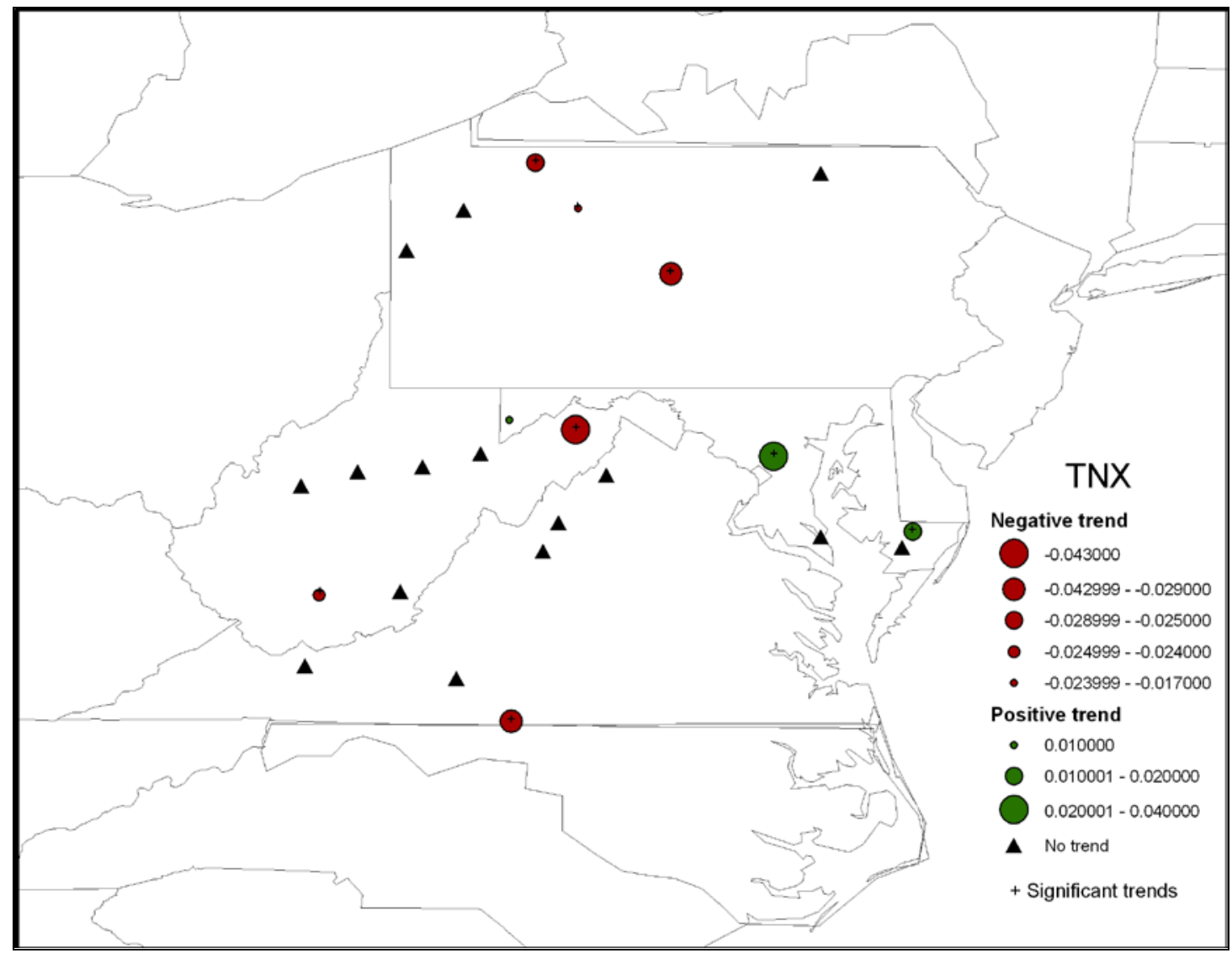

Figure 4-32 Spatial distribution of trends for maximum annual minimum temperature. 


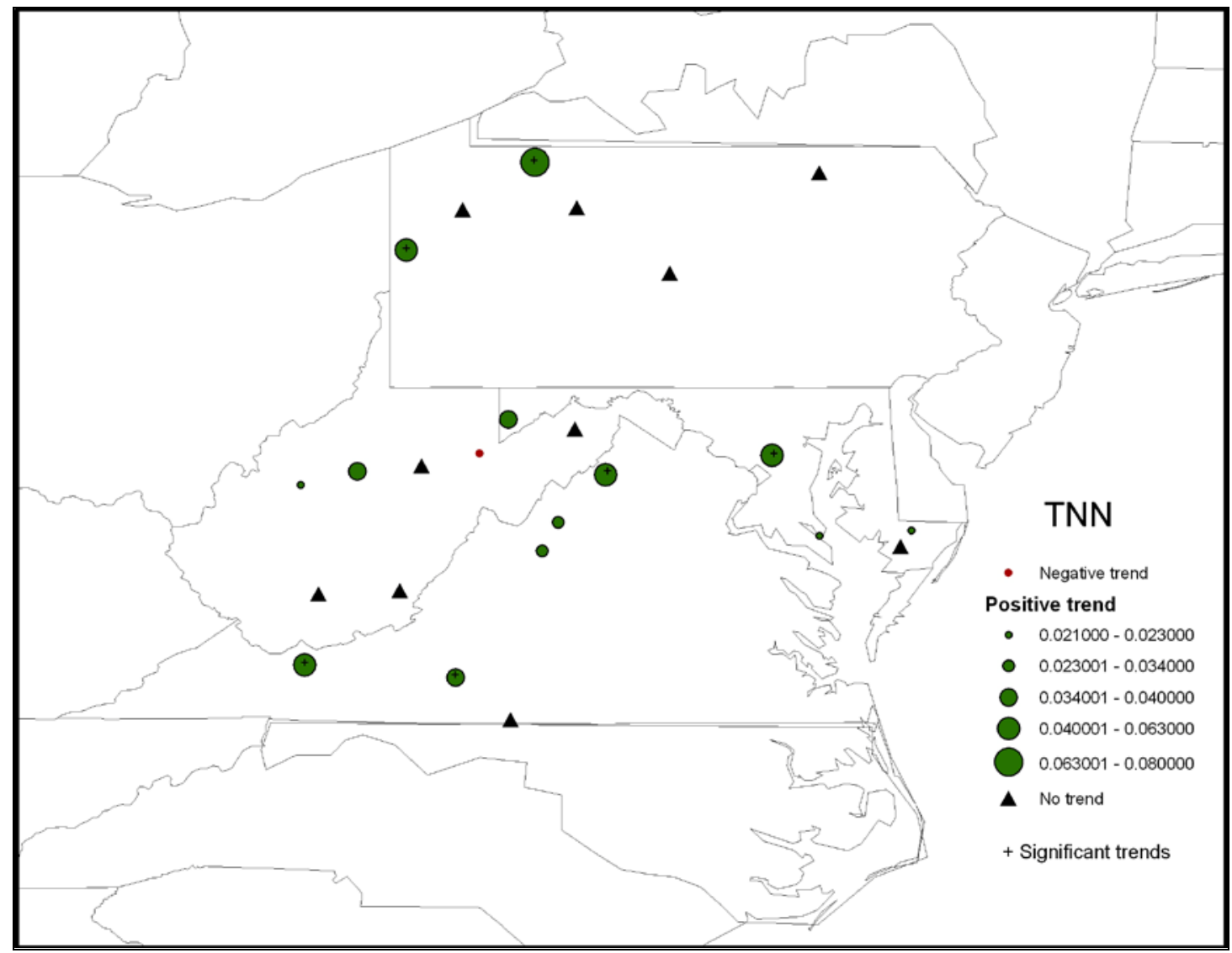

Figure 4-33 Spatial distribution of trends for minimum annual minimum temperature. 


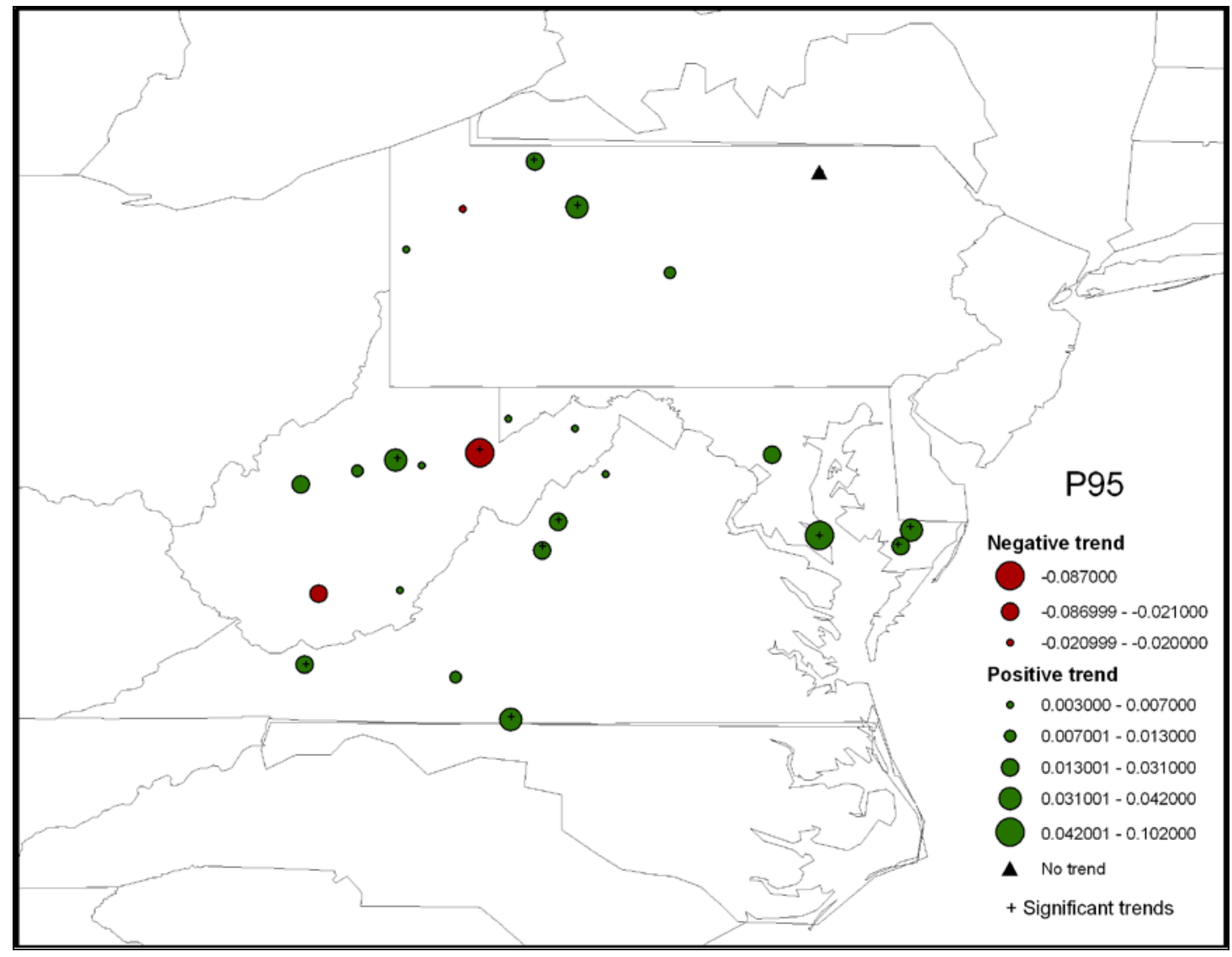

Figure 4-34 Spatial distribution of trends for annual total precipitation exceeding $95^{\text {th }}$ percentile. 


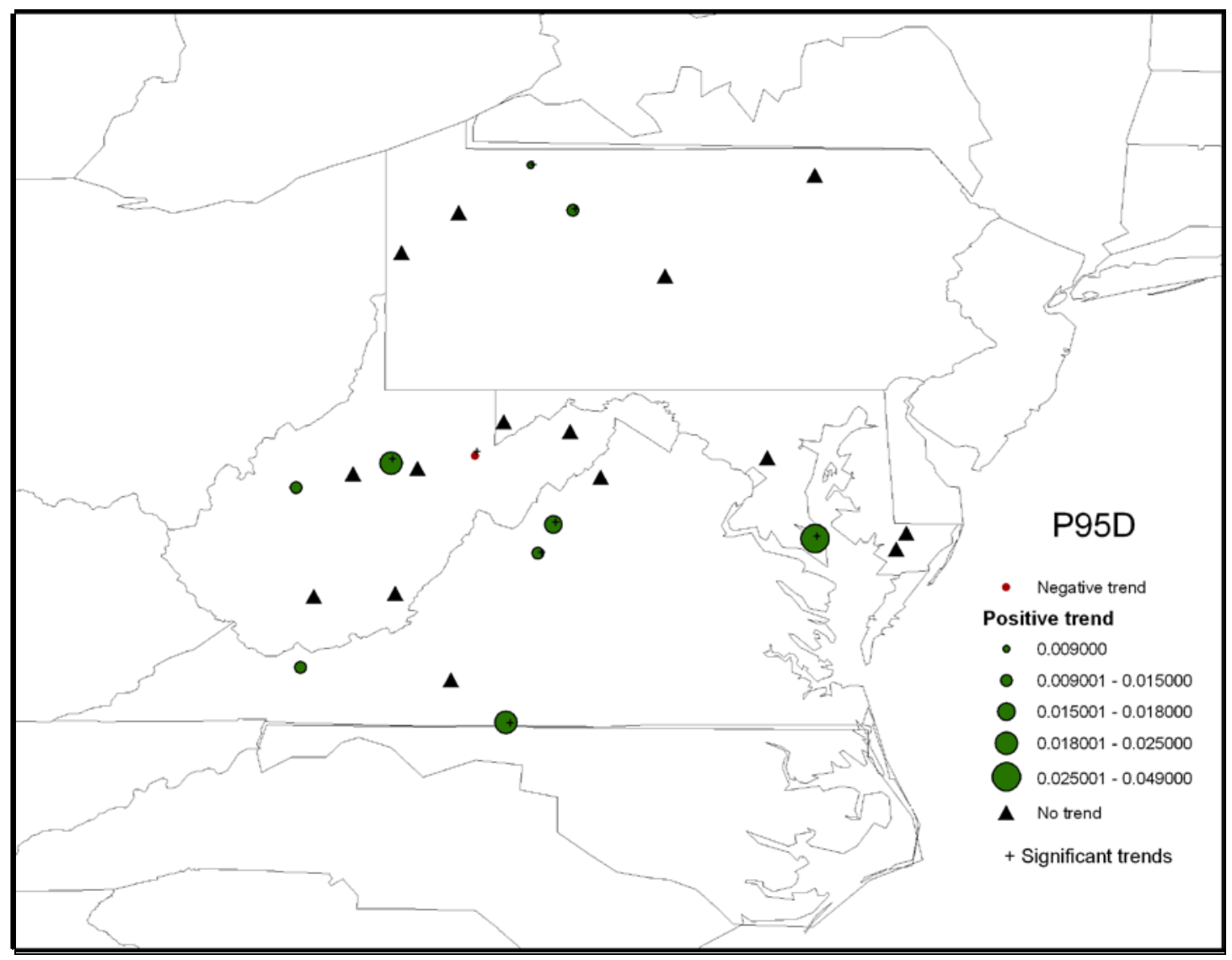

Figure 4-35 Spatial distribution of trends for annual total days with precipitation exceeding $95^{\text {th }}$ percentile. 


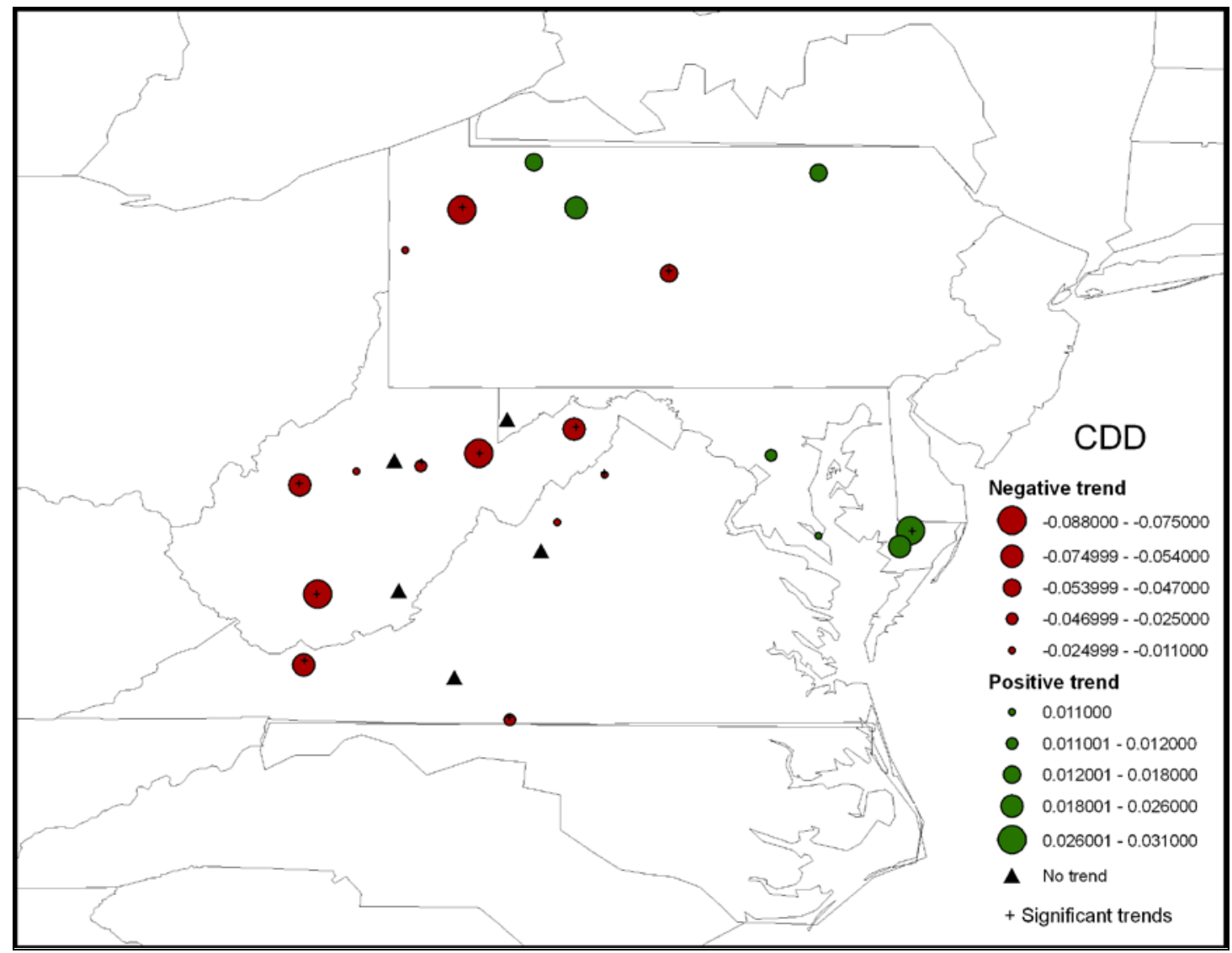

Figure 4-36 Spatial distribution of trends for consecutive dry days. 


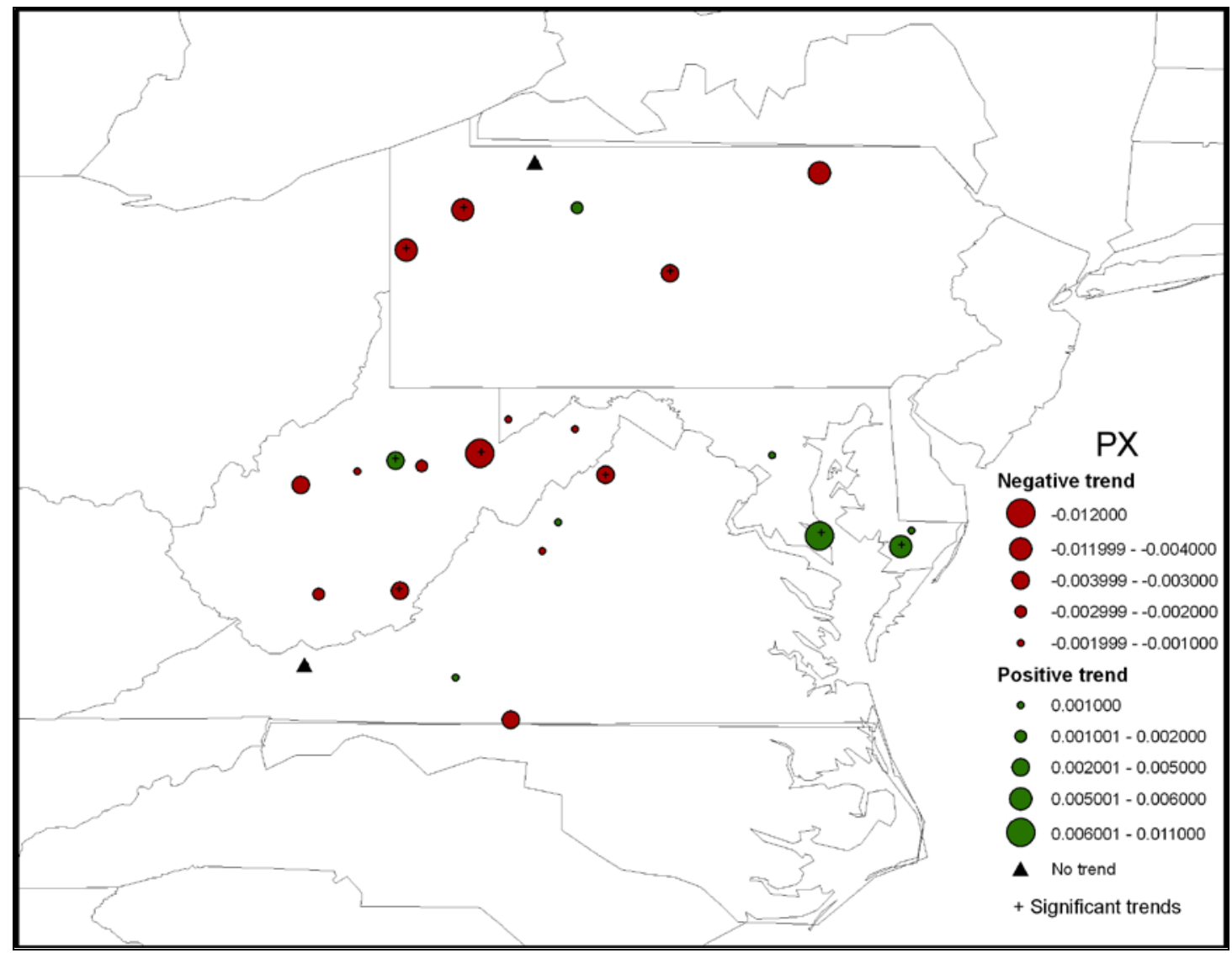

Figure 4-37 Spatial distribution of trends for maximum annual precipitation intensity. 


\section{Chapter 5 Discussion and Conclusion}

To summarize, a focus has been placed on analyzing the long-term trend (100 years) of climate variables for the Mid-Atlantic Region. Average slope of -0.015 ${ }^{\circ} \mathrm{F} / \mathrm{yr}$ in changes for annual mean temperature was detected for inland stations and $0.021^{\circ} \mathrm{F} / \mathrm{yr}$ for coastal stations. Average slope for annual maximum temperature and annual minimum temperature are $-0.019^{\circ} \mathrm{F} / \mathrm{yr}$ and $-0.006^{\circ} \mathrm{F} / \mathrm{yr}$ for inland stations and $0.037^{\circ} \mathrm{F} / \mathrm{yr}$ and $0.037^{\circ} \mathrm{F} / \mathrm{yr}$ for coastal stations. Although the frequency of extreme temperature events did not show significant increase, the magnitude increased $5.5{ }^{\circ} \mathrm{F}$ over the century for all stations for parameter TNN and $3.5^{\circ} \mathrm{F}$ for coastal stations for parameter TNX. Annual precipitation exceeding the $95^{\text {th }}$ percentile increased 0.028 inch per year with a more pronounced increases in the coastal area of 0.056 inch per year. The number of days with precipitation exceeding the $95^{\text {th }}$ percentile also increased by a rate of $0.014 \mathrm{~d} / \mathrm{yr}$.

The results showed great variation among stations. There was a clear discrepancy between coastal stations and inland stations. For most parameters, coastal stations showed opposite results with the stations away from the coast. We could see clearly increasing trends for annual temperatures for the four stations located in Maryland. As well as for the extreme temperature events, the stations showed increased warm days/nights corresponding with decreased cool days/nights. Increasing maximum intensity is observed in coastal stations also compared with negative trends or no trends for the inland stations. Increasing trends in cumulative dry days were also shown in the coastal stations while not much of a change in the inlands. One of the possible reasons of the results could the larger population and faster growth rate at the coastal stations than inland stations. Study suggested rapid urbanization could influence linear trend of temperatures (Englehart and Douglas 2003). Other authors also found this kind of discrepancy between coastal areas and inlands (El Kenawy et al. 2009). They suggested a close relation between air temperature near the coastal with sea surface temperature. Trends for sea surface temperature found in the Northwest Atlantic: between 1961 and 1990 warmed as 
much as $2.6^{\circ} \mathrm{C}$ off the mouth of the Chesapeake Bay, and cooled as much as $5^{\circ} \mathrm{C}$ north of Newfoundland. The Gulf Stream and the North Atlantic Current carry water warmer than average, as indicated by positive anomalies (Lemos and Sanso 2009).

Our seasonal results were consistent with our annual results. Significant difference was only found for warm days during winter season. Annual trends and summer trends mostly showed decreasing trends while winter showed increasing trends. This might indicated milder winter. Correspondingly, temperature for coldest nights which mainly occur in winter time showed no decreasing trends as well. One of the possible explanations for milder winter could be the North Atlantic Oscillation. The greatest climatic influence of the NAO is in the winter half of the year. Positive NAO pushes mild air across Europe and into Russia as well as the strong westerly flow tends to bring mild winter to much of North America (Burroughs 2007).

The changing rate for cool days seemed to be more dramatic at higher elevations as well as for the annual minimum maximum temperature. At stations with higher elevation, results showed more cool days and lower night temperature. Researchers also found similar results at the northwest of America. Largest warming trends rates occurred at lower elevations and smallest warming rates occurs in the Rockies (Mote 2003). Slopes of annual precipitation amount exceeding $95^{\text {th }}$ percentile at lower elevation stations tended to be positive and negative at higher elevations. Similar decreasing distributions from low elevation stations to high elevation stations were found for annual maximum precipitation intensity. The difference between each elevation group could be partly explained by the warming trend in coastal area and cooling trends in inland area. Our study condition differed from other researches in Europe and China. They have much higher elevation level, more than $1000 \mathrm{~m}$. As snow cover is a much import factor there, snow-albedo is used to explain the trend from low elevation to high elevation.

It would be inappropriate to state that the observed trends in air temperature and precipitation in the Mid-Atlantic Region have occurred as a consequence of climate change. Moreover, although both temperature and precipitation trends 
showed dependency on elevation to some degree, other factors might also have influences on trend attribution. Future study must be done to include influences of all possible factors.

In accordance with the global trends, most studies found significant warming trend during the second half of the $20^{\text {th }}$ century. Studies showed two main periods of significant changes from 1900 to 1940 and 1970 to 2000. Differences between each period may compensate each other which results in no trend or none significant trend over the 100-year period. Cumulative deviation approach can be included in future study to detect different changing periods from the entire time frame (Tecer et al. 2009). Furthermore, in future study, all four seasons will be analyzed to get complete understanding of seasonal trends and which season is mainly exposed to changes in climatic parameters.

Regional trends were not found in this study. One of the possible reasons for failing the $\chi^{2}$ test is that the number of the stations is not sufficient enough to cover the whole region. In order to study regional trend in the future, increased density of stations are required to get convincing results. Our study is the first look of the available data, more work are needed to justify the results.

For future study, we also plan to develop the relation between climate change and water resources. In particular, a systematic examination of how water availability in terms of both quantity and quality change with climate. Recent studies have been using dynamical downscaling with a regional climate model (RCM) driven by a general circulation models (GCMs) to simulate climate change scenarios. The simulated results were used to drive hydrology models or water quality models to study the impacts of climate. Results showed that most water parameters including physicochemical basic parameters, micropollutants and biological parameters has been affected by changing in temperature as well as precipitation. We would like to use historical data of hydrology and water quality together with climatic data to develop more direct relations. Numerical relations could be developed between temperature and precipitation trends with water quality trends excluding other affecting factor. Paired correlation test could be done to study the relationship 
between water quality parameters and climatic parameters. Water quality data could be compared after and before the indentified extreme weather events. Sensitivity of the response of the water body to climate change could also be studied using Structure Equation Model (SEM). Two latent growth curves, one for changes in climatic parameters and the other for changes for water quality can be used to test the hypothesis of the relationship between these two types of variables. All these approaches could be used to develop conceptual model for climate change impacts on water availability and quality. 


\section{Reference}

Alexander, L. V., Zhang, X., Peterson T. C., Caesar, J., Gleason, B., Klein Tank, A., Haylock, M., Collins, D., Rahimzadeh, F., Tagipour A., Ambenje, P., Rupa Kumar, K., Revadekar, J., Griffiths, G., Vincent, L., Stephenson, D., Burn, J., Aguilar, E., Brunet ,M., Taylor, M., New, M., Zhai, P., Rusticucci, Vazquez-Aguirre, M. (2006).

"Global observed changes in daily climate extremes of temperature and precipitation." Journal of Geophysical Research 111(3): D05109.

Alexandersson, H. (2007). "A homogeneity test applied to precipitation data." International Journal of Climatology 6(6): 661-675.

Alexandrov, V., Schneider, M., Koleva, E., Moisselin, J. M. (2004). "Climate variability and change in Bulgaria during the 20th century." Theoretical and Applied Climatology 79(3): 133-149.

Arheimer, B., Andréasson, J., Fogelberg, S., Johnsson, H., Pers, C. B., Persson, K. (2005). "Climate change impact on water quality: model results from southern Sweden." AMBIO: A Journal of the Human Environment 34(7): 559-566.

Balling, R. C. Jr, Michaels, P. J., Knappenberger, P. C. (1998). "Analysis of winter and summer warming rates in gridded temperature time series." Climate Research 9: 175-181.

Beniston, M. and Rebetez, M. (1996). "Regional behavior of minimum temperatures in Switzerland for the period 1979-1993." Theoretical and Applied Climatology 53(4): $231-243$

Böhm, R., Auer, I., Brunetti, M., Maugeri, M., Nanni, T., Schöner, W. (2001). "Regional temperature variability in the European Alps: 1760-1998 from 
homogenized instrumental time series." International Journal of Climatology 21(14): 1779-1801.

Both, C., Bouwhuis, S., Lessells, C. M., Visser, M. E. (2006). "Climate change and population declines in a long-distance migratory bird." Nature 441(7089): 81-83.

Bradley, N. L., Leopold, A. C., Ross, J., Huffaker, W. (1999). "Phenological changes reflect climate change in Wisconsin." Proceedings of the National Academy of Sciences of the United States of America 96(17): 9701-9704.

Brunetti, M., Buffoni, L., Maugeri, M., Nanni, T. (2000). "Trends of minimum and maximum daily temperatures in Italy from 1865 to 1996." Theoretical and Applied Climatology 66(1): 49-60.

Brunetti, M., Buffoni, L., Mangianti, F., Maugeri, M., Nanni, T. (2004). "Temperature, precipitation and extreme events during the last century in Italy." Global and planetary change 40(1-2): 141-149.

Brunetti, M., Maugeri, M., Nanni, T. (2001). "Changes in total precipitation, rainy days and extreme events in northeastern Italy." International Journal of Climatology 21(7): 861-871.

Burroughs, W. J. (2007). "Climate change: a multidisciplinary approach." Cambridge University Press.

Chang, H., Evans, B. M., Easterling, D. R. (2001). "The effects of climate change on stream flow and nutrient loading." Journal of the American Water Resources Association 37(4): 973-985.

Chen, Y., Pang, Z., Hao, X., Xu, C., Chen, Y. (2008). "Periodic changes of stream 
flow in the last 40 years in Tarim River Basin, Xinjiang, China." Hydrological Processes 22(21): 4214-4221.

Chmielewski, F. M. and Tzer T. R (2001). "Response of tree phenology to climate change across Europe." Agricultural and Forest Meteorology 108(2): 101-112.

Church, J. A. and White, N. J. (2006). "A 20th century acceleration in global sea-level rise." Geophysical Research Letters 33(1): L01602.

Condit, R., Hubbell, S. P., Foster, R. B. (1996). "Changes in tree species abundance in a neotropical forest: impact of climate change." Journal of Tropical Ecology 12: 231-256.

Conrad, V. (2007). "Methods in climatology." Lancasler Press.

Costa, A. C. and Soares, A. (2008). "Trends in extreme precipitation indices derived from a daily rainfall database for the South of Portugal." International Journal of Climatology 29: 1956-1975.

Craddock, J. M. (1979). "Methods of comparing annual rainfall records for climatic purposes." Weather 34(9): 332-346.

Cruise, J. F., LimayeNassim Al-Abed, A. S. (1999). "Assessment of impacts of climate change on water quality in the southeastern United States." Journal of the American Water Resources Association 35(6): 1539-1550.

Cuo, L., Lettenmaier, D. P., Alberti, M., Richey, J. E. (2009). "Effects of a century of land cover and climate change on the hydrology of the Puget Sound basin." Hydrological Processes 23(6): 907-933. 
De Toffol, S., Laghari, A. N., Rauch, W. (2009). "Are extreme rainfall intensities more frequent? Analysis of trends in rainfall patterns relevant to urban drainage systems." Water Science and Technology 59(9): 1769-1776.

DeGaetano, A. T. (2009). "Time-Dependent Changes in Extreme Precipitation Return Period Amounts in the Continental United States." Journal of Applied Meteorology and Climatology 48(10): 1558-8424.

Duffy, P. B., Doutriaux, C., Santer, B. D., Fodor, I. K. (2001). "Effect of missing data on estimates of near-surface temperature change since 1900." Journal of Climate 14(13): 2809-2814.

El Kenawy, A. M., López-Moreno, J. I., Vicente-Serrano, S. M., Mekld, M. S. (2009). "Temperature trends in Libya over the second half of the 20th century." Theoretical and Applied Climatology 98(1): 1-8.

Elmallah, E. S. and Elsharkawy, S. G. (2009). "Analysis of Summer Temperature Anomalies in Egypt during the 20 th Century." Research Journal of Environmental Sciences 3(5): 530-542.

Englehart, P. J. and Douglas, A. V. (2003). "Urbanization and seasonal temperature trends: observational evidence from a data-sparse part of North America." International Journal of Climatology 23(10): 1253-1263.

Feidas, H., Makrogiannis, T., Bora-Senta, E. (2004). "Trend analysis of air temperature time series in Greece and their relationship with circulation using surface and satellite data: 1955-2001." Theoretical and Applied Climatology 79(3): 185-208.

Frei, C. and Schär, C. (2001). "Detection probability of trends in rare events: Theory and application to heavy precipitation in the Alpine region." Journal of Climate 14(7): 
1568-1584.

Gemmer, M., Becker, S., Jiang, T. (2004). "Observed monthly precipitation trends in China 1951-2002." Theoretical and Applied Climatology 77(1): 39-45.

Giorgi, F., Hurrell, J. W., Marinucci, M. R., Beniston, M. (1997). "Elevation dependency of the surface climate change signal: a model study." Journal of Climate 10(2): 288-296.

Herlihy, A. T., Stoddard, J. L., Johnson, C. B. (1998). "The relationship between stream chemistry and watershed land cover data in the Mid-Atlantic region, US." Water, Air, \& Soil Pollution 105(1): 377-386.

Groisman, P. Y., Knight, R. W., Karl, T. R. (2001). "Heavy precipitation and high streamflow in the contiguous United States: Trends in the twentieth century." Bulletin of the American Meteorological Society 82(2): 219-246.

Harvell, C. D., Mitchell, C. E., Ward, J. R., Altizer, S., Dodson, A. P., Ostfeld, R. S., Samuel, M. D. (2002). "Climate warming and disease risks for terrestrial and marine biota." Science 296(5576): 2158.

Helsel, D. R. and Frans, L. M. (2006). "Regional Kendall test for trend." Environmental science \& technology 40(13): 4066.

Hirsch, R. M., Slack, J. R., Smith, R. A. (1982) "Techniques of trend analysis for monthly water quality data." Water Resources Research 18(1): 107-121.

Hodgkins, G. A., Dudley, R. W., Huntington, T. G. (2003). "Changes in the timing of high river flows in New England over the 20th century." Journal of Hydrology 278(1-4): 244-252. 
Hundecha, Y. and Bárdossy, A. (2005). "Trends in daily precipitation and temperature extremes across western Germany in the second half of the 20th century." International Journal of Climatology 25(9): 1189-1202.

IPCC (2007). "The Physical Science Basis. Contribution of Working Group I to the Fourth Assessment Report of the Intergovernmental Panel on Climate Change." Cambridge University Press.

Inouye, D. W., Barr, B., Armitage, K. B., Inouye, B. D. (2000). "Climate change is affecting altitudinal migrants and hibernating species." Proceedings of the National Academy of Sciences 97(4): 1630-1633.

Jones, K. B., Riitters, K. H., Wickham, J. D., Tankersley, R. D., O’Neill, R. V., Chaloud, D. J., Smith, E. R., Neale, A. C. (1997). "An ecological assessment of the United States Mid-Atlantic region: a landscape atlas." United States Environmental Protection Agency. Office of Research and Development, Washington DC, 20460. EPA/600/R-97/130.

Jung, H. S., Choi, Y., Oh, J. H., Lim, G. H. (2002). "Recent trends in temperature and precipitation over South Korea." International Journal of Climatology 22(11): 1327-1337.

Kahya, E. and Kalayc, S. (2004). "Trend analysis of streamflow in Turkey." Journal of Hydrology 289(1-4): 128-144.

Kirdyanov, A., Hughes, M., Vaganov, E., Schweingruber, F., Silkin, P. (2003). "The importance of early summer temperature and date of snow melt for tree growth in the Siberian Subarctic." Trees-Structure and Function 17(1): 61-69. 
Klein Tank, A. M. G. and Können, G. P. (2003). "Trends in indices of daily temperature and precipitation extremes in Europe, 1946-99." Journal of Climate 16(22): 3665-3680.

Klein Tank, J. B. W., Können, G. P., Böhm, R., Demarée, G., Gocheva, A., Mileta, M., Pashiardis, S., Kern-Hansen, L., Heino, R., Bessemoulin, P., Müller-Westermeier, G., Tzanako,u M., Szalai, S., Pálsdóttir, T., Fitzgerald, D., Rubin, S., Capaldo, M., Maugeri M., Leitass, A., Bukantis, A., Aberfeld, R., Van Engelen, A. F. V., Forland, E., Mietus, M., Coelho, F., Mares, C., Razuvaev, V., Nieplova, E., Cegnar, T., Antonio López, J., Dahlström, B., Moberg, A., Kirchhofer, W., Ceylan, A., Pachaliuk, O., Alexander, L. V., Petrovic, P. (2002). "Daily dataset of 20th-century surface air temperature and precipitation series for the European Climate Assessment." International Journal of Climatology 22: 1441-1453.

Knowles, N., Dettinger, M. D., Cayan, D. R. (2006). "Trends in snowfall versus rainfall in the western United States." Journal of Climate 19(18): 4545-4559.

Komatsu, E., Fukushima, T., Harasawa, H. (2007). "A modeling approach to forecast the effect of long-term climate change on lake water quality." Ecological Modelling 209(2-4): 351-366.

Kotsiantis, S., Kostoulas, A., Lykoudis, S., Argiriou, A., Menagias, K. (2006). "Filling missing temperature values in weather data banks." $2^{\text {nd }}$ IET International Conference on Intelligent Environments CP518

Kouremenos, D. A. and Antonopoulos, K. A. (1993). "Temperature data for 35 Greek cities." Greek. Athens.

Kunkel, K. E., Andsager, K., Easterling, D. R. (1999). "Long-term trends in extreme precipitation events over the conterminous United States and Canada." Journal of 
Climate 12(8): 2515-2527.

Lazaro, R., Rodrigo, F. S., Gutiérrez, L., Domingo, F., Puigdefábregas, J. (2001). "Analysis of a 30 year Temperature Record (1967-1997) in Semi-arid SE Spain for Implications on Vegetation." Journal of Arid Environments 48(3): 373-395.

Lemos, R. T. and Sanso, B. (2009) "A Spatio-Temporal Model for Mean, Anomaly, and Trend Fields of North Atlantic Sea Surface Temperature." Journal of the American Statistical Association 104(485).

Lettenmaier, D. P. "Detection of trends in water quality data from records with dependent observations." Water Resources Research 12(5).

Levitus, S., Antonov, J. I., Boyer, T. P., Locamini, R. A., Garcia, H. E. (2009). "Global ocean heat content 1955-2008 in light of recently revealed instrumentation problems." Geophysical Research Letters 36(7): L07608.

Liu, X., Cheng, Z., Yan, L., Yin, Z. (2009). "Elevation dependency of recent and future minimum surface air temperature trends in the Tibetan Plateau and its surroundings." Global and planetary change 68(3): 164-174.

Manton, M. J., Della-Marta, P. M., Haylock, M. R., Hennessy, K. J., Nicholls, N., Cham, L. E., Collins, D. A., Daw, G., Finet, A., Gunawan, D., Inape, K., Isobe, H., Kestin, T. S., Lefal, P., Leyu, C. H., Lwin, T., Maitrepierre, L., Ouprasitwong, N., Page, C. M., Pahalad, J., Plum, N., Salinger, M. J., Suppiah, R., Tran, V. L., Trewin, B., Tibig, I., Ye, D. (2001). "Trends in extreme daily rainfall and temperature in Southeast Asia and the South Pacific: 1961-1998." International Journal of Climatology 21(3): 269-284.

McKnight, T. L.; Darrel, H. (2000). "Climate Zones and Types: The Köppen System". 
Physical Geography: A Landscape Appreciation Prentice hall, New Jersey.

Menzel, A., Sparks, T. H., Estrell, N., Koch, E., Aasa, A., Alm-Kuübler, K., Bissolli, P. (2006). "European phenological response to climate change matches the warming pattern." Global Change Biology 12(10): 1969-1976.

Mimikou, M. A., Baltas E., Varanou, E., Pantazis, K. (2000). "Regional impacts of climate change on water resources quantity and quality indicators." Journal of Hydrology 234(1-2): 95-109.

Moberg, A., Jones P. D., David, L., Alexander, W., Manola, B., Jucundus, J. (2006). "Indices for daily temperature and precipitation extremes in Europe analyzed for the period 1901-2000." Journal of Geophysical Research 111: D22106.

Mulholland, P. J., Best, G. R., Coutant, C., Hornberger, G. M., Meyer, J. L., Robinson, P. J., Stemberg, J. R., Turner, R. E., Vera-Herrera, F., Wetzel, R. (1997). "Effects of climate change on freshwater ecosystems of the south-eastern United States and the Gulf Coast of Mexico." Hydrological Processes 11(8): 949-970.

Murawski, S. A. (1993). "Climate change and marine fish distributions: forecasting from historical analogy." Transactions of the American Fisheries Society 122(5): 647-658.

Naurzbaev, M. M., Vaganov, E. A., Schweingruber, F. H. (2002). "Summer temperatures in eastern Taimyr inferred from a 2427-year late-Holocene tree-ring chronology and earlier floating series." The Holocene 12(6): 727.

Neelin, J. D., Münnich, M., Meyerson, J. E., Holloway, C. E. (2006). "Tropical drying trends in global warming models and observations." Proceedings of the National Academy of Sciences of the United States of America 103(16): 6110-6115. 
Neff, R., Chang, H., Knight, C. G., Najjar, R. G., Yarnal, B., Walker, H. A. (2000). "Impact of climate variation and change on Mid-Atlantic Region hydrology and water resources." Climate Research 14(3): 207-218.

Olsen, J. R., Stedinger, J. R., MatalasEugene, C., Stakhiv, Z. (1999). "Climate variability and flood frequency estimation for the Upper Mississippi and Lower Missouri Rivers." Journal of the American Water Resource Association 35(6): 1509-1523.

Önöz, B. and Bayazit, M. (2003). "The power of statistical tests for trend detection." Turkish Journal of Engineering and Environmental Sciences 27(4): 247-251.

Pearson, R. G. and Dawson, T. P. (2003). "Predicting the impacts of climate change on the distribution of species: are bioclimate envelope models useful?" Global Ecology and Biogeography 12(5): 361-371.

Pepin, N. C. and Lundquist, J. D. (2008). "Temperature trends at high elevations: Patterns across the globe." Geophysical Research Letter 35: L14701.

Perry, A. L., Low, P. J., Ellis, J. R., Reynolds, J. D. (2005). "Climate change and distribution shifts in marine fishes." Science 308(5730): 1912.

Peterson, T. C., Easterling, D. R., Karl, T., Groisman, P., Nicholls, N., Plummer, N., Torok, S., Auer, I., Boehm, R., Gullett, D., Vincent, L. (1998). "Homogeneity adjustments of in situ atmospheric climate data: a review." International Journal of Climatology 18(13): 1493-1517.

Pidwirny, M., Sidney, D. (2010). "Causes of climate change." Encyclopedia of Earth.

Rhoades, D. A. and Salinger, M. J. (1993). "Adjustment of temperature and rainfall 
records for site changes." International Journal of Climatology 13: 899-899.

Regonda, S. K., Rajagopalan, B., Clark, M., Pitlick, J. (2005). "Seasonal cycle shifts in hydroclimatology over the western United States." Journal of Climate 18(2): 372-384.

Robeson, S. M. (2004). "Trends in time-varying percentiles of daily minimum and maximum temperature over North America." Geophysical Research Letters 31(4): L04203.

Rogers, C. E. and McCarty, J. P. (2000). "Climate change and ecosystems of the Mid-Atlantic Region." Climate Research 14(3): 235-244.

Schmidli, J. and Frei, C. (2005). "Trends of heavy precipitation and wet and dry spells in Switzerland during the 20th century." International Journal of Climatology 25(6): 753-772.

Schneider, T. (2001). "Analysis of incomplete climate data: Estimation of mean values and covariance matrices and imputation of missing values." Journal of Climate 14(5): 853-871.

Sen, P. K. (1968). "Estimates of the regression coefficient based on Kendall's tau." Journal of the American Statistical Association 63(324): 1379-1389.

Shapiro, S. S. and Wilk, M. B. (1965). "An analysis of variance test for normality (complete samples)." Biometrika 52(3-4): 591-611.

Shrestha, A. B., Wake, C. P., Mayewski, P. A., Dibb, J. E. (1999). "Maximum temperature trends in the Himalaya and its vicinity: an analysis based on temperature records from Nepal for the period 1971-94." Journal of Climate 12(9): 2775-2786. 
Simpson, S. L., Fitzpatrick, R. W., Shand, P., Angel, B., Spadaro, D. A., Mosley, L. (2009) "Climate-driven mobilisation of acid and metals from acid sulfate soils." Marine and Freshwater Research 61: 129-138.

Stooksbury, D. E., Idso, C. D., Hubbard, K. G. (1999). "The effects of data gaps on the calculated monthly mean maximum and minimum temperatures in the continental United States: A spatial and temporal study." Journal of Climate 12(5): 1524-1533.

Suppiah, R. and Hennessy, K. J. (1998). "Trends in total rainfall, heavy rain events and number of dry days in Australia, 1910-1990." International Journal of Climatology 18(10): 1141-1164.

Tecer, L. H. and Cerit, O. (2009). "Temperature Trends and Changes in Rize, Turkey, for the Period 1975 to 2007." Clean: Soil, Air, Water 37(2): 150-159.

Twala, B. (2009). "Empirical comparison of techniques for handling incomplete data using decision trees." Applied Artificial Intelligence: 1-35.

U.S.G.S. (2008) “Final Report, Synthesis and Assessment Product 3.4: Abrupt Climate Change."

Van Belle, G. and Hughes, J. P. (1984). "Nonparametric tests for trend in water quality." Water Resources Research 20(1).

VanRheenen, N. T., Wood, A. W., Palmer, R. N., Lettenmaier, D. P. (2004). "Potential implications of PCM climate change scenarios for Sacramento-San Joaquin River basin hydrology and water resources." Climatic Change 62(1): 257-281.

Vincent, d. N. (2008). "Global Warming is Man-made: Key Points in The International Panel on Climate Change 2007 report." Cambridge University Press. 
Vuille, M. and Bradley, R. S. (2000). "Mean annual temperature trends and their vertical structure in the tropical Andes." Geophysical Research Letter 27(23): 3885-3888.

Walther, G. R., Post, E., Convey, P., Menzel, A., Parmesan, C., Beebee, J. C., Fromentin, J. M., Hoegh-Guldberg, O., Bairlein, F. (2002). "Ecological responses to recent climate change." Nature 416(6879): 389-395.

Wang, Y. and Zhou, L. (2005). "Observed trends in extreme precipitation events in China during 1961-2001 and the associated changes in large-scale circulation." Geophysical Reserach Letter 32(9).

Weyhenmeyer, G. A., Blenckner, T., Pettersson, K. (1999). "Changes of the plankton spring outburst related to the North Atlantic Oscillation." Limnology and Oceanography 44(7): 1788-1792.

Whitfield, P. H. and Cannon, A. J. (2000). "Recent variations in climate and hydrology in Canada." Canadian Water Resources Journal/Revue Canadienne des Ressources Hydriques 25(1): 19-66.

Wilby, R. L., Whitehead, P. G., Wade, A. J., Butterfield, D., Davis, R. J., Watts, G. (2006). "Integrated modelling of climate change impacts on water resources and quality in a lowland catchment: River Kennet, UK." Journal of Hydrology 330(1-2): 204-220.

You, Q., Kang, S., Pepin, N., Yan, Y. (2008). "Relationship between trends in temperature extremes and elevation in the eastern and central Tibetan Plateau, 1961-2005." Geophysical Research Letters 35(4): L04704.

Yue, S. and Pilon, P. (2004). "A comparison of the power of the t test, Mann-Kendall and bootstrap tests for trend detection." Hydrological Sciences Journal 49(1): 21-37. 
Yue, S., Pilon, P., Cavadias, G. (2002). "Power of the Mann-Kendall and Spearman's rho tests for detecting monotonic trends in hydrological series." Journal of Hydrology 259(1-4): 254-271.

Xu, Z. X., Gong, T. L., Li, J. Y. (2008). "Decadal trend of climate in the Tibetan Plateau-regional temperature and precipitation." Hydrological Processes 22(16): 3056-3065.

Zhai, P., Sun, A., Ren, F., Liu, X., Gao, B., Zhang, Q. (1999). "Changes of climate extremes in China." Climatic Change 42(1): 203-218.

Zhang, Q., Xu, C. Y., Becker, S., Zhang, Z. X., Chen, Y. D., Coulibaly, M. (2009b). "Trends and abrupt changes of precipitation maxima in the Pearl River basin, China." Atmospheric Science Letters 10(2): 132-144.

Zhang, Q., Xu, C. Y., Zhang, Z., Chen. X., Han, Z. (2009a) "Precipitation extremes in a karst region: a case study in the Guizhou province, southwest China." Theoretical and Applied Climatology: 1-13.

Zhang, X., Vincent, L. A., Hogg, W. D., Niitsoo, A. (2000). "Temperature and precipitation trends in Canada during the 20th century." Atmosphere-Ocean 38(3): 395-429.

Zhao, F. F., Xu, Z. X., Huang, J. X., Li, J. Y. (2008). "Monotonic trend and abrupt changes for major climate variables in the headwater catchment of the Yellow River basin." Hydrological Processes 22(23): 4587-4599.

Zhao, G. J., Hömann, G., Fohrer, N., Gao, J. F., Zhai, J. Q., Zhang, Z. X. (2009). "Spatial and temporal characteristics of wet spells in the Yangtze River Basin from 1961 to 2003." Theoretical and Applied Climatology 98(1): 107-117. 
Zurbenko, I., Porter, P. S., Gui, R., Rao, S. T., Ku, J. Y., Eskridge, R. E. (1996).

"Detecting discontinuities in time series of upper-air data: Development and demonstration of an adaptive filter technique." Journal of Climate 9(12): 3548-3560. 